\title{
Beyond the Mind-Serum Trace Element Levels in Schizophrenic Patients: A Systematic Review
}

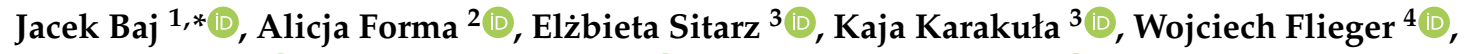 \\ Monika Sitarz ${ }^{5}\left(\right.$, Cezary Grochowski ${ }^{6} \oplus$, Ryszard Maciejewski ${ }^{1}{ }^{\circledR}$ \\ and Hanna Karakula-Juchnowicz 3,7 (i) \\ 1 Department of Human Anatomy, Medical University of Lublin, 20-400 Lublin, Poland; \\ maciejewski.r@gmail.com \\ 2 Chair and Department of Forensic Medicine, Medical University of Lublin, 20-090 Lublin, Poland; \\ aforma@onet.pl \\ 3 Chair and 1st Department of Psychiatry, Psychotherapy and Early Intervention, Medical University of \\ Lublin, Gluska Street 1, 20-439 Lublin, Poland; e.sitarz@hotmail.com (E.S.); kaja.karakula@gmail.com (K.K.); \\ karakula.hanna@gmail.com (H.K.-J.) \\ 4 Faculty of Medicine, Medical University of Lublin, Aleje Racławickie 1, 20-059 Lublin, Poland; \\ wwoj24@wp.pl \\ 5 Department of Conservative Dentistry with Endodontics, Medical University of Lublin, 20-090 Lublin, \\ Poland; mksitarz@gmail.com \\ 6 Laboratory of Virtual Man, Chair of Anatomy, Medical University of Lublin, 20-400 Lublin, Poland; \\ cezary.grochowski@o2.pl \\ 7 Department of Clinical Neuropsychiatry, Medical University of Lublin, Gluska Street 1, \\ 20-439 Lublin, Poland \\ * Correspondence: jacek.baj@umlub.pl
}

Received: 30 October 2020; Accepted: 12 December 2020; Published: 15 December 2020

\begin{abstract}
The alterations in serum trace element levels are common phenomena observed in patients with different psychiatric conditions such as schizophrenia, autism spectrum disorder, or major depressive disorder. The fluctuations in the trace element concentrations might act as potential diagnostic and prognostic biomarkers of many psychiatric and neurological disorders. This paper aimed to assess the alterations in serum trace element concentrations in patients with a diagnosed schizophrenia. The authors made a systematic review, extracting papers from the PubMed, Web of Science, and Scopus databases according to the Preferred Reporting Items for Systematic Reviews and Meta-Analyses (PRISMA) guidelines. Among 5009 articles identified through database searching, 59 of them were assessed for eligibility. Ultimately, 33 articles were included in the qualitative synthesis. This review includes the analysis of serum levels of the following trace elements: iron, nickel, molybdenum, phosphorus, lead, chromium, antimony, uranium, magnesium, aluminum, zinc, copper, selenium, calcium, and manganese. Currently, there is no consistency regarding serum trace element levels in schizophrenic patients. Thus, it cannot be considered as a reliable prognostic or diagnostic marker of schizophrenia. However, it can be assumed that altered concentrations of those elements are crucial regarding the onset and exaggeration of either psychotic or negative symptoms or cognitive dysfunctions.
\end{abstract}


Keywords: schizophrenia; trace element; serum; psychiatry

\section{Introduction}

Schizophrenia is a multifactorial psychiatric condition with a complex pathophysiological theory. It is described as a disruption of thought processes and an inconsistency between thoughts, emotions, and behavior. Schizophrenia prevalence is about $0.7 \%$, with an onset in the early 20 s among males and approximately 3 to 4 years later among females; its incidence is also 1.15-fold higher for men $[1,2]$. Patients diagnosed with schizophrenia suffer from psychotic symptoms: hallucinations, delusions, and negative symptoms, which include social withdrawal or flat affect, as well as cognitive impairments [3-5]. As a multifaceted condition, schizophrenia has a wide spectrum of hypotheses, among which alterations and abnormalities within neurotransmission (dopamine hypothesis) seem to be of primary relevance [6-11]. Other hypotheses refer to genetic predisposition, altered $\gamma$-aminobutyric acid (GABA) levels, nicotinic receptors, the endocannabinoid system, inflammation with oxidative stress, sex and developmental differences in brain anatomy, the protective role of estrogens, gut microbiota, or vitamin D deficiency [12-23].

The onset of psychiatric conditions or exaggerations of their symptoms might be induced by numerous factors including genetic predispositions, infections, inflammations, trace elements and vitamin levels, severe stress, postpartum complications, intellectual disability, neurodegenerative diseases, trauma, stimulants, and socio-economic and psychological factors [24-31]. The importance of various trace elements' concentrations in human organisms cannot be underestimated since they are a crucial factor responsible for either induction or exaggeration of numerous disease symptoms (Table 1) [32-38]. 
Table 1. Physiological ranges and biological functions of trace elements in the human organism.

\begin{tabular}{|c|c|c|c|c|}
\hline \multirow{2}{*}{ Element } & \multicolumn{2}{|c|}{ Healthy Ranges } & \multirow{2}{*}{ Biological Functions } & \multirow{2}{*}{ References } \\
\hline & Male & Female & & \\
\hline Iron $(\mathrm{Fe})$ & $14-32 \mu \mathrm{mol} / \mathrm{L}$ (serum) & $11-29 \mu \mathrm{mol} / \mathrm{L}$ (serum) & $\begin{array}{l}\text { Fe is an essential trace element for all living organisms, as it } \\
\text { constitutes a component of hemoglobin that is crucial in the storage } \\
\text { and delivery of oxygen. Fe is required for the synthesis of } \\
\text { hemoglobin, myoglobin, catalase, peroxidase, and cytochromes. Fe is } \\
\text { a component of numerous proteins that are involved in DNA } \\
\text { synthesis and cell proliferation. Fe homeostasis is crucial for proper } \\
\text { mitochondrial functioning, cellular respiration, and subsequent ATP } \\
\text { production; Fe is a component of several proteins involved in the } \\
\text { electron transport chain. Fe is the most abundant trace element } \\
\text { within the central nervous system (CNS), being involved in a vast } \\
\text { number of processes including neurotransmitter synthesis } \\
\text { (dopamine, serotonin), synaptic plasticity, and myelination. } \\
\text { Proper Fe concentrations in the brain are regulated by ferritin. Thus, } \\
\text { balanced Fe homeostasis and concentrations are crucial in the } \\
\text { maintenance of proper cognitive functions and neurodevelopmental } \\
\text { processes. Psychologically, Fe accumulation within the brain occurs } \\
\text { in the elderly and might be associated with an induction of cognitive } \\
\text { and motor dysfunctions. Any imbalances in Fe levels-either } \\
\text { deficiency or overload-results in impaired monoamine } \\
\text { neurotransmission, or cellular toxicity with } \\
\text { neuronal damage respectively. }\end{array}$ & [39-46] \\
\hline Molybdenum (Mo) & $0.28 \mathrm{ng} / \mathrm{mL}-$ & /mL (serum) & $\begin{array}{l}\text { Mo is a cofactor for three main enzymes: sulphite oxidase } \\
\text { (involved in the metabolism of sulfur-containing amino acids), } \\
\text { xanthine oxidase/dehydrogenase (catalyzes oxidative hydroxylation } \\
\text { of purines and pyridines), and aldehyde oxidase (oxidizes purines, } \\
\text { pyrimidines, and pteridines). Sulphite oxidase deficiency might } \\
\text { induce neurological symptoms. Low dietary Mo intake leads to } \\
\text { decreased serum and urinary uric acid concentrations, as well as } \\
\text { excessive xanthine excretion. Since Mo is required only in small } \\
\text { amounts, its deficiency is infrequent. However, the so-called } \\
\text { 'acquired Mo deficiency' is characterized by high blood methionine, } \\
\text { low blood uric acid, and low levels of urinary sulfate and uric acid. } \\
\text { Mo deficiency might be associated with motor dysfunctions. }\end{array}$ & {$[47-52]$} \\
\hline
\end{tabular}


Table 1. Cont

\begin{tabular}{|c|c|c|c|}
\hline \multirow{2}{*}{ Element } & Healthy Ranges & \multirow{2}{*}{ Biological Functions } & \multirow{2}{*}{ References } \\
\hline & Female & & \\
\hline Phosphorus (P) & 2.5 to $4.5 \mathrm{mg} / \mathrm{dL}$ (blood) & $\begin{array}{l}\text { P is an essential element for DNA and ATP synthesis, } \\
\text { membrane synthesis, and protein phosphorylation. P constitutes a } \\
\text { crucial component of DNA and RNA. Inorganic phosphate is crucial } \\
\text { for proper skeletal mineralization-approximately } 85 \% \text { of P is } \\
\text { distributed within bones and teeth, whereas the remaining } \\
\text { quantities-in blood and other tissues. P is involved (either directly } \\
\text { or indirectly) in the regulation of gene transcription, cell signaling } \\
\text { (phosphorylation reactions regulation of acid-base homeostasis } \\
\text { (maintenance of physiological pH of fluids), activation of numerous } \\
\text { enzymes, or maintenance of proper storage of energy. P is also a } \\
\text { component of 2,3-diphosphoglycerate. P deficiency is associated with } \\
\text { numerous bone-related symptoms such as increased bone pain, } \\
\text { fragility, or joint stiffness. Muscle dysfunctions are also very common } \\
\text { and these mainly concern major muscles; severe cases might include } \\
\text { respiratory depression and low cardiac output. Chronic P deficiency } \\
\text { might result in proximal myopathy, rhabdomyolysis (risk of } \\
\text { hemolytic anemia), and impaired erythrocyte synthesis. } \\
\text { Hypophosphatemia is further characterized by neurological or } \\
\text { cognitive symptoms such as fatigue, weakness, irritability, apathy, } \\
\text { intention tremors, or even delirium, or coma. Contrarily, } \\
\text { hyperphosphatemia manifests itself as enhanced vascular or soft } \\
\text { tissue calcification, risk of secondary hyperparathyroidism, } \\
\text { or renal osteodystrophy. }\end{array}$ & [53-59] \\
\hline
\end{tabular}

$\mathrm{Ni}$ is highly abundant in nucleic acids, especially in RNA.

Ni constitutes a component of several enzymes such as glyoxalase I,

acireductone dioxygenase, nickel superoxide dismutase, ureases,

$\mathrm{Ni}$-Fe hydrogenase, methyl-CoM reductase, and CO dehydrogenase.

$\mathrm{Ni}$ is involved in Fe absorption and erythrocytes synthesis, as well as adrenaline, glucose, hormones, lipids, and cell membranes

Nickel (Ni) $\quad 0.2 \mu \mathrm{g} / \mathrm{L}$ (serum)

metabolism. The most common side effects of excessive Ni exposure are lung fibrosis, skin allergies, and nasal, laryngeal, and lung

cancers. So-called 'Ni toxicity syndrome' includes a vast number of

symptoms including hypoglycemia, shortness of breath, nausea,

lowered pulse, headache, diarrhea, vomiting. Severe Ni intoxication

affects the respiratory tract and gastrointestinal system; the most

common causes of death due to Ni intoxication are

$$
\text { pneumonitis and cerebral edema. }
$$


Table 1. Cont.

\begin{tabular}{|c|c|c|c|}
\hline \multirow{2}{*}{ Element } & Healthy Ranges & \multirow{2}{*}{ Biological Functions } & \multirow{2}{*}{ References } \\
\hline & Female & & \\
\hline Magnesium (Mg) & $\begin{array}{c}0.65-1.05 \mathrm{mmol} / \mathrm{L} \text { (total } \mathrm{Mg} \text { in serum) } \\
0.55-0.75 \mathrm{mmol} / \mathrm{L} \text { (ionized } \mathrm{Mg} \text { in serum) }\end{array}$ & $\begin{array}{l}\text { Approximately } 99 \% \text { of total body } \mathrm{Mg} \text { in bones and muscles. } \mathrm{Mg} \text { is a } \\
\text { cofactor of more than } 300 \text { enzymes, which are involved in a vast } \\
\text { number of functions including neuromuscular conduction, } \\
\text { muscle contraction, myocardial contraction, or maintenance of blood } \\
\text { pressure. Mg is required for glycolysis, energy production, } \\
\text { and oxidative phosphorylation. It is involved in controlling } \\
\text { N-methyl-D-aspartate (NMDA) receptors, preventing neuronal } \\
\text { overstimulation. Mg is a crucial mineral for bone mineralization. It is } \\
\text { essential for the maintenance of the structures of proteins, } \\
\text { nucleic acids and mitochondria, and proper transmembrane } \\
\text { transport of ions. Mg is also involved in several immunological } \\
\text { functions such as macrophage activation, or lymphocyte proliferation. } \\
\text { Mg deficiency might affect every system resulting in neurological } \\
\text { (higher risk of migraine, stroke, seizure), } \\
\text { gastrointestinal (insulin resistance, increased levels of triglycerides } \\
\text { and total cholesterol), cardiovascular (increased risk of hypertension } \\
\text { and atherosclerosis) symptoms. Such patients also present with a } \\
\text { higher risk of osteoporosis. Hypermagnesemia manifests itself as } \\
\text { hypotension, nausea, vomiting, cutaneous flushing, whereas more } \\
\text { severe symptoms include neuromuscular dysfunctions, bradycardia, } \\
\text { atrial fibrillation, respiratory depression, or a coma. }\end{array}$ & [65-71] \\
\hline Aluminium (Al) & $<10 \mu \mathrm{g} / \mathrm{L}$ (serum) & $\begin{array}{l}\text { Patients who are exposed to high doses of } \mathrm{Al} \text { are presented with } \mathrm{Al} \\
\text { accumulation in both blood plasma and brain. The entering of } \mathrm{Al} \text { to } \\
\text { the CNS is possible via transferrin and it mainly accumulates in those } \\
\text { regions that are rich in transferrin receptors. Levels of } \mathrm{Al}, \\
\text { which might result in early symptoms of neurotoxicity are }>13 \mu \mathrm{g} / \mathrm{L} \\
\text { (plasma). Excessive Al exposure might induce inflammatory } \\
\text { responses due to the increased expression of NF-kB and TNF- } \alpha \text {. } \\
\text { Cumulation of } \mathrm{Al} \text { in the brain might induce several cognitive } \\
\text { dysfunctions and in advanced stages-dementia. Further, it might } \\
\text { impair hippocampal calcium (Ca) signaling pathways. } \\
\text { Al neurotoxicity is associated with oxidative stress and impaired } \\
\text { synthesis of acetylcholine due to the susceptibility of cholinergic } \\
\text { neurons to Al; its excessive amounts also affect acetylcholinesterase } \\
\text { (AChE) activity and impairs glial cells functions. Chronic Al } \\
\text { exposure results in aluminosis, encephalopathy, breast cancer, } \\
\text { or Alzheimer's disease. Physiologically, Al content increases within } \\
\text { the brain with age. Further, some research suggests that Al might be } \\
\text { involved in chromatic compaction and epigenetics. }\end{array}$ & [72-79] \\
\hline
\end{tabular}


Table 1. Cont.

\begin{tabular}{|c|c|c|c|}
\hline \multirow{2}{*}{ Element } & Healthy Ranges & \multirow{2}{*}{ Biological Functions } & \multirow{2}{*}{ References } \\
\hline & Female & & \\
\hline Zinc (Zn) & 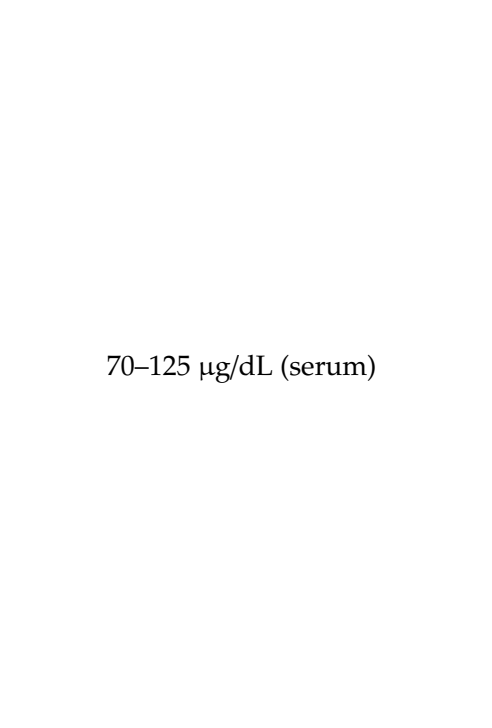 & $\begin{array}{l}\text { Zn is the second most abundant trace element in the human organism. } \\
\mathrm{Zn} \text { is involved in the maintenance of protein structure, regulation of gene } \\
\text { expression, RNA, and DNA synthesis; thus, it is crucial in proper cell } \\
\text { development, replication, and metabolism. Zn is a cofactor of numerous } \\
\text { enzymes, including dopamine b-hydroxylase, monoamine oxidase, } \\
\text { thyrosinase, alkaline phosphatase, carbonic anhydrase, } \\
\text { superoxide dismutase, DNA and RNA polymerases, } \\
\text { alcohol dehydrogenase, or matrix metalloproteinases. Zn is crucial for } \\
\text { adult neurogenesis and proper hippocampal functioning. Zn inhibits the } \\
\text { release of glutamate (Glu), as it inhibits } \gamma \text {-aminobutyric acid type A } \\
\text { (GABAA) receptors. Within the CNS, Zn is most abundant in the } \\
\text { hippocampus and the olfactory bulb, in the synaptic vesicles of } \\
\text { glutaminergic neurons. Further, Zn-containing neurons are found within } \\
\text { the forebrain in the highest amounts. At a presynaptic level, it can block } \\
\text { Ca2+ channels, inhibiting neurotransmission. Zn-related alterations within } \\
\text { the CNS can lead to cognitive impairments, mood disorders, anxiety, } \\
\text { depression, epilepsy, Alzheimer's disease, or dementia; generally, Zn is } \\
\text { involved in the neuronal damage. Symptoms of Zn deficiency include } \\
\text { growth retardation, mental lethargy, alterations in hormone metabolism, } \\
\text { impaired immunity, and cognitive dysfunctions. Further, Zn deficiency is } \\
\text { implemented in the promotion of inflammation. }\end{array}$ & {$[39,80-84]$} \\
\hline Copper $(\mathrm{Cu})$ & 70-140 mcg/dL (blood) & $\begin{array}{l}\mathrm{Cu} \text { is the third most abundant transition element in the human organism } \\
\text { and its highest concentrations are primarily found in the liver and brain. } \\
\mathrm{Cu} \text { is involved in proper Fe homeostasis, myelination, neurotransmitter } \\
\text { synthesis, antioxidative defense, cellular proliferation, and signalling. } \\
\text { Approximately } 80-95 \% \text { of plasma } \mathrm{Cu} \text { is bound to ceruloplasmin; } \\
\text { metallothionein constitutes a major protein for copper storage. It is a } \\
\text { component of several enzymes such as tyrosine hydroxylase, dopamine } \\
\text { hydroxylase (involved in dopamine and norepinephrine production), } \\
\text { superoxide dismutase, and cytochrome coxidase. Cu is capable to bind to } \\
\text { GABAA, NMDA receptors, and voltage-gated Ca } \mathrm{a}^{2+} \text { channels, } \\
\text { affecting synaptic transmission. Cu toxicity is primarily associated with } \\
\text { free radical-induced oxidative damage. Cu is also crucial in the induction } \\
\text { of inflammation, as it affects a lymphocytic release of interleukin-2 (IL-2). } \\
\text { Imbalances in Cu concentrations and metabolism might be associated with } \\
\text { neurodegenerative diseases such as Alzheimer's disease, Menkes disease, } \\
\text { Wilson's disease, or spongiform encephalopathies. Further, Cu deficiency } \\
\text { primarily results in } \mathrm{B}_{12} \text { and folate deficiency, aplastic anemia, } \\
\text { leucopenia, or myeloneuropathy. }\end{array}$ & {$[39,85-94]$} \\
\hline
\end{tabular}


Table 1. Cont.

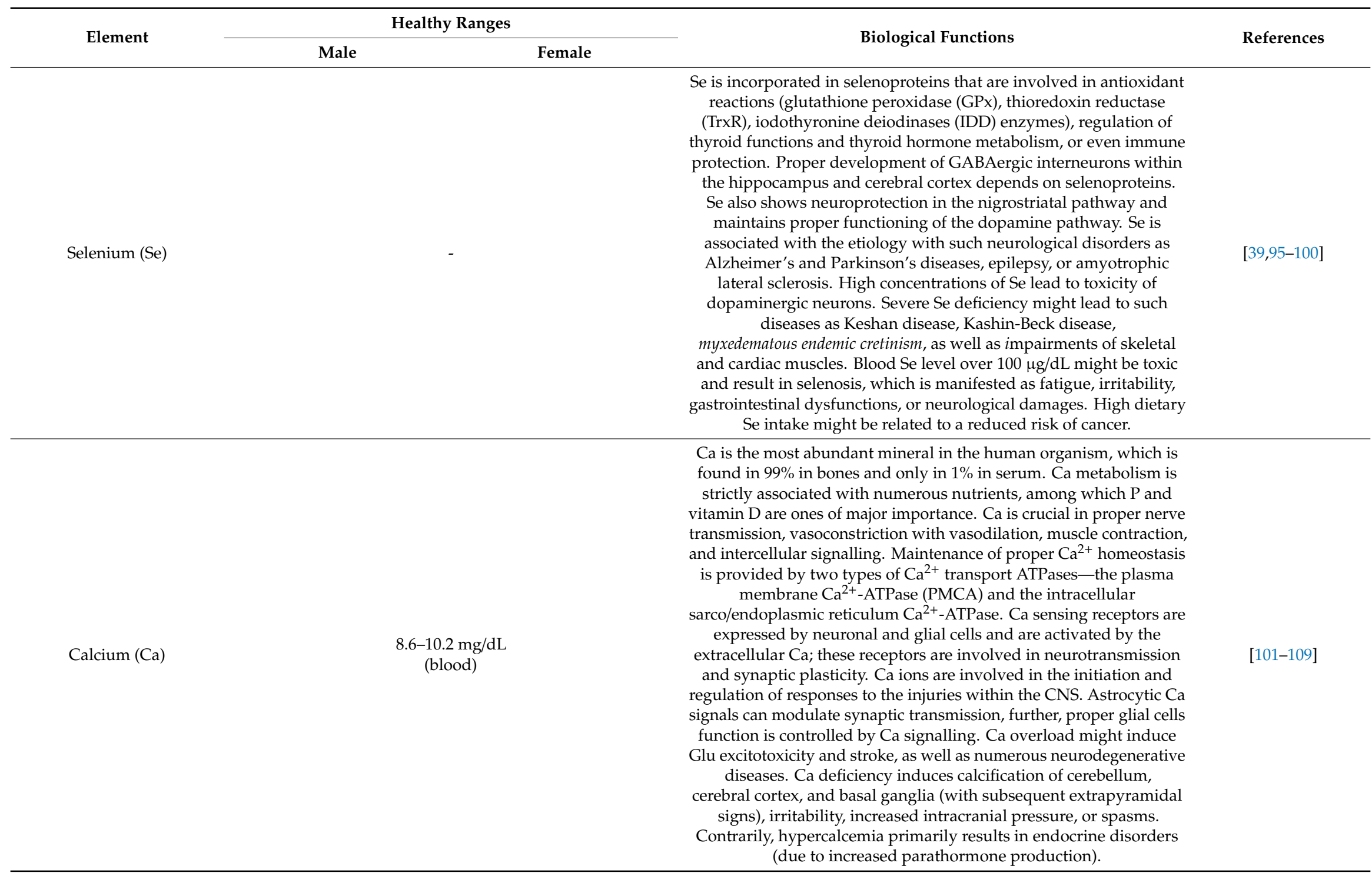


Table 1. Cont.

\begin{tabular}{|c|c|c|c|c|}
\hline \multirow{2}{*}{ Element } & \multicolumn{2}{|r|}{ Healthy Ranges } & \multirow{2}{*}{ Biological Functions } & \multirow{2}{*}{ References } \\
\hline & Male & Female & & \\
\hline Manganese (Mn) & & $\begin{array}{l}0.4-0.85 \mu \mathrm{g} / \mathrm{L} \\
\quad(\text { serum) }\end{array}$ & $\begin{array}{l}\text { Mn is a crucial element involved in the regulation of glucose and } \\
\text { lipids metabolism, as well as synthesis and activation of many } \\
\text { enzymes such as arginase, isocitrate dehydrogenase, } \\
\text { phosphoenolpyruvate carboxykinase, manganese superoxide } \\
\text { dismutase (MnSOD), glutamine synthetase, glycosyl transferases, } \\
\text { pyruvate carboxylase. Thus, Mn is involved in proper development, } \\
\text { antioxidant defense, energy production, immune responses, } \\
\text { and neuronal activity. The highest concentrations of manganese } \\
\text { within the CNS are primarily found in the putamen, caudate nucleus, } \\
\text { and globus pallidus. Molecular mechanisms associated with Mn } \\
\text { toxicity are numerous, among which oxidative stress, } \\
\text { mitochondrial dysfunction, autophagy dysregulation, and apoptosis } \\
\text { are one of the most important ones. Mn toxicity is associated with a } \\
\text { disruption of the glutamine (Gln)/glutamate (Glu)- (GABA) } \\
\text { cycle (GGC) between astrocytes and neurons impairing } \\
\text { neurotransmission and Gln metabolism. Imbalances in Mn levels are } \\
\text { implicated in neurodegenerative diseases. Excessive Mn levels } \\
\text { (manganism) resemble Parkinson's disease and include similar } \\
\text { cognitive, motor, and emotional impairments; they might also induce } \\
\text { encephalopathy. Excessive amounts of Mn are neurotoxic and the } \\
\text { mechanism is enhanced by Mn-related overactivation of glial cells } \\
\text { and further neuroinflammatory responses. }\end{array}$ & {$[39,110-116]$} \\
\hline Lithium (Li) & & $\begin{array}{l}0.14-8.6 \mu \mathrm{mol} / \mathrm{L} \\
\quad(\text { serum})\end{array}$ & $\begin{array}{l}\mathrm{Li} \text { is an alkali metal that except for human serum, it can be found in } \\
\text { the erythrocytes, liver, and uterus. Li presents anti-manic properties } \\
\text { and it is currently widely used in such psychiatric conditions as } \\
\text { bipolar disorder, major depressive disorder, or mania. Similar to } \\
\text { therapeutic Li, endogenous Li also has physiological functions in } \\
\text { regulating mood. Lithium ions prevent the induction of the } \\
\text { functional hypersensitivity to dopamine and acetylcholine receptors; } \\
\text { it also increases the serotoninergic activities. Li affects } \\
\text { neurotransmission by modulating Glu, dopamine, GABA, glycine, } \\
\text { and acetylocholine transmission. Several studies showed positive } \\
\text { effects of Li supplementation on the volume of gray matter and } \\
\text { integrity of the white matter of the brain. Besides, Li is believed to } \\
\text { increase the number of neutrophils and eosinophils as well as a } \\
\text { proliferation of the T-cells. Li presents the ability to reserve the effects } \\
\text { of oxidative stress. }\end{array}$ & [117-124] \\
\hline
\end{tabular}


Table 1. Cont

\begin{tabular}{|c|c|c|c|c|}
\hline \multirow{2}{*}{ Element } & \multicolumn{2}{|r|}{ Healthy Ranges } & \multirow{2}{*}{ Biological Functions } & \multirow{2}{*}{ References } \\
\hline & Male & Female & & \\
\hline Rubidium (Rb) & & - & $\begin{array}{l}\text { Rubidium is a metal belonging to the alkali metal group. Rubidium is } \\
\text { considered to be the most abundant metal in the human organism } \\
\text { that lacks any major biological function. Its half-life in the human } \\
\text { organism is estimated to } 31-46 \text { days. Generally, this metal seems not } \\
\text { to be toxic for humans, however, it is also easily absorbed. Rb ions } \\
\text { are treated similarly to K ions and are stored in the body's } \\
\text { intracellular fluid. Since Rb ions resemble K ions, it is believed that } \\
\text { those might present similar functions. However, the replacement of } \mathrm{K} \\
\text { ions with } \mathrm{Rb} \text { ions (about } 50 \% \text { ) was fatal, according to the results of } \\
\text { the animal model. It was demonstrated that Rb might facilitate the } \\
\text { turnover of the brain noradrenaline in rats and monkeys. }\end{array}$ & [125-128] \\
\hline Potassium (K) & & $\begin{array}{l}\text { 3.5-5.0 mmol/L } \\
\text { (blood) }\end{array}$ & $\begin{array}{l}\text { Proper } \mathrm{K} \text { homeostasis is crucial in the maintenance of physiological, } \\
\text { cellular functions. } \mathrm{K} \text { is primarily an intracellular ion; only } 2 \% \text { of } \mathrm{K} \\
\text { ions are localized in the extracellular fluid. The physiological } \\
\text { membrane potential is controlled by the } \mathrm{Na}^{+}-\mathrm{K}^{+} \mathrm{ATPase} \text { exchanger, } \\
\text { which pumps } \mathrm{Na}^{+} \text {outside the cell, replacing it with } \mathrm{K}^{+} \text {ions. } \mathrm{K} \text { ions } \\
\text { are crucial for the maintenance of physiological fluid balance at the } \\
\text { same time enabling proper nerve signaling and muscle contractions. } \\
\text { Disturbed K levels are associated with the alterations of the blood } \\
\text { pressure- greater } \mathrm{K} \text { concentrations lead to lowered blood pressure, } \\
\text { whereas low K levels induce hypertension. Na/K ratio is linearly } \\
\text { associated with blood pressure. Besides, reduced } \mathrm{K} \text { levels promote } \\
\text { vascular calcification and aortic stiffness. Hypokalemia is much more } \\
\text { common than hyperkalemia and is usually caused by chronic } \\
\text { diarrhea, vomiting, or excessive loss of bodily fluids. Hyperkalemia } \\
\text { is associated with muscle weakness and cardiac arrhythmias. } \\
\text { K supplementation might be associated with a decreased risk of } \\
\text { stroke; it also shows protective effects against several pathologies of } \\
\text { kidneys (e.g., kidney stones) and bones. }\end{array}$ & [129-131] \\
\hline
\end{tabular}


Table 1. Cont.

\begin{tabular}{|c|c|c|c|}
\hline \multirow{2}{*}{ Element } & Healthy Ranges & \multirow{2}{*}{ Biological Functions } & \multirow{2}{*}{ References } \\
\hline & Female & & \\
\hline Uranium (U) & - & $\begin{array}{l}\mathrm{U} \text { is a heavy metal that might be absorbed into the human organism } \\
\text { via several routes including inhalation, ingestion (of U-contaminated } \\
\text { food and water), and dermal contact (e.g., damaged tissues). } \\
\mathrm{U} \text { toxicity is either acute or chronic and the most vulnerable organs } \\
\text { include the kidneys; other organs such as bones, liver, lungs, } \\
\text { orreproductive organs might also be affected by chronic toxicity. } \\
\text { Since U was showed to pass through the brain-blood barrier, it is also } \\
\text { believed to have neurotoxic effects; so far U showed its toxic } \\
\text { properties mostly towards dopaminergic cells. Besides, chronic U } \\
\text { exposure may affect the immune system resulting in a wide spectrum } \\
\text { of infectious diseases autoimmune diseases, or even } \\
\text { induction of carcinogenesis. }\end{array}$ & [132-136] \\
\hline Cadmium (Cd) & $0.5-2.0 \mathrm{ng} / \mathrm{mL}$ (blood) & $\begin{array}{l}\text { Cd is a toxic heavy metal of no major biological function in the } \\
\text { human organism. Cd has been classified as a human carcinogen since } \\
\text { it disrupts DNA repair enhancing uncontrolled cellular proliferation. } \\
\text { Further, Cd facilitates the overexpression of numerous } \\
\text { proto-oncogenes such as c-myc or c-jun [AE]. Cd also facilitates the } \\
\text { induction of oxidative stress. Contamination with Cd is currently } \\
\text { quite prevalent in most food products and Cd tends to accumulate in } \\
\text { the human organism with age. Cd was observed to mostly } \\
\text { accumulate in the liver, lungs, and eye tissues. Chronic Cd exposure } \\
\text { might be associated with such diseases as Itai-itai disease or tubular } \\
\text { impairments which is further linked to bone demineralization and } \\
\text { osteoporosis. It was demonstrated that there is an association } \\
\text { between Cd levels and the risk of diabetes, diabetic nephropathy, } \\
\text { hypertension, or periodontal diseases. As a carcinogenic agent, } \\
\text { chronic Cd exposure might induce tumorigenesis in various organs } \\
\text { leading to lung, pancreatic, prostate, stomach, or bladder cancers. } \\
\text { Moreover, chronic Cd exposure might lead to several } \\
\text { neuropsychological dysfunctions including cognitive delay. }\end{array}$ & [137-143] \\
\hline
\end{tabular}


Furthermore, trace elements' imbalances might constitute indicators of disease remission or progression. It is still debatable whether altered trace elements' concentrations could be implicated in the increased probability of schizophrenia onset. Numerous trace elements are crucial in the maintenance of proper functioning within the central nervous system (CNS) and these include physiological ranges of chromium $(\mathrm{Cr}), \mathrm{Cu}, \mathrm{Fe}, \mathrm{Mn}, \mathrm{Se}$, or $\mathrm{Zn}$. Therefore, pathological alterations in trace elements' levels might contribute to the adverse impairments of the biological processes, inducing various diseases of the CNS or exacerbate already existing symptoms of autism spectrum disorder (ASD), neurodegenerative disorders (Alzheimer, Parkinson, Huntington diseases), dementia, major depressive disorder, or attention deficit hyperactivity disorder (ADHD) [144-150]. Several studies have shown altered levels of serum trace elements' concentrations, as well as their impaired distribution within CNS in schizophrenic patients. Among numerous triggering factors, nutritional deprivation significantly affects the levels of certain trace elements, inducing oxidative stress, irrational behavior, and impaired cognition [151]. Besides, an association between metal exposure with subsequent concentration imbalances and psychotic symptoms' severity was stated [152].

\section{Aim of the Review and Search Strategy}

The objective of this paper was to conduct a review of the available literature regarding serum trace elements' concentrations in schizophrenic patients. A systematic literature review of PubMed, Web of Science, and Scopus databases was performed by two identifications in March 2020. The first identification included the search strategy as follows: (schizophrenia OR schizophrenic) AND (trace element). After reviewing 373 articles searching for serum trace elements' concentrations that had already been investigated in sera of schizophrenic patients, we chose the following ones to include in this review: magnesium, aluminum, zinc, copper, selenium, rubidium, potassium, cadmium, calcium, lithium, molybdenum, phosphorus, antimony, uranium, and manganese. We continued as the second identification with the use of the following search string: (schizophrenia OR schizophrenic) AND (magnesium OR aluminum OR cobalt OR zinc OR copper OR selenium OR rubidium OR potassium OR cadmium OR calcium OR lithium OR molybdenum OR phosphorus OR antimony OR uranium OR manganese). Eventually, 33 articles were included in a qualitative synthesis. The literature search included both human and animal studies. There were no restrictions regarding the year of a publication. The authors chose only articles in English. In the final analysis, regarding serum trace element concentrations in schizophrenics, we included only human studies. Twenty-six articles were excluded for several reasons: concentrations were measured in blood plasma, within erythrocytes, or in hair samples only; the aim of the study was not specifically focused on serum level of particular trace element; there were no sufficient, relevant, or accurate data; or it was investigated in a study, but lack of specific significant results disabled it from further analysis and description (Figure 1). 


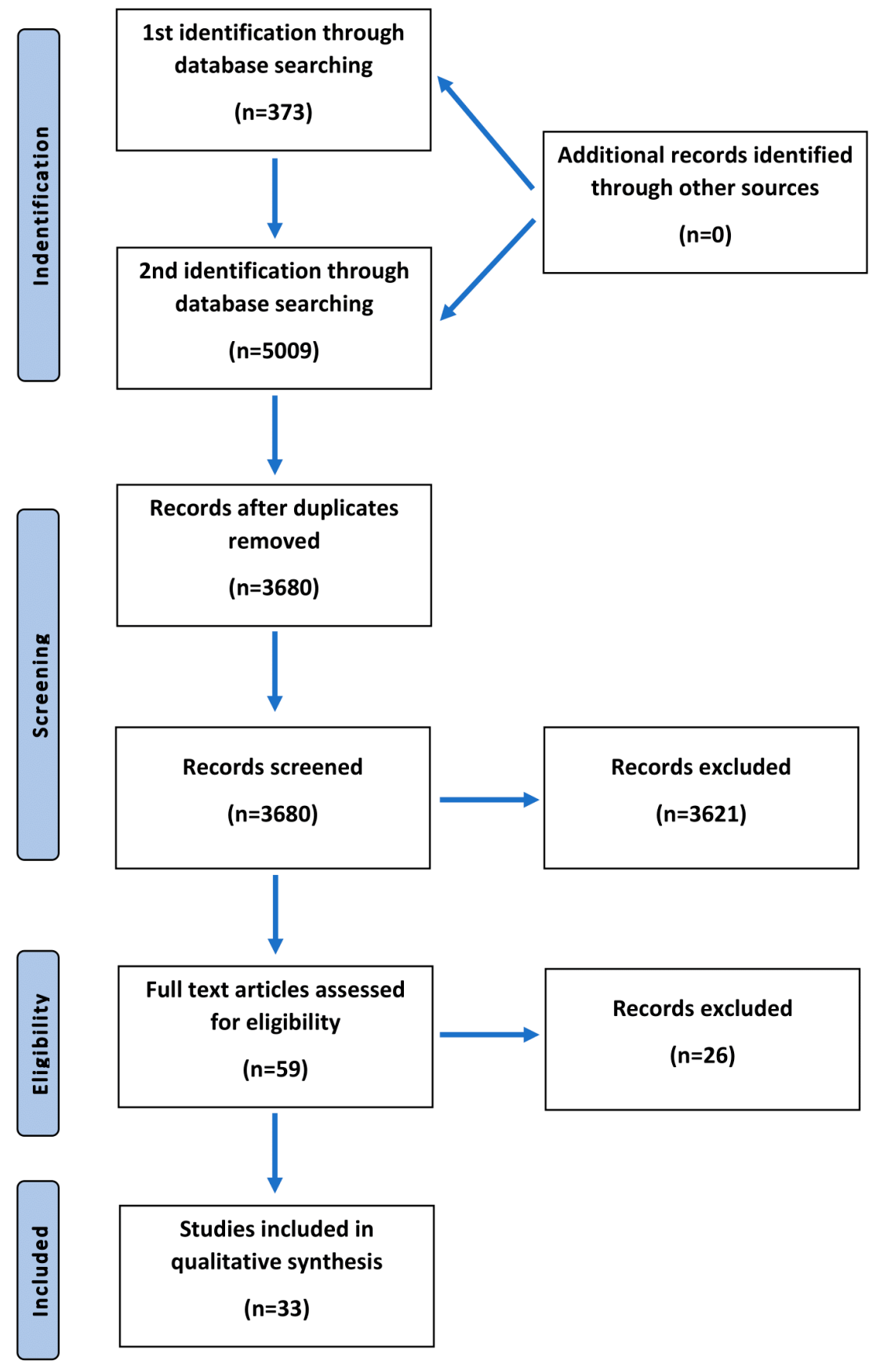

Figure 1. Flowchart presenting the process of article selection, according to Preferred Reporting Items for Systematic Review and Meta-Analyses (PRISMA) guidelines.

\section{Results}

After two identifications and duplicates were removed, we assessed 59 articles for eligibility, among which 33 of them were chosen in a qualitative synthesis. The articles included concerned the studies performed on humans. The time range of the published articles was 1950-2020. Two major inclusion criteria were the diagnosis of schizophrenia among patients and the examined trace elements' concentrations in patients' sera. Trace elements that were taken into consideration in this analysis included iron, nickel, molybdenum, phosphorus, lead, chromium, antimony, uranium, magnesium, aluminum, zinc, copper, selenium, calcium, and manganese. The results of the systematic review are included in Table 2. 
Table 2. The studies about serum trace element concentrations in schizophrenic patients included in the systematic review.

\begin{tabular}{|c|c|c|c|c|c|c|c|c|c|c|c|c|c|}
\hline Ref. & Authors & Year & Origin & $\begin{array}{c}\text { No. } \\
\text { Patients }\end{array}$ & $\begin{array}{c}\text { No. } \\
\text { Controls }\end{array}$ & $\begin{array}{l}\text { Age } \\
\text { (SG) }\end{array}$ & $\begin{array}{l}\text { Age } \\
\text { (CG) }\end{array}$ & Sex & $\begin{array}{c}\text { Trace } \\
\text { Elements }\end{array}$ & $\begin{array}{l}\text { Analytical Methods } \\
\text { for Serum Trace } \\
\text { Elements Detection }\end{array}$ & Results & $\begin{array}{c}\text { Drugs/ } \\
\text { Treatment }\end{array}$ & $\begin{array}{l}\text { Additional } \\
\text { Information }\end{array}$ \\
\hline [153] & Liu et al. & 2015 & China & 114 & 114 & $32.8 \pm 11.3$ & $33.0 \pm 10.7$ & 152 Females $^{1}$ & $\begin{array}{c}\mathrm{Ni}, \mathrm{Mo}, \mathrm{As}, \\
\mathrm{Al}, \mathrm{Cr}, \mathrm{Mn}, \\
\mathrm{Se}, \mathrm{Cu} \\
\mathrm{Fe}, \mathrm{Zn}\end{array}$ & $\begin{array}{c}\text { Samples were } \\
\text { determined by } \\
\text { inductively coupled } \\
\text { plasma-mass } \\
\text { spectrometry (ICP-MS). }\end{array}$ & $\begin{array}{l}\mathrm{Ni}, \mathrm{As}, \mathrm{Al}, \mathrm{Cr}, \mathrm{Mn}, \mathrm{Se}, \mathrm{Cu} \text {, } \\
\mathrm{Fe} \text { are associated with the } \\
\text { risk of fschizophrenia } \\
\text { (specifically: lower Ni, } \\
\mathrm{Cu} \text {, Se, As, and Al levels, } \\
\text { as well as, higher } \\
\text { concentrations of Cr and } \\
\mathrm{Mn})(p<0.05) \text {, except for } \\
\mathrm{Zn} \text { and Mo. Further, the } \\
\text { results showed that } \\
\mathrm{Cu} \leq 0.97 \mathrm{\mu g} / \mathrm{mL} \text {, } \\
\mathrm{Se} \leq 72 \mathrm{ng} / \mathrm{mL} \text {, and } \\
\mathrm{Mn}>3.95 \mathrm{ng} / \mathrm{mL} \text { are } \\
\text { associated with he risk of } \\
\text { schizophrenia. SC present } \\
\text { lower Se and Cu, as well } \\
\text { as higher Mn levels } \\
\text { compared to CG. }\end{array}$ & $\begin{array}{c}\text { Patients were } \\
\text { not treated with } \\
\text { any mineral or } \\
\text { vitamin } \\
\text { supplements. } \\
\text { ND about other } \\
\text { treatment } \\
\text { strategies. }\end{array}$ & $\begin{array}{l}\text { All of the patients were } \\
\text { diagnosed with } \\
\text { schizophrenia. Patients } \\
\text { with diabetes, , kidney } \\
\text { failure, or other } \\
\text { coexisting diseases, as } \\
\text { well as those with } \\
\text { schizophrenia, but with } \\
\text { additional psychiatric } \\
\text { conditions-were } \\
\text { excluded from the study. }\end{array}$ \\
\hline [154] & $\begin{array}{l}\text { Santa Cruz } \\
\text { et al. }\end{array}$ & 2020 & Brazil & 11 & 11 & $33.7 \pm 7.9$ & $35.9 \pm 7.0$ & $\begin{array}{c}3(\mathrm{SG}) \\
7(\mathrm{CG}) \\
\text { Females }\end{array}$ & $\begin{array}{l}\mathrm{Cu}, \mathrm{Fe}, \mathrm{Zn} \\
\mathrm{Mg}, \mathrm{Se}, \mathrm{K} \\
\mathrm{P}, \mathrm{Ca}\end{array}$ & $\begin{array}{l}\text { Elements concentrations } \\
\text { were determined by } \\
\text { the ICP-MS. }\end{array}$ & $\begin{array}{c}\text { Schizophrenics present } \\
\text { significantly lower serum } \\
\text { Se and Zn concentrations } \\
\text { compared to CG. Serum } \\
\text { Fe levels are significantly } \\
\text { higher }(p<0.05) \text { in SC } \\
\text { compared to CG. A } \\
\text { significantly higher } \\
\text { Cu/Zn ratio was } \\
\text { determined in SG } \\
\text { (ratio }=2.4, p=0.028) \text {. }\end{array}$ & $\begin{array}{l}1 \text { patient was } \\
\text { treated with } \\
\text { anticonvulsants, } \\
2 \text { with } \\
\text { anxiolytics, } \\
9 \text { with } \\
\text { antipsychotics, } \\
\text { and } 3 \text { with } \\
\text { antidepressants. }\end{array}$ & $\begin{array}{l}\text { The whole studied } \\
\text { cohort included } 37 \\
\text { patients-11 } \\
\text { schizophrenics, } \\
11 \text { controls, } 7 \text { with } \\
\text { bipolar disorder treated } \\
\text { with Li and } 8 \text { with } \\
\text { bipolar disorder treated } \\
\text { with medicaments other } \\
\text { than Li. Control group } \\
\text { included patients } \\
\text { without any recognized } \\
\text { psychiatric conditions. } \\
\text { All of the patients did } \\
\text { not have diabetes, } \\
\text { kidney failure, or any } \\
\text { other coexisting } \\
\text { diseases. }\end{array}$ \\
\hline
\end{tabular}


Table 2. Cont

\begin{tabular}{|c|c|c|c|c|c|c|c|c|c|c|c|c|c|}
\hline Ref. & Authors & Year & Origin & $\begin{array}{c}\text { No. } \\
\text { Patients }\end{array}$ & $\begin{array}{c}\text { No. } \\
\text { Controls }\end{array}$ & $\begin{array}{l}\text { Age } \\
\text { (SG) }\end{array}$ & $\begin{array}{l}\text { Age } \\
\text { (CG) }\end{array}$ & Sex & $\begin{array}{c}\text { Trace } \\
\text { Elements }\end{array}$ & $\begin{array}{l}\text { Analytical Methods } \\
\text { for Serum Trace } \\
\text { Elements Detection }\end{array}$ & Results & $\begin{array}{c}\text { Drugs/ } \\
\text { Treatment }\end{array}$ & $\begin{array}{l}\text { Additional } \\
\text { Information }\end{array}$ \\
\hline [155] & Herrán et al. & 2000 & Spain & 62 & 62 & $38.9 \pm 11.7$ & $38.0 \pm 9.3$ & 32 (SG) Males & $\mathrm{Cu}, \mathrm{Zn}$ & $\begin{array}{c}\mathrm{Cu} \text { and } \mathrm{Zn} \\
\text { concentrations were } \\
\text { measured by atomic } \\
\text { absorption } \\
\text { spectrophotometry. }\end{array}$ & $\begin{array}{c}\text { Cu levels were } \\
\text { significantly higher } \\
(p=0.004) \text { in SG than in } \\
\text { CG. There was a } \\
\text { relationship within } \\
\text { sex-females had greater } \\
\text { serum Cu levels. Patients } \\
\text { with neuroleptic } \\
\text { treatment had higher } \mathrm{Cu} \\
\text { levels (mean } 127.9 \mu \mathrm{d} / \mathrm{dL} ; \\
\pm 23.3) \text {, than those treated } \\
\text { with oral antipsychotics } \\
(113.7 \pm 22.8)(p=0.036) \text {. } \\
\text { Serum Cu levels were not } \\
\text { affected by } \\
\text { typical/atypical } \\
\text { antipsychotics or current } \\
\text { neuroleptic dosage. } \\
\text { Zn levels were } \\
\text { non-significantly higher } \\
\text { in SG and male patients } \\
\text { presented higher serum } \\
\text { Zn levels. There were no } \\
\text { differences in serum } \mathrm{Zn} \\
\text { levels in patients treated } \\
\text { with neuroleptics. }\end{array}$ & $\begin{array}{c}\text { Out of } 62 \\
\text { patients, } 5 \text { were } \\
\text { without } \\
\text { pharmacological } \\
\text { treatment. } 17 \\
\text { patients were } \\
\text { taking depot } \\
\text { neuroleptics, } \\
\text { and 19-atypical } \\
\text { antipsychotics. }\end{array}$ & $\begin{array}{l}\text { Patients with } \\
\text { schizophrenia and other } \\
\text { coexisting psychiatric } \\
\text { conditions were } \\
\text { excluded from the study. } \\
\text { Additional exclusion } \\
\text { criteria included: } \\
\text { pregnancy, medical } \\
\text { disorders (immune, } \\
\text { endocrine, liver, } \\
\text { cirrhosis), and drugs } \\
\text { (which are known to } \\
\text { affect trace elements } \\
\text { levels). CG were not } \\
\text { diagnosed with any } \\
\text { psychiatric disorder, CG } \\
\text { had never taken } \\
\text { psychotropic drugs, or } \\
\text { any kind of psychiatric } \\
\text { treatment. None of the } \\
\text { patients presented } \\
\text { gastrointestinal } \\
\text { disorders, or signs of } \\
\text { malnutrition. Median of } \\
\text { schizophrenia duration } \\
\text { among SG is } 1 \text { years } \\
\text { and } 2 \text { hospital } \\
\text { admissions. SG } \\
\text { primarily included } \\
\text { patients with negative } \\
\text { symptoms and residual } \\
\text { schizophrenia. }\end{array}$ \\
\hline
\end{tabular}


Table 2. Cont

\begin{tabular}{|c|c|c|c|c|c|c|c|c|c|c|c|c|c|}
\hline Ref. & Authors & Year & Origin & $\begin{array}{c}\text { No. } \\
\text { Patients }\end{array}$ & $\begin{array}{c}\text { No. } \\
\text { Controls }\end{array}$ & $\begin{array}{l}\text { Age } \\
\text { (SG) }\end{array}$ & $\begin{array}{l}\text { Age } \\
\text { (CG) }\end{array}$ & Sex & $\begin{array}{c}\text { Trace } \\
\text { Elements }\end{array}$ & $\begin{array}{l}\text { Analytical Methods } \\
\text { for Serum Trace } \\
\text { Elements Detection }\end{array}$ & Results & $\begin{array}{c}\text { Drugs/ } \\
\text { Treatment }\end{array}$ & $\begin{array}{l}\text { Additional } \\
\text { Information }\end{array}$ \\
\hline [156] & Cao et al. & 2019 & China & 105 & 106 & $29.3 \pm 5.6$ & $30.65 \pm 4.6$ & $\begin{array}{c}4 \text { (SG) } \\
38 \text { (CG) Males }\end{array}$ & $\begin{array}{c}\mathrm{Zn}, \mathrm{Mn}, \mathrm{Cu} \\
\mathrm{Fe}, \mathrm{Co} \\
\mathrm{Ni}, \mathrm{Mo}\end{array}$ & $\begin{array}{l}\text { Elements concentrations } \\
\text { were determined by } \\
\text { the ICP-MS. }\end{array}$ & $\begin{array}{l}\text { SG has reduced serum } \\
\text { Mn }(\mathrm{q}<0.001) \text { and Mo } \\
(\mathrm{q}=0.009) \text { concentrations, } \\
\text { and increased Ni } \\
(\mathrm{q}=0.009) \text { and } \mathrm{Fe} \\
(\mathrm{q}=0.012) \text { concentrations } \\
\text { compared to CG. No } \\
\text { significant changes were } \\
\text { observed in cases of other } \\
\text { trace element levels. } \\
\text { First-episode } \\
\text { schizophrenia } \\
\text { characterized with lower } \\
\text { Mn concentrations, } \\
\text { whereas recurrent } \\
\text { schizophrenia - with } \\
\text { lowered Mn and Mo } \\
\text { levels, compared to CG. } \\
\text { Recurrent schizophrenia } \\
\text { characterized with } \\
\text { elevated serum Fe and Ni } \\
\text { levels compared to CG. }\end{array}$ & $\begin{array}{c}\text { SG was not } \\
\text { taking any } \\
\text { antipsychotic } \\
\text { drugs for a } \\
\text { minimum } 1 \\
\text { month before } \\
\text { hospitalization. }\end{array}$ & $\begin{array}{l}\text { SG included patients } \\
\text { who did not receive } \\
\text { antipsychotic treatment } \\
\text { for a minimum } 1 \text { month } \\
\text { before hospitalization. } \\
\text { HC was a group of } \\
\text { patients without any } \\
\text { current and/or past } \\
\text { psychiatric conditions. } \\
\text { Exclusion criteria were } \\
\text { as following: }<18 \text { or > } 40 \\
\text { years old, exposure to } \\
\text { heavy metal industry, } \\
\text { coexisting diseases, } \\
\text { presence of additional } \\
\text { psychiatric conditions, } \\
\text { current or recent } \\
\text { pregnancy and/or } \\
\text { breastfeeding. } 24 \text { of } 105 \\
\text { patients from SG were } \\
\text { drug-naïve and during } \\
\text { first-episode } \\
\text { schizophrenia, } \\
\text { remaining 81 had } \\
\text { recurrent and/or chronic } \\
\text { schizophrenia. } \\
\text { Additionally, several } \\
\text { other paratemeters were } \\
\text { studied: fasting blood } \\
\text { glucose (FBG), } \\
\text { triglycerides (TG), total } \\
\text { cholesterol (TC), } \\
\text { aspartate } \\
\text { aminotransferase (AST), } \\
\text { alanine } \\
\text { aminotransferase (ALT), } \\
\text { albumin (ALB), total } \\
\text { protein (TP), creatinine } \\
\text { (CREA), and uric } \\
\text { acid (UA). }\end{array}$ \\
\hline
\end{tabular}


Table 2. Cont.

\begin{tabular}{|c|c|c|c|c|c|c|c|c|c|c|c|c|c|}
\hline Ref. & Authors & Year & Origin & $\begin{array}{c}\text { No. } \\
\text { Patients }\end{array}$ & $\begin{array}{c}\text { No. } \\
\text { Controls }\end{array}$ & $\begin{array}{l}\text { Age } \\
\text { (SG) }\end{array}$ & $\begin{array}{l}\text { Age } \\
\text { (CG) }\end{array}$ & Sex & $\begin{array}{c}\text { Trace } \\
\text { Elements }\end{array}$ & $\begin{array}{l}\text { Analytical Methods } \\
\text { for Serum Trace } \\
\text { Elements Detection }\end{array}$ & Results & $\begin{array}{c}\text { Drugs/ } \\
\text { Treatment }\end{array}$ & $\begin{array}{l}\text { Additional } \\
\text { Information }\end{array}$ \\
\hline [157] & Chen et al. & 2017 & China & 165 & 614 & $28.83 \pm 12.54$ & $37.45 \pm 12.12$ & $\begin{array}{c}66(\mathrm{SG}) \\
518(\mathrm{CG}) \\
\text { Males }\end{array}$ & $\begin{array}{l}\mathrm{Mg}, \mathrm{Cu}, \mathrm{Ca}, \\
\mathrm{P}, \mathrm{Fe}, \mathrm{Zn}\end{array}$ & $\begin{array}{c}\text { Serum } \mathrm{Cu}, \mathrm{Zn} \text {, and } \mathrm{Fe} \\
\text { were determined by the } \\
\text { colorimetric method, } \\
\text { serum Ca-by arsenazo } \\
\text { III method, serum } \\
\text { Mg-by xylidyl blue } \\
\text { method, and serum } \\
\text { P-by ultraviolet } \\
\text { spectrophotometry } \\
\text { method. }\end{array}$ & 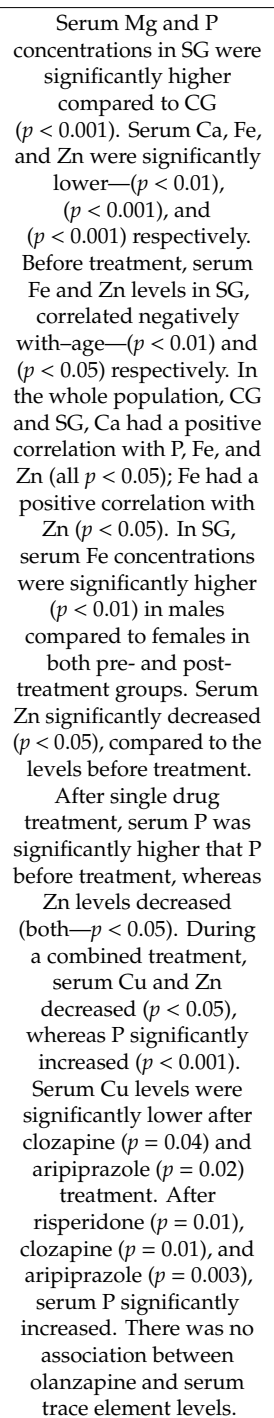 & $\begin{array}{l}\text { Antipsychotic } \\
\text { drugs included: } \\
\text { risperidone, } \\
\text { clozapine, } \\
\text { olanzapine, } \\
\text { aripiprazole, } \\
\text { quetiapine, } \\
\text { perphenazine, } \\
\text { sulpiride, and } \\
\text { ziprasidone. }\end{array}$ & $\begin{array}{c}\text { Schizophrenic } \\
\text { patients with } \\
\text { cardiovascular/cerebral } \\
\text { vascular disease, liver } \\
\text { disease, nephropathy, } \\
\text { and/or immunological } \\
\text { diseases, as well as } \\
\text { other concurrent } \\
\text { diseases, were excluded } \\
\text { from the study. SG was } \\
\text { classified into four } \\
\text { groups: mixed type SZ } \\
(n=103), \text { paranoid SZ } \\
(n=21) \text {, acute SZ } \\
(n=19) \text {, and } \\
\text { schizotypal SZ }(n=15) \text {. }\end{array}$ \\
\hline
\end{tabular}


Table 2. Cont

\begin{tabular}{|c|c|c|c|c|c|c|c|c|c|c|c|c|c|}
\hline Ref. & Authors & Year & Origin & $\begin{array}{c}\text { No. } \\
\text { Patients }\end{array}$ & $\begin{array}{c}\text { No. } \\
\text { Controls }\end{array}$ & $\begin{array}{l}\text { Age } \\
\text { (SG) }\end{array}$ & $\begin{array}{l}\text { Age } \\
\text { (CG) }\end{array}$ & Sex & $\begin{array}{c}\text { Trace } \\
\text { Elements }\end{array}$ & $\begin{array}{l}\text { Analytical Methods } \\
\text { for Serum Trace } \\
\text { Elements Detection }\end{array}$ & Results & $\begin{array}{c}\text { Drugs/ } \\
\text { Treatment }\end{array}$ & $\begin{array}{l}\text { Additional } \\
\text { Information }\end{array}$ \\
\hline & & & & & & & & & & & $\begin{array}{c}\text { After treatment, serum } \mathrm{P} \\
\text { increased significantly in } \\
\text { mixed type schizophrenia } \\
(p<0.001), \text { paranoid } \\
\text { schizophrenia }(p<0.05), \\
\text { and acute schizophrenia } \\
(p<0.05) \text {. Serum } \mathrm{Zn} \\
\text { levels decreased } \\
\text { significantly in mixed } \\
\text { schizophrenia }(p<0.01), \\
\text { acute schizophrenia } \\
(p<0.05) \text { and schizotypal } \\
\text { schizophrenia }(p<0.05) \\
\text { compared to levels before } \\
\text { treatment. Further, Fe } \\
\text { levels were significantly } \\
\text { higher in acute } \\
\text { schizophrenic patients } \\
\text { compared to schizotypal } \\
\text { schizophrenia before } \\
\text { treatment }(p<0.05) .\end{array}$ & & \\
\hline [158] & $\begin{array}{l}\text { Devanarayanan } \\
\text { et al. }\end{array}$ & 2016 & India & 40 & 40 & $29 \pm 6$ & $27 \pm 4$ & 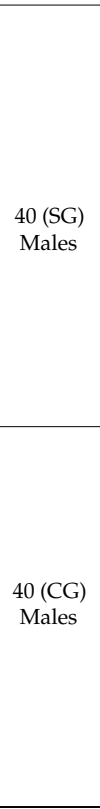 & $\mathrm{Cu}$ & $\begin{array}{c}\text { Cu levels were } \\
\text { measured applying } \\
\text { reagent kits by } \\
\text { micro-titer plate reader } \\
\text { by colorimetric method. }\end{array}$ & $\begin{array}{c}\text { Drug naive patients } \\
(n=22) \text { had significantly } \\
\text { higher serum Cu levels } \\
\text { compared to CG } \\
(p=0.026) \text {. Serum Cu } \\
\text { correlated significantly } \\
\text { with high-sensitivity } \\
\text { C-reactive } \\
\text { High-sensitivity } \\
\text { C-reactive Protein } \\
\text { (h-CRP) }(p=0.003) \text {. } \\
\text { Serum Cu levels did not } \\
\text { correlate with PANSS } \\
\text { scores; serum Cu levels } \\
\text { are not associated with } \\
\text { the severity of } \\
\text { schizophrenia. }\end{array}$ & $\begin{array}{l}\text { SG was not } \\
\text { taking any } \\
\text { drugs for } \\
\text { schizophrenia } \\
\text { for } 4 \text { weeks } \\
\text { before study. }\end{array}$ & $\begin{array}{c}\text { SG constituted of } 40 \\
\text { male patients (22 drug } \\
\text { naive and } 18 \text { drug free). } \\
\text { Patients from SG } \\
\text { included those who } \\
\text { were not on any } \\
\text { treatment for SZ for at } \\
\text { least } 4 \text { weeks. Exclusion } \\
\text { criteria were: } \\
\text { concurrent psychiatric } \\
\text { conditions, dependency } \\
\text { on drugs (other than } \\
\text { caffeine), unstable } \\
\text { medicala and//or } \\
\text { neurological conditions. } \\
\text { The same exclusion } \\
\text { criteria were for CG. } \\
\text { Despite serum Cu } \\
\text { levels, blood glucose, } \\
\text { total cholesterol, } \\
\text { triaacylglycerol, } \\
\text { high-density } \\
\text { lipoprotein (HDL), } \\
\text { very-low-density } \\
\text { lipoprotein (VLDL), and } \\
\text { low-density lipoprotein } \\
\text { (LDL)-cholesterol, } \\
\text { ceruloplasmin, and } \\
\text { hs-C-reactive protein } \\
\text { were investigated. }\end{array}$ \\
\hline
\end{tabular}


Table 2. Cont.

\begin{tabular}{|c|c|c|c|c|c|c|c|c|c|c|c|c|c|}
\hline Ref. & Authors & Year & Origin & $\begin{array}{c}\text { No. } \\
\text { Patients }\end{array}$ & $\begin{array}{c}\text { No. } \\
\text { Controls }\end{array}$ & $\begin{array}{l}\text { Age } \\
\text { (SG) }\end{array}$ & $\begin{array}{l}\text { Age } \\
\text { (CG) }\end{array}$ & Sex & $\begin{array}{c}\text { Trace } \\
\text { Elements }\end{array}$ & $\begin{array}{l}\text { Analytical Methods } \\
\text { for Serum Trace } \\
\text { Elements Detection }\end{array}$ & Results & $\begin{array}{c}\text { Drugs/ } \\
\text { Treatment }\end{array}$ & $\begin{array}{l}\text { Additional } \\
\text { Information }\end{array}$ \\
\hline [159] & $\begin{array}{l}\text { Edelstein } \\
\text { et al. }\end{array}$ & 1959 & Jerusalem & 20 & 10 & $\begin{array}{l}22-45 \\
\text { (range) }\end{array}$ & 22-45 (range) & ND & $\mathrm{Cu}$ & $\begin{array}{l}\text { Cu levels were } \\
\text { determined by a } \\
\text { photo-electric } \\
\text { colorimeter (Lumetron } \\
\text { model 402-E) }\end{array}$ & $\begin{array}{l}\text { No significant increase in } \\
\text { serum Cu in SG was } \\
\text { found, compared to CG. }\end{array}$ & $\begin{array}{l}\text { Patients did not } \\
\text { receive any SZ } \\
\text { treatment. }\end{array}$ & $\begin{array}{c}\text { Among } 20 \\
\text { schizophrenics, } 10 \text { were } \\
\text { paranoid, } 3 \text { catatonics, } \\
2 \text { hebephrenics, } 3 \\
\text { simplex, and } 2 \text { of the } \\
\text { circular form. } \\
\end{array}$ \\
\hline [160] & $\begin{array}{l}\text { Frohman } \\
\text { et al. }\end{array}$ & 1958 & USA & 16 & $\begin{array}{c}11 \\
\text { (healthy) } \\
+9 \text { (with } \\
\text { psychiatric } \\
\text { conditions } \\
\text { other } \\
\text { than SZ) }\end{array}$ & ND & ND & ND & $\mathrm{Cu}, \mathrm{Fe}$ & $\begin{array}{l}\text { Bausch \& Lomb } \\
\text { spectrophotometer at } \\
485 \mathrm{~m} / \mu \text { wavelength }\end{array}$ & $\begin{array}{l}\text { CG and SG did not differ } \\
\text { in serum cu levels. Serum } \\
\text { Fe levels were lower in SG } \\
(p=0.05) \text {, however serum } \\
\text { Fe levels were lowered in } \\
\text { all of the patients sera. }\end{array}$ & & $\begin{array}{l}\text { Among } 16 \text { patients, } \\
11 \text { had chronic } S Z \text { and } 5 \\
\text { acute SZ. The duration } \\
\text { of } S Z \text { was more than } \\
2 \text { years. In a CG: } \\
3 \text { patients were } \\
\text { diagnosed as neurotic, } 3 \\
\text { with manic-depressive } \\
\text { disorder, } 2 \text { with } \\
\text { personality disorder, } \\
\text { and } 1 \text { with organic brain } \\
\text { syndrome. SG and CG } \\
\text { were on the same diet. }\end{array}$ \\
\hline [161] & Li et al. & 2017 & China & 158 & 669 & $45.46 \pm 11.00$ & $46.73 \pm 12.58$ & 72 (SG) Males & $\begin{array}{c}\mathrm{Cr}, \mathrm{Zn}, \mathrm{Se}, \\
\mathrm{Cd}, \mathrm{Cu}, \mathrm{Pb}, \\
\mathrm{As}, \mathrm{K}, \mathrm{Ca} \\
\mathrm{Mg}, \mathrm{Fe} \\
\mathrm{B}, \mathrm{Mn}\end{array}$ & $\begin{array}{l}\text { Elements were detected } \\
\text { by the ICP-MS. }\end{array}$ & $\begin{array}{l}\text { Serum } \mathrm{Mn}, \mathrm{Se}, \mathrm{Cd}, \mathrm{Pb}, \mathrm{Ca} \text {, } \\
\mathrm{Cu} \text {, and } \mathrm{Fe} \text { in } \mathrm{SG} \text { were } \\
\text { lower compared to CG. } \\
\text { Serum } \mathrm{B}, \mathrm{Cr}, \mathrm{As}, \mathrm{K}, \text { and } \\
\mathrm{Mg} \text { levels were higher in } \\
\mathrm{SG} \text { compared to CG. } \\
\text { Serum Pb levels were the } \\
\text { highest in the group }<29 \\
\text { years old. }\end{array}$ & $\begin{array}{l}\text { Therapy } \\
\text { included } \\
\text { risperidone, } \\
\text { olanzapine, and } \\
\text { quetiapine. } \\
\text { 21 patients were } \\
\text { taking Se } \\
\text { supplements. }\end{array}$ & $\begin{array}{c}\text { The duration of male SZ } \\
\text { was between } 1 \text { and } 45 \\
\text { years (mean } 13 \text { years). } \\
\text { The course of female SZ } \\
\text { was between } 1 \text { and } 43 \\
\text { years (mean } 12 \text { years). } \\
21 \text { SZ patients } \\
\text { (16 females, } 5 \text { males) } \\
\text { with low Se levels were } \\
\text { selected to take Se } \\
\text { supplements. Daily } \\
\text { dose of Se was about } 60 \\
\text { } 6 \text {. Serum was } \\
\text { collected after } 1 \text { and } 3 \\
\text { months after Se } \\
\text { supplementation. CG } \\
\text { did not have any } \\
\text { concurrent diseases. } \\
\text { Exclusion criteria for } \\
\text { both groups (SG and } \\
\text { CG) were: smoking } \\
\text { and/or drinking, } \\
\text { immune system disease, } \\
\text { malnutrition, history of } \\
\text { cardiovascular disease, } \\
\text { trace elements } \\
\text { supplementation. } \\
\end{array}$ \\
\hline
\end{tabular}


Table 2. Cont

\begin{tabular}{|c|c|c|c|c|c|c|c|c|c|c|c|c|c|}
\hline Ref. & Authors & Year & Origin & $\begin{array}{c}\text { No. } \\
\text { Patients }\end{array}$ & $\begin{array}{c}\text { No. } \\
\text { Controls }\end{array}$ & $\begin{array}{l}\text { Age } \\
\text { (SG) }\end{array}$ & $\begin{array}{l}\text { Age } \\
\text { (CG) }\end{array}$ & Sex & $\begin{array}{c}\text { Trace } \\
\text { Elements }\end{array}$ & $\begin{array}{l}\text { Analytical Methods } \\
\text { for Serum Trace } \\
\text { Elements Detection }\end{array}$ & Results & $\begin{array}{c}\text { Drugs/ } \\
\text { Treatment }\end{array}$ & $\begin{array}{l}\text { Additional } \\
\text { Information }\end{array}$ \\
\hline [162] & Maas et al. & 1961 & USA & 20 & 20 & ND & ND & ND & $\mathrm{Cu}$ & $\begin{array}{l}\text { Sample incubation for } \\
10 \text { min with } \\
\text { hydrochloric acid. }\end{array}$ & $\begin{array}{l}\text { Serum Cu levels were not } \\
\text { significantly different in } \\
\text { SG compared to CG } \\
\text { (patients with neuroses or } \\
\text { personality disorder). } \\
\text { There was also no } \\
\text { significant difference } \\
\text { between anxious and } \\
\text { non-anxious groups. }\end{array}$ & ND & $\begin{array}{l}\text { The whole study group } \\
\text { included: } 10 \text { extremely } \\
\text { anxious schizophrenics, } \\
10 \text { non-anxious } \\
\text { schizophrenics, } 10 \\
\text { extremely anxious } \\
\text { nonpsychotic patients, } \\
\text { and } 10 \text { non-anxious } \\
\text { non-psychotic patients. } \\
\text { Patients who have taken } \\
\text { phenothiazines, } \\
\text { antidepressants, or } \\
\text { psychic energizers } 2 \\
\text { weeks before, were } \\
\text { excluded from the study. } \\
\text { Patients with additional } \\
\text { concurrent diseases } \\
\text { were excluded. }\end{array}$ \\
\hline [163] & Munch-Petersen & 1950 & Denmark & 40 & ND & $\begin{array}{c}21-50 \text { (range) } \\
\text { Males } \\
23-48 \\
\text { (range) } \\
\text { Females }\end{array}$ & ND & $\begin{array}{c}24(\mathrm{SG}) \\
\text { Males } \\
16(\mathrm{SG}) \\
\text { Females }\end{array}$ & $\mathrm{Cu}$ & $\begin{array}{l}\text { Cu determination was } \\
\text { done by the color } \\
\text { reaction with sodium } \\
\text { diethyldithiocarbamate. }\end{array}$ & $\begin{array}{c}\text { Serum Cu levels in SG are } \\
\text { within the } \\
\text { physiological limits. }\end{array}$ & $\begin{array}{l}\text { Most of the } \\
\text { patients were } \\
\text { treated with } \\
\text { shock (by means } \\
\text { of insulin, or } \\
\text { combined with } \\
\text { metrazol shock, } \\
\text { or electroshock) }\end{array}$ & $\begin{array}{l}\text { The duration of } \mathrm{SZ} \text { in } \\
\text { patients was between } 2 \\
\text { and } 32 \text { years, and } 4 \text { and } \\
24 \text { years in males and } \\
\text { females respectively. }\end{array}$ \\
\hline [164] & $\begin{array}{l}\text { Olatunbosun } \\
\text { et al. }\end{array}$ & 1975 & Nigeria & 102 & 95 & $\begin{array}{c}33(\mathrm{SG}) \\
\text { Males } \\
32(\mathrm{SG}) \\
\text { Females }\end{array}$ & $\begin{array}{c}32(\mathrm{CG}) \\
\text { Males } \\
31(\mathrm{CG}) \\
\text { Females }\end{array}$ & $\begin{array}{c}74(\mathrm{SG}) \\
\text { Males } \\
28(\mathrm{SG}) \\
\text { Females } \\
67(\mathrm{CG}) \\
\text { Males } \\
44(\mathrm{CG}) \\
\text { Females } \\
\end{array}$ & $\mathrm{Cu}$ & $\begin{array}{l}\text { Cu levels were } \\
\text { determined in } \\
\text { deproteinized serum in } \\
\text { a Beckman Model } 495 \\
\text { Atomic Absorption } \\
\text { Spectrophotometer. }\end{array}$ & $\begin{array}{c}\text { The average serum Cu } \\
\text { levels in SZ males was } \\
\text { significantly higher } \\
\text { compared to CG }(p< \\
\text { 0.001). Likewise, serum } \\
\text { Cu levels in SZ females } \\
\text { was significantly higher } \\
\text { compared to CG, however } \\
\text { without any } \\
\text { statistical significance. }\end{array}$ & $\begin{array}{l}\text { Treatment of all } \\
\text { patients was } \\
\text { similar and } \\
\text { included: } \\
\text { chlorpromazine, } \\
\text { amitriptyline, } \\
\text { trifluoperazine, } \\
\text { thioridazine, and } \\
\text { electroconvulsive } \\
\text { therapy. }\end{array}$ & $\begin{array}{l}\text { The duration of } S Z \\
\text { varied from } 3 \text { months to } \\
15 \text { years. }\end{array}$ \\
\hline [165] & Wolf et al. & 2006 & USA & 10 & 8 & $\begin{array}{c}34.5 \\
\text { (mean age of } \\
\text { SG + CG) }\end{array}$ & - & $\begin{array}{l}10(\mathrm{SG}) \\
\text { Males }\end{array}$ & $\mathrm{Cu}, \mathrm{Fe}$ & $\begin{array}{l}\text { In the serum samples, } \\
\text { Fe was assayed by } \\
\text { absorbance photometry } \\
\text { by guanidine/ferrozine } \\
\text { method. Cu was } \\
\text { assayed by atomic } \\
\text { absorption } \\
\text { spectrophotometry. }\end{array}$ & $\begin{array}{l}\text { SG had significantly } \\
\text { higher serum Cu levels. } \\
\text { Fe levels and iron binding } \\
\text { capacity did not differ in } \\
\text { both groups. }\end{array}$ & $\begin{array}{l}\text { Three subjects } \\
\text { did not receive } \\
\text { any treatment, } \\
7 \text { were on } \\
\text { 'typical' } \\
\text { antipsychotic } \\
\text { treatment. None } \\
\text { of the subjects } \\
\text { received typical } \\
\text { antipsychotics. }\end{array}$ & $\begin{array}{c}\text { All of the subjects met } \\
\text { RDC broad criteria for } \\
\text { schizophrenia. } \\
8 \text { subjects met } \\
\text { DSM-III-R criteria for } \\
\text { schizophrenia, } \\
2 \text { subjects-for } \\
\text { schizoaffective disorder. } \\
\text { All of the subjects did } \\
\text { not have concurrent } \\
\text { diseases, or history of } \\
\text { substance abuse. } \\
\text { CG did not have any } \\
\text { psychiatric or } \\
\text { physical disorders. }\end{array}$ \\
\hline
\end{tabular}


Table 2. Cont.

\begin{tabular}{|c|c|c|c|c|c|c|c|c|c|c|c|c|c|}
\hline Ref. & Authors & Year & Origin & $\begin{array}{c}\text { No. } \\
\text { Patients }\end{array}$ & $\begin{array}{c}\text { No. } \\
\text { Controls }\end{array}$ & $\begin{array}{l}\text { Age } \\
\text { (SG) }\end{array}$ & $\begin{array}{l}\text { Age } \\
\text { (CG) }\end{array}$ & Sex & $\begin{array}{c}\text { Trace } \\
\text { Elements }\end{array}$ & $\begin{array}{l}\text { Analytical Methods } \\
\text { for Serum Trace } \\
\text { Elements Detection }\end{array}$ & Results & $\begin{array}{c}\text { Drugs/ } \\
\text { Treatment }\end{array}$ & $\begin{array}{l}\text { Additional } \\
\text { Information }\end{array}$ \\
\hline [166] & Wasti et al. & 2013 & Pakistan & 120 & 44 & $\begin{array}{c}29.07 \pm 9.05 \\
\text { (SG treated } \\
\quad \text { with } \\
\text { haloperidol) } \\
27.0 \pm 7.10 \\
\text { (SG treated } \\
\text { with } \\
\text { clozapine) }\end{array}$ & ND & ND & $\mathrm{Fe}$ & ND & $\begin{array}{l}\text { SG presented decreased } \\
\text { serum Fe and ferritin } \\
\text { levels, and increased level } \\
\text { of total iron-binding } \\
\text { capacity (TIBC) in SG } \\
\text { treated with haloperidol } \\
\text { compared to CG. Patients } \\
\text { treated with clozapine did } \\
\text { not show any significant } \\
\text { changes in serum Fe } \\
\text { levels, except for lowered } \\
\text { ferritin levels. }\end{array}$ & $\begin{array}{l}\text { SG was on a } \\
\text { chronic } \\
\text { haloperidol } \\
(n=92) \text { and } \\
\text { clozapine } \\
(n=28) \\
\text { treatment for } \\
\text { more than } \\
12 \text { weeks. }\end{array}$ & $\begin{array}{l}\text { CG included only } \\
\text { patients with o history } \\
\text { of psychiatric } \\
\text { conditions, or other } \\
\text { concurrent diseases. } \\
\text { Besides serum Fe levels, } \\
\text { TIBC, and serum ferritin } \\
\text { levels were measured. }\end{array}$ \\
\hline [167] & Barnes et al. & 1992 & UK & 105 & ND & $\begin{array}{l}31-65 \\
\text { (range) }\end{array}$ & ND & $\begin{array}{l}26(\mathrm{SG}) \\
\text { Females }\end{array}$ & $\mathrm{Fe}$ & ND & $\begin{array}{l}\text { There was no significant } \\
\text { correlation between } \\
\text { serum Fe levels and daily } \\
\text { dose of antipsychotic } \\
\text { drug }(\mathrm{r}=0.03) \text {. There was } \\
\text { also a significant } \\
\text { correlation between } \\
\text { serum Fe levels in groups } \\
\text { either receiving and those } \\
\text { who were not receiving } \\
\text { oral antipsychotic } \\
\text { medication. There was no } \\
\text { strong relationship } \\
\text { between serum Fe } \\
\text { concentrations and the } \\
\text { severity of akathisia } \\
\text { (r }=0.16, p=0.45) \text {. Serum } \\
\text { Fe levels were lower in } \\
\text { chronic akathisia patients } \\
\text { compared to those } \\
\text { without akathisia, } \\
\text { however, without a } \\
\text { statistical significance } \\
\text { (p=0.224). Serum Fe } \\
\text { levels were higher in the } \\
\text { pseudoakathisia group } \\
\text { compared to } \\
\text { non-akathisia group, and } \\
\text { significantly higher } \\
\text { compared to chronic } \\
\text { akathisia group }(p=0.051 \\
\text { and } p=0.004 \\
\text { respectively). Serum Fe } \\
\text { levels were slightly higher } \\
\text { in males compared to } \\
\text { females, but without any } \\
\text { statistical significance. }\end{array}$ & $\begin{array}{c}\text { For each patient, } \\
\text { the antipsychotic } \\
\text { drug was } \\
\text { converted to } \\
\text { chlorpromazine } \\
\text { equivalents in } \\
\text { mg per day. } 26 \\
\text { patients were } \\
\text { taking depot, } \\
\text { but not oral } \\
\text { medication, } \\
\text { whereas } 3 \\
\text { patients were } \\
\text { not receiving } \\
\text { any antipsychotic } \\
\text { drugs. Patients } \\
\text { with chronic } \\
\text { akathisia were } \\
\text { taking higher } \\
\text { doses of } \\
\text { antipsychotic } \\
\text { drugs compared } \\
\text { to those } \\
\text { without akathisia. }\end{array}$ & $\begin{array}{l}\text { A total sample of } 105 \\
\text { subjects included: } 24 \\
\text { with chronic akathisia, } \\
21 \text { with } \\
\text { pseudoakathisia, and } 60 \\
\text { with no akathisia. The } \\
\text { severity of akathisia } \\
\text { was mild in } 13 \text { cases, } \\
\text { moderate in } 8, \text { marked } \\
\text { in 2, and severe in } 1 \text { case. }\end{array}$ \\
\hline
\end{tabular}


Table 2. Cont

\begin{tabular}{|c|c|c|c|c|c|c|c|c|c|c|c|c|c|}
\hline Ref. & Authors & Year & Origin & $\begin{array}{c}\text { No. } \\
\text { Patients }\end{array}$ & $\begin{array}{c}\text { No. } \\
\text { Controls }\end{array}$ & $\begin{array}{l}\text { Age } \\
\text { (SG) }\end{array}$ & $\begin{array}{l}\text { Age } \\
\text { (CG) }\end{array}$ & Sex & $\begin{array}{c}\text { Trace } \\
\text { Elements }\end{array}$ & $\begin{array}{l}\text { Analytical Methods } \\
\text { for Serum Trace } \\
\text { Elements Detection }\end{array}$ & Results & $\begin{array}{c}\text { Drugs/ } \\
\text { Treatment }\end{array}$ & $\begin{array}{l}\text { Additional } \\
\text { Information }\end{array}$ \\
\hline [168] & $\begin{array}{l}\text { Hofmann } \\
\text { et al. }\end{array}$ & 2000 & Switzerland & 33 & 23 & $38.5 \pm 14.5$ & $34.0 \pm 9.6$ & $\begin{array}{c}13(\mathrm{CG}) \\
\text { Males } \\
10(\mathrm{CG}) \\
\text { Females }\end{array}$ & $\mathrm{Fe}$ & $\mathrm{ND}$ & $\begin{array}{l}\text { SG has serum Fe levels, } \\
\text { which were within } \\
\text { physiological range. Male } \\
\text { patients had slightly } \\
\text { higher serum Fe levels } \\
\text { than females, and } \\
\text { pre-menopausal females } \\
\text { had higher serum Fe } \\
\text { levels than } \\
\text { post-menopausal serum } \\
\text { Fe levels. However the } \\
\text { above-mentioned results } \\
\text { were not statistically } \\
\text { significant. No significant } \\
\text { differences were found } \\
\text { between SG and CG. }\end{array}$ & $\begin{array}{l}\text { Neuroleptic } \\
\text { medicamention } \\
\text { used in either } \\
\text { akathisic or } \\
\text { non-akathisic } \\
\text { group included: } \\
\text { haloperidol, } \\
\text { benperidol, } \\
\text { bromperidol, } \\
\text { perazine, } \\
\text { flupenthixol, } \\
\text { trifuopenazine, } \\
\text { pimozide, } \\
\text { chlopenthixol, or } \\
\text { chlorpromazine. } \\
\text { None of the } \\
\text { patients received } \\
\text { atypical } \\
\text { antipsychotics. }\end{array}$ & $\begin{array}{l}\text { SG included } 33 \text { subjects } \\
\text { among whom } 18 \text { had } \\
\text { SZ-13 paranoid, } \\
\text { episodic, and } 5 \\
\text { disorganized, catatonic } \\
\text { type. Non-akathisic } \\
\text { group included } 13 \mathrm{SZ} \\
\text { patients - } 8 \text { paranoid, } \\
\text { episodic, and } 5 \\
\text { disorganized, catatonic. } \\
\text { SG (akathisia group), } \\
\text { despite SZ, also } \\
\text { included patients with } \\
\text { schizoaffective disorder, } \\
\text { affective disorder } \\
\text { (psychotic mania or } \\
\text { depression), or } \\
\text { drug-induced psychosis } \\
\text { (amphetamine). CG } \\
\text { included patients with } \\
\text { SZ, schizoaffective } \\
\text { disorder, or mania with } \\
\text { psychotic features. } \\
\text { Besides serum Fe, } \\
\text { serum ferritin was } \\
\text { studied in both groups. }\end{array}$ \\
\hline [169] & Kim et al. & 2018 & Korea & 121 & ND & $\begin{array}{c}22.0-32.0 \\
\text { (range) }\end{array}$ & $\mathrm{ND}$ & $\begin{array}{l}73(\mathrm{SG}) \\
\text { Females }\end{array}$ & $\mathrm{Fe}$ & ND & $\begin{array}{l}\text { Latent Fe deficiency is } \\
\text { significantly associated } \\
\text { with negative symptoms } \\
\text { of SZ. SZ patients with } \\
\text { prominent negative } \\
\text { symptoms have also } \\
\text { significantly lower } \\
\text { ferritin levels. }\end{array}$ & $\begin{array}{c}\text { Patients were } \\
\text { taking: } \\
\text { amispulrpide } \\
(n=32), \\
\text { aripiprazole } \\
(n=21), \\
\text { paliperidone } \\
(n=53), \\
\text { risperidone } \\
(n=5), \\
\text { quetiapine } \\
(n=7), \text { and } \\
\text { none }(n=3) .\end{array}$ & $\begin{array}{l}\text { Inclusion criteria were } \\
\text { duration of treatment } \\
\text { for psychotic symptoms } \\
\text { less than } 2 \text { years, first } \\
\text { episode of } \\
\text { schizophrenia, } \\
\text { schizophreniform } \\
\text { disorder, or other } \\
\text { specified schizophrenia } \\
\text { spectrum disorder and } \\
\text { duration of treatment } \\
\text { less than } 2 \text { months. } \\
\text { Exclusion criteria } \\
\text { included: age less than } \\
18 \text { years, diagnosis of a } \\
\text { substance or medication } \\
\text { induced psychotic } \\
\text { disorder, psychotic } \\
\text { disorder due to other } \\
\text { medical conditions, or } \\
\text { other concurrent severe } \\
\text { medical conditions. } \\
\text { Among } 121 \text { subjects, } \\
77 \text { were diagnosed with } \\
\text { SZ, } 32 \text { were } \\
\text { schizophreniform, } \\
12 \text { were other specified. }\end{array}$ \\
\hline
\end{tabular}


Table 2. Cont

\begin{tabular}{|c|c|c|c|c|c|c|c|c|c|c|c|c|c|}
\hline Ref. & Authors & Year & Origin & $\begin{array}{c}\text { No. } \\
\text { Patients }\end{array}$ & $\begin{array}{c}\text { No. } \\
\text { Controls }\end{array}$ & $\begin{array}{l}\text { Age } \\
\text { (SG) }\end{array}$ & $\begin{array}{l}\text { Age } \\
\text { (CG) }\end{array}$ & Sex & $\begin{array}{c}\text { Trace } \\
\text { Elements }\end{array}$ & $\begin{array}{l}\text { Analytical Methods } \\
\text { for Serum Trace } \\
\text { Elements Detection }\end{array}$ & Results & $\begin{array}{c}\text { Drugs/ } \\
\text { Treatment }\end{array}$ & $\begin{array}{l}\text { Additional } \\
\text { Information }\end{array}$ \\
\hline [170] & Kuloglu et al. & 2003 & Turkey & 60 & 30 & $34.8 \pm 9.5$ & $35.1 \pm 9.2$ & 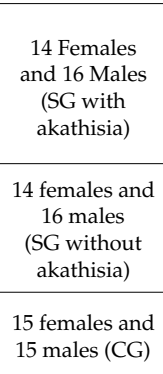 & $\mathrm{Fe}$ & $\begin{array}{l}\text { Serum Fe was measured } \\
\text { using Olympus } \\
\text { AU600 autoanalyzer. }\end{array}$ & $\begin{array}{c}\text { Serum Fe levels were } \\
\text { significantly lower in the } \\
\text { akathisic group }(p<0.001) \\
\text { and non-akathisic groups } \\
(p<0.001) \text { compared to } \\
\text { CG. TIBC was in akathisic } \\
\text { patients compared to CG } \\
(p<0.01) \text {. Ferritin levels } \\
\text { decreased in both SG } \\
\text { groups compared to CG } \\
(p<0.01) \text {. Transferrin } \\
\text { levels were not } \\
\text { statistically different } \\
\text { among studied groups. }\end{array}$ & $\begin{array}{l}\text { SZ patients were } \\
\text { treated with } \\
\text { chlorpromazine. }\end{array}$ & $\begin{array}{l}\text { SG included patients } \\
\text { with SZ-- } 30 \text { with } \\
\text { akathisia, and } 30 \\
\text { non-akathistic. Other } \\
\text { studied parameters } \\
\text { included TIBC, ferritin, } \\
\text { and transferrin. }\end{array}$ \\
\hline [171] & Soni et al. & 1993 & UK & 22 & 22 & 52 & $\mathrm{ND}$ & $\begin{array}{c}13(\mathrm{SG}) \\
\text { Females }\end{array}$ & $\mathrm{Fe}$ & $\begin{array}{l}\text { Serum Fe levels were } \\
\text { measured by the } \\
\text { ferrozine method. }\end{array}$ & $\begin{array}{l}\text { SG presented a higher } \\
\text { level of psychopathology } \\
\text { and positive symptoms; } \\
\text { such differences were not } \\
\text { observed in case of } \\
\text { negative symptoms. } \\
\text { Serum Fe, iron binding } \\
\text { capacity, and ferritin } \\
\text { levels did not differ } \\
\text { significantly between } \\
\text { both groups. Only } 2 \\
\text { patients showed low } \\
\text { serum Fe concentrations, } \\
\text { but finding was not } \\
\text { associated with increased } \\
\text { TIBC. Serum ferritin } \\
\text { levels were low in } 14 \\
\text { patients-6 from SG, and } \\
8 \text { from CG. } 1 \text { patient from } \\
\text { each group had increased } \\
\text { TIBC with low serum } \\
\text { ferritin levels. There was } \\
\text { no correlation between } \\
\text { akathisia severity and } \\
\text { serum Fe levels }(p=0.36), \\
\text { serum iron binding } \\
\text { capacity }(p=0.11), \text { or } \\
\text { serum ferritin }(p=0.49) \text {. }\end{array}$ & $\begin{array}{l}\text { All patients } \\
\text { except for four } \\
\text { subjects were } \\
\text { receiving depot } \\
\text { neuroleptic drugs, } \\
\text { either alone } \\
\text { (11 subjects), or } \\
\text { in combination } \\
\text { with oral } \\
\text { neuroleptics. } \\
15 \text { patients } \\
\text { (8 from akathisia } \\
\text { group), received } \\
\text { anticholinergic } \\
\text { drugs } \\
\text { (+ neuroleptic } \\
\text { medication) a } \\
\text { fortnight before } \\
\text { testing. } \\
3 \text { subjects were } \\
\text { treated with } \\
\text { antidepressants. }\end{array}$ & $\begin{array}{l}\text { Patients who were } \\
\text { included in the study } \\
\text { had to be in good } \\
\text { physical health and on } \\
\text { no other medication } \\
\text { than neuroleptics. } \\
\text { Exclusion criteria were } \\
\text { organic brain } \\
\text { syndromes, a history of } \\
\text { alcoholism or drug } \\
\text { abuse, Fe therapy, } \\
\text { cimetidine, or antacids. } \\
\text { A mean duration of } \\
\text { illness was estimated to } \\
22.8 \pm 14.9 \text {. }\end{array}$ \\
\hline
\end{tabular}


Table 2. Cont

\begin{tabular}{|c|c|c|c|c|c|c|c|c|c|c|c|c|c|}
\hline Ref. & Authors & Year & Origin & $\begin{array}{c}\text { No. } \\
\text { Patients }\end{array}$ & $\begin{array}{c}\text { No. } \\
\text { Controls }\end{array}$ & $\begin{array}{l}\text { Age } \\
\text { (SG) }\end{array}$ & $\begin{array}{l}\text { Age } \\
\text { (CG) }\end{array}$ & Sex & $\begin{array}{c}\text { Trace } \\
\text { Elements }\end{array}$ & $\begin{array}{l}\text { Analytical Methods } \\
\text { for Serum Trace } \\
\text { Elements Detection }\end{array}$ & Results & $\begin{array}{c}\text { Drugs/ } \\
\text { Treatment }\end{array}$ & $\begin{array}{l}\text { Additional } \\
\text { Information }\end{array}$ \\
\hline \multirow[t]{2}{*}{ [172] } & \multirow[t]{2}{*}{ Spina et al. } & \multirow[t]{2}{*}{1994} & \multirow[t]{2}{*}{ Italy } & $17^{* * *}$ & 16 & $42.5 \pm 5.3$ & $43.1 \pm 4.8$ & $\begin{array}{c}4(\mathrm{SG}) \\
\text { Females } \\
13(\mathrm{SG}) \\
\text { Males }\end{array}$ & $\mathrm{Fe}$ & \multirow[t]{2}{*}{$\begin{array}{c}\text { Serum Fe } \\
\text { concentrations were } \\
\text { measured using a } \\
\text { colorimetric method. }\end{array}$} & $\begin{array}{l}\text { There were no significant } \\
\text { differences in Fe, ferritin, } \\
\text { and transferrin levels in } \\
\text { both groups. }\end{array}$ & $\begin{array}{l}\text { Patients were } \\
\text { chronically } \\
\text { treated with oral } \\
\text { neuroleptics and } \\
\text { antiparkinsonian } \\
\text { drugs. Later, } \\
\text { neuroleptic } \\
\text { drugs were } \\
\text { converted to } \\
\text { chlorpromazine } \\
\text { equivalents. }\end{array}$ & $\begin{array}{l}\text { SG constituted a group } \\
\text { of } 17 \text { subjects who have } \\
\text { experienced one or } \\
\text { more dystonic reactions } \\
\text { during neurolpetic } \\
\text { treatment. A CG } \\
\text { constituted of } 16 \mathrm{SZ}, \\
\text { however, without a } \\
\text { history of } \\
\text { neuroleptic-induced } \\
\text { extrapyramidal } \\
\text { disorders. Exclusion } \\
\text { criteria were } \\
\text { non-steroid } \\
\text { anti-inflammatory } \\
\text { drugs, } \mathrm{H}_{2} \text {-histamine } \\
\text { antagonists, or antacids. }\end{array}$ \\
\hline & & & & $44^{* * * *}$ & ND & $\begin{array}{l}19-39 \\
\text { (range) }\end{array}$ & ND & $\begin{array}{l}44(\mathrm{SG}) \\
\text { Males }\end{array}$ & $\mathrm{Fe}$ & & $\begin{array}{l}\text { Serum Fe levels did not } \\
\text { differ significantly } \\
\text { between patients with or } \\
\text { without dystonia, either } \\
\text { on admission, or after } 3 \\
\text { weeks before } \\
\text { neuroleptic treatment. }\end{array}$ & $\begin{array}{l}37 \text { patients were } \\
\text { treated with } \\
\text { haloperidol, } \\
7 \text { with } \\
\text { bromperidol. }\end{array}$ & $\begin{array}{l}6 \text { patients experienced } \\
\text { acute dystonic reactions } \\
\text { during the } \\
\text { observation period. }\end{array}$ \\
\hline [173] & $\begin{array}{l}\text { Wirshing et } \\
\text { al. }\end{array}$ & 1998 & USA & 30 & $\mathrm{ND}$ & $40.1 \pm 8.2$ & ND & $\begin{array}{l}30(\mathrm{SG}) \\
\text { Males }\end{array}$ & $\mathrm{Fe}$ & $\mathrm{ND}$ & $\begin{array}{l}\text { There is a significant } \\
\text { correlation between score } \\
\text { of AIMS and serum } \\
\text { ferritin levels ( } p=0.018) \text {. } \\
\text { There was no significant } \\
\text { correlation between AIMS } \\
\text { score and serum Fe and } \\
\text { TIBC capacity levels. } \\
\text { There was no significant } \\
\text { correlation between } \\
\text { serum Fe levels and } \\
\text { akathisia ratings or } \\
\text { choreoathetoid } \\
\text { movement ratings. Only } \\
\text { serum ferritin levels are } \\
\text { arsociated significantly } \\
\text { with choreoathetoid } \\
\text { movements in male SZ } \\
\text { patients chronically } \\
\text { treated with } \\
\text { fluphenazine decanoate. }\end{array}$ & $\begin{array}{l}\text { All of the } \\
\text { subjects from SG } \\
\text { were treated } \\
\text { with fluphenazine } \\
\text { decanoate every } \\
\text { two weeks. The } \\
\text { mean duration } \\
\text { of treatment was } \\
73 \pm 51 \text { weeks. }\end{array}$ & $\begin{array}{l}\text { The severity of } \\
\text { choreoathetoid } \\
\text { movements was } \\
\text { assessed with AIMS and } \\
\text { akathisia was assessed } \\
\text { using Barnes scale. }\end{array}$ \\
\hline
\end{tabular}


Table 2. Cont.

\begin{tabular}{|c|c|c|c|c|c|c|c|c|c|c|c|c|c|}
\hline Ref. & Authors & Year & Origin & $\begin{array}{c}\text { No. } \\
\text { Patients }\end{array}$ & $\begin{array}{c}\text { No. } \\
\text { Controls }\end{array}$ & $\begin{array}{l}\text { Age } \\
\text { (SG) }\end{array}$ & $\begin{array}{l}\text { Age } \\
\text { (CG) }\end{array}$ & Sex & $\begin{array}{c}\text { Trace } \\
\text { Elements }\end{array}$ & $\begin{array}{l}\text { Analytical Methods } \\
\text { for Serum Trace } \\
\text { Elements Detection }\end{array}$ & Results & $\begin{array}{c}\text { Drugs/ } \\
\text { Treatment }\end{array}$ & $\begin{array}{l}\text { Additional } \\
\text { Information }\end{array}$ \\
\hline [174] & Weiser et al. & 1994 & Israel & 26 & 12 & 16-76 (range) & 24-51 (range) & $\begin{array}{c}16(\mathrm{SG}) \\
\text { Males } \\
10(\mathrm{SG}) \\
\text { Females } \\
11(\mathrm{CG}) \\
\text { Males } \\
1(\mathrm{CG}) \\
\text { Female }\end{array}$ & $\mathrm{Fe}$ & $\begin{array}{c}\text { Fe concentration was } \\
\text { determined using a } \\
\text { Krone diagnostic kit. }\end{array}$ & $\begin{array}{l}\text { Mean morning serum Fe } \\
\text { levels were lower in SG } \\
\text { compared to CG, } \\
\text { however, the difference } \\
\text { was not statistically } \\
\text { significant }(p=0.17) \text {. }\end{array}$ & $\begin{array}{l}\text { Patients were } \\
\text { medication free } \\
\text { for minimum } \\
\text { one month } \\
\text { before } \\
\text { admission. }\end{array}$ & $\begin{array}{l}\text { SG consisted of subjects } \\
\text { with either SZ or } \\
\text { schizoaffective disorder. }\end{array}$ \\
\hline [175] & $\begin{array}{l}\text { Alexander } \\
\text { et al. }\end{array}$ & 1978 & USA & 31 & 173 & $24 \pm 1$ & $22 \pm 1$ & 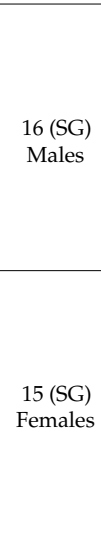 & $\mathrm{Ca}, \mathrm{Mg}$ & $\begin{array}{l}\mathrm{Ca} \text { and } \mathrm{Mg} \text { levels were } \\
\text { determined by atomic } \\
\text { absorption spectroscopy. }\end{array}$ & $\begin{array}{l}\text { SZ patients did not show } \\
\text { any statistical difference } \\
\text { in serum Ca and Mg } \\
\text { levels compared to CG. } \\
\text { Significantly lower serum } \\
\text { Ca levels were observed } \\
\text { in patients who remitted a } \\
\text { following neuroleptic } \\
\text { withdrawal compared to } \\
\text { patients who relapsed } \\
(p<0.02) \text {. SZ patients } \\
\text { treated with pimozide } \\
\text { showed decreased serum } \\
\text { Mg and Ca levels. } \\
\text { Generally, SZ patients } \\
\text { present with } \\
\text { physiological ranges of } \\
\text { serum Ca and Mg, which } \\
\text { are decreased only during } \\
\text { neuroleptic treatment. }\end{array}$ & $\begin{array}{l}\text { Pimozide, } \\
\text { fluphenazine } \\
\text { (either } \\
\text { hydrochloride or } \\
\text { decanoate), } \\
\text { benztropine, } \\
\text { diphenhydramine } \\
\text { (the last two } \\
\text { were prescribed } \\
\text { when } \\
\text { extrapyramidal } \\
\text { symptoms } \\
\text { occurred) }\end{array}$ & $\begin{array}{l}\text { SG consisted of subjects } \\
\text { with either SZ od } \\
\text { schizoaffective disorder. } \\
\text { Blood tests performed } \\
\text { on admission show } \\
\text { physiological serum } \\
\text { concentrations of } \mathrm{Ca} \text {, } \\
\mathrm{Mg}, \mathrm{Na}, \mathrm{K}, \mathrm{P} \text {, and } \mathrm{Cl} \text {. }\end{array}$ \\
\hline [176] & $\begin{array}{l}\text { Alexander } \\
\text { et al. }\end{array}$ & 1979 & USA & 22 & $\mathrm{ND}$ & 22 & ND & $\begin{array}{l}11(\mathrm{SG}) \\
\text { Females }\end{array}$ & $\mathrm{Ca}, \mathrm{Mg}$ & $\begin{array}{l}\mathrm{Ca} \text { and } \mathrm{Mg} \text { levels were } \\
\text { determined by atomic } \\
\text { absorption spectroscopy. }\end{array}$ & $\begin{array}{l}\text { During pimozide } \\
\text { treatment, among } 22 \mathrm{SZ} \\
\text { patients, } 16 \text { developed } \\
\text { extrapyramidal } \\
\text { symptoms. These } 16 \\
\text { patients with EPS had } \\
\text { significantly lower } \\
\text { drug-free serum Ca levels } \\
\text { compared to patients } \\
\text { without EPS }(p<0.05) \text {. } \\
\text { Serum drug-free Ca or } \\
\text { Mg levels did not } \\
\text { correlate with the dosage } \\
\text { of pimizode at which EPS } \\
\text { started. However, serum } \\
\text { Ca and Mg levels together } \\
\text { correlated with pimizode } \\
\text { dosage at which EPS } \\
\text { developed. Higher } \\
\text { drug-free serum Ca and } \\
\text { Mg levels were observed } \\
\text { in patients who tolerated } \\
\text { higher doses } \\
\text { of neuroleptics. }\end{array}$ & $\begin{array}{c}\text { Pimozide } \\
\text { treatment (1-2 } \\
\text { mg per day) } \\
\text { until } \\
\text { extrapyramidal } \\
\text { symptoms } \\
\text { developed or } \\
\text { maximal clinical } \\
\text { improvement } \\
\text { was reached. } \\
\text { Benztropine or } \\
\text { diphenhydramine } \\
\text { were prescribed } \\
\text { were needed } \\
\text { during } \\
\text { neuroleptic } \\
\text { treatment trials. }\end{array}$ & $\begin{array}{l}\text { SG included patients } \\
\text { diagnosed with SZ or } \\
\text { schizoaffective disorder. } \\
\text { Blood tests performed } \\
\text { on admission show } \\
\text { physiological serum } \\
\text { concentrations of } \mathrm{Ca} \text {, } \\
\mathrm{Mg}, \mathrm{Na}, \mathrm{K}, \mathrm{P} \text {, and } \mathrm{Cl} \text {. }\end{array}$ \\
\hline
\end{tabular}


Table 2. Cont.

\begin{tabular}{|c|c|c|c|c|c|c|c|c|c|c|c|c|c|}
\hline Ref. & Authors & Year & Origin & $\begin{array}{c}\text { No. } \\
\text { Patients }\end{array}$ & $\begin{array}{c}\text { No. } \\
\text { Controls }\end{array}$ & $\begin{array}{l}\text { Age } \\
\text { (SG) }\end{array}$ & $\begin{array}{l}\text { Age } \\
\text { (CG) }\end{array}$ & Sex & $\begin{array}{c}\text { Trace } \\
\text { Elements }\end{array}$ & $\begin{array}{l}\text { Analytical Methods } \\
\text { for Serum Trace } \\
\text { Elements Detection }\end{array}$ & Results & $\begin{array}{c}\text { Drugs/ } \\
\text { Treatment }\end{array}$ & $\begin{array}{l}\text { Additional } \\
\text { Information }\end{array}$ \\
\hline [177] & $\begin{array}{l}\text { Athanassenas } \\
\text { et al. }\end{array}$ & 1983 & Greece & 29 & $\mathrm{ND}$ & $46.3 \pm 1.8$ & & 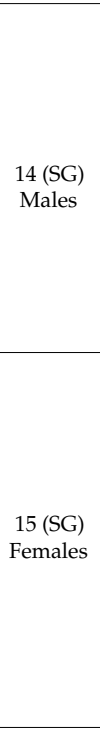 & $\mathrm{Ca}, \mathrm{Mg}$ & $\begin{array}{l}\mathrm{Ca} \text { and } \mathrm{Mg} \text { levels were } \\
\text { determined by atomic } \\
\text { absorption spectroscopy. }\end{array}$ & $\begin{array}{c}\text { During drug-free period, } \\
\text { serum Ca and Mg levels } \\
\text { did not significantly differ } \\
\text { compared to CG. No } \\
\text { significant differences } \\
\text { were stated between } \\
\text { females and males. Both } \\
\text { serum Ca and Mg } \\
\text { decreased significantly } \\
\text { during treatment } \\
\text { ( }<\text { <. 0.011). } 19 \text { patients, } \\
\text { who developed EPS, had } \\
\text { nearly identical serum Ca } \\
\text { and Mg levels compared } \\
\text { to CG, whereas } 10 \\
\text { patients without EPS had } \\
\text { lower drug-free serum Ca } \\
\text { levels and higher serum } \\
\text { Mg levels. } 3 \text { male patients } \\
\text { developed catatonic } \\
\text { episodes, and at the } \\
\text { beginning of these } \\
\text { pisodes presented } \\
\text { significantly higher Ca } \\
\text { levels }(p<0.02) \text {, whereas } \\
\text { Mg increased, but without } \\
\text { statistical significance. }\end{array}$ & $\begin{array}{l}\text { Patients were } \\
\text { treated with } \\
\text { pimozide }(n=9) \text {, } \\
\text { fluphenazine } \\
(n=8), \text { and } \\
\text { loxapine }(12) . \\
\text { Trihexyphenidyl } \\
\text { or biperiden } \\
\text { were prescribed } \\
\text { when EPS } \\
\text { occurred. }\end{array}$ & $\begin{array}{l}\text { The mean } \\
\text { hospitalization duration } \\
\text { was } 9.6 \pm 1 \text { year. } \\
\text { Among } 15 \text { female } \\
\text { patients, } 8 \text { were } \\
\text { postmenopausal. All of } \\
\text { the patients did not } \\
\text { have any additional } \\
\text { concurrent medical } \\
\text { conditions. Patients } \\
\text { were drug free } 3 \text { weeks } \\
\text { before blood collection. }\end{array}$ \\
\hline [178] & Levine et al. & 1994 & Israel & 16 & ND & $\begin{array}{c}42.7 \pm 24 \\
\text { (acute) } \\
48.3 \pm 19 \\
\text { (remission) }\end{array}$ & ND & ND & $\mathrm{Ca}, \mathrm{Mg}$ & $\begin{array}{l}\text { Ca and } \mathrm{Mg} \text { levels were } \\
\text { determined by the } \\
\text { colorimetric } \\
\text { determination. }\end{array}$ & $\begin{array}{l}\text { There was no correlation } \\
\text { between dosage of } \\
\text { neuroleptics and serum } \\
\mathrm{Ca} \text { and } \mathrm{Mg} \\
\text { concentrations. }\end{array}$ & $\begin{array}{l}\text { Treatment } \\
\text { included } \\
\text { neuroleptic } \\
\quad \text { drugs } \\
\text { (chlorpromazine } \\
\text { equivalents)—-820 } \\
\text { mg/day in acute } \\
\text { and } 470 \mathrm{mg} / \text { day } \\
\text { in remission } \\
\text { schizophrenics. }\end{array}$ & $\begin{array}{c}\text { Among SG, } 8 \mathrm{SZ} \\
\text { patients were acute and } \\
8 \text { were on remission. All } \\
\text { of the patients did not } \\
\text { have any concurrent } \\
\text { disease. Despite serum } \\
\text { Ca and Mg levels, also } \\
\text { Ca and Mg levels were } \\
\text { determined in } \\
\text { cerebrospinal fluid. }\end{array}$ \\
\hline [179] & Alertsen et al. & 1986 & Norway & 61 & 35 & ND & ND & $\begin{array}{l}17(\mathrm{CG}) \\
\text { Males }\end{array}$ & Se & $\begin{array}{l}\text { Se levels were } \\
\text { determined by } \\
\text { fluorimetric method. }\end{array}$ & $\begin{array}{l}\text { There was no statistical } \\
\text { difference in serum Se } \\
\text { concentrations between } \\
\text { SG and CG. }\end{array}$ & ND & $\begin{array}{c}\text { A group of } 61 \\
\text { psychiatric patients } \\
\text { included: } \\
17 \text { schizophrenics, } \\
7 \text { with paranoid } \\
\text { disorder, } 6 \text { with affective } \\
\text { psychosis, } 4 \text { with } \\
\text { reactive psychosis, } \\
11 \text { with dementia senilis, } \\
17 \text { with neurosis and } \\
\text { psychopathia, and } 2 \\
\text { with delirium tremens. }\end{array}$ \\
\hline
\end{tabular}


Table 2. Cont

\begin{tabular}{|c|c|c|c|c|c|c|c|c|c|c|c|c|c|}
\hline Ref. & Authors & Year & Origin & $\begin{array}{c}\text { No. } \\
\text { Patients }\end{array}$ & $\begin{array}{c}\text { No. } \\
\text { Controls }\end{array}$ & $\begin{array}{l}\text { Age } \\
\text { (SG) }\end{array}$ & $\begin{array}{l}\text { Age } \\
\text { (CG) }\end{array}$ & Sex & $\begin{array}{c}\text { Trace } \\
\text { Elements }\end{array}$ & $\begin{array}{l}\text { Analytical Methods } \\
\text { for Serum Trace } \\
\text { Elements Detection }\end{array}$ & Results & $\begin{array}{c}\text { Drugs/ } \\
\text { Treatment }\end{array}$ & $\begin{array}{l}\text { Additional } \\
\text { Information }\end{array}$ \\
\hline [180] & $\begin{array}{l}\text { Ruljancic } \\
\text { et al. }\end{array}$ & 2013 & Croatia & 71 & 99 & $\begin{array}{l}45 \pm 12.9 \\
\text { (a group } \\
\text { without } \\
\text { suicide } \\
\text { attempt) } \\
42 \pm 15.6 \\
\text { (a group } \\
\text { who } \\
\text { attempted } \\
\text { suicide) }\end{array}$ & $49 \pm 11.6$ & $\begin{array}{c}28 \text { (SG without } \\
\text { suicide } \\
\text { attempt) } \\
\text { Males } \\
20 \text { (SG without } \\
\text { suicide } \\
\text { attempt) } \\
\text { Females } \\
7 \text { (SG who } \\
\text { attempted } \\
\text { suicide) } \\
\text { Males } \\
16 \text { (SG who } \\
\text { attempted } \\
\text { suicide) } \\
\text { Females } \\
48 \text { (CG) } \\
\text { Males } \\
51 \text { (CG) } \\
\text { Females }\end{array}$ & $\mathrm{Ca}, \mathrm{Mg}$ & $\begin{array}{l}\text { Serum Ca and Mg levels } \\
\text { were measured using } \\
\text { atomic absorption } \\
\text { spectrophotometry. }\end{array}$ & $\begin{array}{l}\text { Serum Ca levels were } \\
\text { lower in SG with a } \\
\text { medical history of suicide } \\
\text { attempt compared to both } \\
\text { CG and SG without } \\
\text { suicide attempt. There } \\
\text { were no differences in } \\
\text { serum Mg levels between } \\
\text { the three groups. }\end{array}$ & ND & $\begin{array}{l}\text { Among } 71 \text { subjects from } \\
\text { SG, } 48 \text { patients were } \\
\text { schizophrenics without } \\
\text { history of suicide } \\
\text { attempt, whereas } 23 \\
\text { patients had } \\
\text { attempted suicide. }\end{array}$ \\
\hline [181] & Jamilian et al. & 2012 & Iran & $\begin{array}{l}68 \\
\text { (SZ } \\
\text { group) } \\
35 \\
\text { (depression } \\
\text { group) }\end{array}$ & 50 & $\begin{array}{c}35.67 \pm 10.46 \\
\text { (SZ group) } \\
35.84 \pm 8.20 \\
\text { (depression } \\
\text { group) }\end{array}$ & $35.26 \pm 4.82$ & $\begin{array}{l}68 \text { (SG SZ } \\
\text { group) } \\
\text { Males } \\
35 \text { (SG } \\
\text { depression } \\
\text { group) } \\
\text { Males }\end{array}$ & $\mathrm{Ca}, \mathrm{P}$ & $\begin{array}{l}\text { Serum Ca and P levels } \\
\text { measured using routine } \\
\text { laboratory methods. }\end{array}$ & $\begin{array}{l}\text { Serum } \mathrm{P} \text { levels were } \\
\text { significantly lower in } \\
\text { schizophrenics, compared } \\
\text { to healthy controls } \\
(p=0.016) \text {; there was no } \\
\text { difference in serum } \mathrm{P} \\
\text { levels between depressed } \\
\text { patients and either } \\
\text { schizophrenics }(p=0.379) \\
\text { or healthy subjects } \\
(p=0.323) \text {. Final results } \\
\text { showed that only vitamin } \\
\mathrm{D} \text { (and not } \mathrm{Ca}, \mathrm{P} \text {, or } \\
\text { parathyroid hormone) } \\
\text { levels are lower in } \\
\text { psychiatric patients } \\
\text { compared to CG. }\end{array}$ & ND & $\begin{array}{l}\text { Exclusion criteria were: } \\
\text { renal insufficiency, } \\
\text { liver dysfunction, } \\
\text { parathyroid disorders, } \\
\text { administration of drugs } \\
\text { which might alter Ca, } \mathrm{P}, \\
\text { vitamin D, or } \\
\text { parathyroid hormone } \\
\text { levels. All of the } \\
\text { patients were in an } \\
\text { acute stage of the } \\
\text { disease. } 7 \text { schizopherenic } \\
\text { patients suffered from } \\
\text { following diseases: } 2 \\
\text { were diabetics, } 2 \text { had } \\
\text { hyperlipidemia, } 1 \text { had } \\
\text { thyroid dysfunction, } 1 \\
\text { had a history of seizure } \\
\text { attacks, and } 1 \text { had a } \\
\text { history of head trauma. } \\
12 \text { schizophrenic } \\
\text { patients were abusing } \\
\text { drugs: } 8 \text { used opium, } 2 \\
\text { cannabis, crack, and } 1 \\
\text { multiple drugs. } 11 \\
\text { schizophrenic patients } \\
\text { had a positive } \\
\text { family history. } \\
\end{array}$ \\
\hline
\end{tabular}


Table 2. Cont.

\begin{tabular}{|c|c|c|c|c|c|c|c|c|c|c|c|c|c|}
\hline Ref. & Authors & Year & Origin & $\begin{array}{c}\text { No. } \\
\text { Patients }\end{array}$ & $\begin{array}{c}\text { No. } \\
\text { Controls }\end{array}$ & $\begin{array}{l}\text { Age } \\
\text { (SG) }\end{array}$ & $\begin{array}{l}\text { Age } \\
\text { (CG) }\end{array}$ & Sex & $\begin{array}{c}\text { Trace } \\
\text { Elements }\end{array}$ & $\begin{array}{l}\text { Analytical Methods } \\
\text { for Serum Trace } \\
\text { Elements Detection }\end{array}$ & Results & $\begin{array}{c}\text { Drugs/ } \\
\text { Treatment }\end{array}$ & $\begin{array}{l}\text { Additional } \\
\text { Information }\end{array}$ \\
\hline [182] & Lin et al. & 2017 & China & 114 & 114 & $32.8 \pm 11.3$ & $32.9 \pm 10.7$ & ND & $\begin{array}{c}\mathrm{Al}, \mathrm{As}, \mathrm{B}, \mathrm{Ba} \text {, } \\
\mathrm{Bi}, \mathrm{Ca}, \mathrm{Cd}, \\
\mathrm{Ce}, \mathrm{C}, \mathrm{Cr}, \\
\mathrm{Cs}, \mathrm{Cu}, \mathrm{Fe}, \\
\mathrm{Gd}, \mathrm{Ge}, \mathrm{Hg}, \\
\mathrm{La}, \mathrm{Li}, \mathrm{Mg}, \\
\mathrm{Mn}, \mathrm{Mo}, \mathrm{Na} \\
\mathrm{Nd}, \mathrm{Ni}, \mathrm{P}, \mathrm{Pb}, \\
\mathrm{Pr}, \mathrm{Rb}, \mathrm{S}, \mathrm{Sb}, \\
\mathrm{Se}, \mathrm{Sn}, \mathrm{Sr}, \mathrm{Th} \\
\text { Ti, Th, U, } \\
\text { V, } \mathrm{Zn}\end{array}$ & $\begin{array}{l}\text { Serum elements levels } \\
\text { were measured by } \\
\text { ICP-MS and inductively } \\
\text { coupled plasma atomic } \\
\text { emission spectroscopy } \\
\text { (ICP-AES). }\end{array}$ & $\begin{array}{c}\text { Serum } \mathrm{Al}, \mathrm{As}, \mathrm{B}, \mathrm{Bi}, \mathrm{Ca} \text {, } \\
\mathrm{Cd}, \mathrm{Co}, \mathrm{Cu}, \mathrm{Fe}, \mathrm{Gd}, \mathrm{Li} \text {, } \\
\mathrm{Mn}, \mathrm{Na}, \mathrm{Ni}, \mathrm{Pr}, \mathrm{Rb}, \mathrm{S}, \mathrm{Se}, \\
\mathrm{Sn}, \mathrm{Sr}, \mathrm{Th}, \mathrm{Ti}, \mathrm{Tl} \text {, and } \mathrm{V} \\
\text { differed significantly } \\
\text { between schizophrenics } \\
\text { group and control group } \\
\quad \text { (all } p<0.05) .\end{array}$ & ND & $\begin{array}{l}\text { Inclusion criteria were: } \\
\text { age between } 18 \text { and } 65, \\
\text { no exposure to heavy } \\
\text { industry, noadditional } \\
\text { diseases (infectious, } \\
\text { traumatic), no use of } \\
\text { hormone therapy. } \\
\text { Patients who were } \\
\text { taking mineral or } \\
\text { vitamin supplements } \\
\text { were excluded. }\end{array}$ \\
\hline \multirow{4}{*}{ [183] } & \multirow{4}{*}{ Cai et al. } & \multirow{4}{*}{2015} & \multirow{4}{*}{ China } & \multirow{4}{*}{$\begin{array}{l}50(\mathrm{SZ}) * \\
49(\mathrm{CG}) *\end{array}$} & \multirow{4}{*}{$\begin{array}{l}61(\mathrm{SZ})^{* *} \\
61 \\
(\mathrm{CG})^{* *}\end{array}$} & \multirow{4}{*}{$\begin{array}{c}36.8 \pm 2.5 \\
(\mathrm{SZ}) * \\
28.4 \pm 8.5 \\
(\mathrm{CG}) *\end{array}$} & \multirow{4}{*}{$\begin{array}{c}36.9 \pm 2.02 \\
(\mathrm{SZ}) * * \\
36.9 \pm 9.7(\mathrm{CG})^{* *}\end{array}$} & $\begin{array}{c}21(\mathrm{SZ})^{*} \text { Males } \\
29(\mathrm{SZ})^{*} \\
\text { Females }\end{array}$ & \multirow{4}{*}{$\begin{array}{c}\mathrm{Ag}, \mathrm{Al}, \mathrm{As}, \mathrm{B}, \\
\mathrm{Ba}, \mathrm{Be}, \mathrm{Bi}, \mathrm{Ca}, \\
\mathrm{Cd}, \mathrm{Co}, \mathrm{Cr}, \\
\mathrm{Cs}, \mathrm{Cu}, \mathrm{Er}, \\
\mathrm{Fe}, \mathrm{Ga}, \mathrm{Ge} \\
\mathrm{Li}, \mathrm{Mg}, \mathrm{Mn}, \\
\mathrm{Mr}, \mathrm{P}, \mathrm{Pb}, \\
\mathrm{Rb}, \mathrm{Sb}, \mathrm{Se}, \mathrm{Sr} \\
\mathrm{Tb}, \mathrm{Te}, \mathrm{Ti}, \mathrm{Tl} \\
\mathrm{U}, \mathrm{V}, \mathrm{Yb}, \mathrm{Zn}\end{array}$} & \multirow{4}{*}{$\begin{array}{l}\text { Serum elements levels } \\
\text { were determined by } \\
\text { the ICP-MS. }\end{array}$} & \multirow{4}{*}{$\begin{array}{l}\text { Only serum levels of } \mathrm{Cs}, \\
\mathrm{Zn} \text {, and Se were } \\
\text { significantly reduced in } \\
\text { SZ patients compared to } \\
\text { healthy controls in both } \\
\text { the training group } \\
\text { ( } p=0.0004,0.0002, \text { and } \\
0.0004 \text { respectively) and } \\
\text { the test group } \\
\left(p=1.4 \times 10^{-6}, 2.8 \times 10^{-6}\right. \\
\text { and } 7.3 \times 10^{-6} \\
\text { respectively). For all } \\
\text { samples, serum } \mathrm{P} \text {, Pb, and } \\
\text { Yb levels were } \\
\text { significantly associated } \\
\text { with schizophrenia. }\end{array}$} & \multirow{4}{*}{$\begin{array}{l}\text { Serum was } \\
\text { collected before } \\
\text { the initiation of } \\
\text { antipsychotic } \\
\text { treatment. }\end{array}$} & \multirow{4}{*}{$\begin{array}{c}\text { Inclusion criteria were: } \\
\text { no cases of alimentary } \\
\text { restriction or clinical } \\
\text { malnutrition, no history } \\
\text { of substance abuse, no } \\
\text { current drug or } \\
\text { supplement intake for } \\
\text { at least one month, no } \\
\text { concurrent disorders } \\
\text { which are known to } \\
\text { affect trace element } \\
\text { metabolism and levels. }\end{array}$} \\
\hline & & & & & & & & $\begin{array}{c}1(\mathrm{CG})^{*} \\
\text { Males } \\
48(\mathrm{CG})^{*} \\
\text { Females }^{*} \\
\end{array}$ & & & & & \\
\hline & & & & & & & & $\begin{array}{c}25(\mathrm{SZ})^{* *} \\
\text { Males } \\
36(\mathrm{SZ})^{* *} \\
\text { Females } \\
\end{array}$ & & & & & \\
\hline & & & & & & & & $\begin{array}{l}25(\mathrm{CG})^{* *} \\
\text { Males } \\
36(\mathrm{CG})^{* *} \\
\text { Females }\end{array}$ & & & & & \\
\hline [184] & Ma et al. & 2018 & China & 109 & 106 & $\begin{array}{l}18-65 \\
\text { (range) }\end{array}$ & $\begin{array}{l}18-65 \\
\text { (range) }\end{array}$ & $\begin{array}{l}38(\mathrm{CG}) \\
\text { Males } \\
68(\mathrm{CG}) \\
\text { Females }\end{array}$ & $\begin{array}{l}\mathrm{Pb}, \mathrm{Mg}, \mathrm{Cr}, \\
\mathrm{Sb}, \mathrm{Ag}, \mathrm{U}\end{array}$ & $\begin{array}{l}\text { Elements concentrations } \\
\text { were measured } \\
\text { using ICP-MS. }\end{array}$ & $\begin{array}{l}\text { Only } \mathrm{Ag}, \mathrm{Sb} \text {, and } \mathrm{U} \text { levels } \\
\text { had } 100 \% \text { detection rates } \\
\text { in sera of the studied } \\
\text { patients. Sb and U levels } \\
\text { were significantly higher } \\
\text { in both case and control } \\
\text { groups. Sb and U levels } \\
\text { did not differ significantly } \\
\text { between first-episode and } \\
\text { recurrent SZ patients. } \\
\text { Higher Sb and U serum } \\
\text { concentrations are } \\
\text { associated with the higher } \\
\text { risk of schizophrenia. }\end{array}$ & $\begin{array}{l}\text { Patients did not } \\
\text { take any } \\
\text { antipsychotic } \\
\text { drugs for at least } \\
1 \text { month before } \\
\text { hospitalization. }\end{array}$ & $\begin{array}{c}\text { Inclusion criteria were: } \\
18-65 \text { years of age, no } \\
\text { previous exposure to } \\
\text { heavy industryy, no acute } \\
\text { infections and traumatic } \\
\text { diseases, first-episode } \\
\text { and drug-naive } \\
\text { schizophrenia, no use of } \\
\text { hormone therapy. } \\
\text { Exclusion criteria were: } \\
\text { concurrent psychiatric } \\
\text { disorders, additional } \\
\text { metabolic or chronic } \\
\text { diseases, receiving } \\
\text { mineral or } \\
\text { vitamin supplements. }\end{array}$ \\
\hline
\end{tabular}


Table 2. Cont

\begin{tabular}{|c|c|c|c|c|c|c|c|c|c|c|c|c|c|}
\hline Ref. & Authors & Year & Origin & $\begin{array}{c}\text { No. } \\
\text { Patients }\end{array}$ & $\begin{array}{c}\text { No. } \\
\text { Controls }\end{array}$ & $\begin{array}{l}\text { Age } \\
\text { (SG) }\end{array}$ & $\begin{array}{l}\text { Age } \\
\text { (CG) }\end{array}$ & Sex & $\begin{array}{c}\text { Trace } \\
\text { Elements }\end{array}$ & $\begin{array}{l}\text { Analytical Methods } \\
\text { for Serum Trace } \\
\text { Elements Detection }\end{array}$ & Results & $\begin{array}{c}\text { Drugs/ } \\
\text { Treatment }\end{array}$ & $\begin{array}{l}\text { Additional } \\
\text { Information }\end{array}$ \\
\hline [185] & Ma et al. & 2019 & China & 95 & 95 & $\begin{array}{l}18-60 \\
\text { (range) }\end{array}$ & $\begin{array}{l}18-60 \\
\text { (range) }\end{array}$ & $\begin{array}{c}41(\mathrm{SG}) \\
\text { Males } \\
54(\mathrm{SG}) \\
\text { Females } \\
49(\mathrm{CG}) \\
\text { Males } \\
46 \text { (CG) } \\
\text { Females }\end{array}$ & $\begin{array}{c}\mathrm{Cr}, \underset{\mathrm{Cd}, \mathrm{Pb}}{\mathrm{Ps}} \\
\text {, }\end{array}$ & $\begin{array}{l}\text { Elements concentrations } \\
\text { were measured using } \\
\text { ICP-MS. }\end{array}$ & $\begin{array}{c}\text { Serum concentration of } \\
\text { As was significantly lower } \\
\text { in SG compared to CG } \\
(p<0.05) \text { while serum } \mathrm{Pb} \\
\text { level was significantly } \\
\text { higher in SG compared to } \\
\text { CG. Serum Pb levels, } \\
\text { under drug-free } \\
\text { conditions are associated } \\
\text { with an increased risk } \\
\text { of schizophrenia. }\end{array}$ & ND & $\begin{array}{l}\text { The inclusion criteria } \\
\text { were: } 18-60 \text { years of } \\
\text { age, no history of } \\
\text { exposure to heavy } \\
\text { industry, no acute } \\
\text { infectious and traumatic } \\
\text { diseases, no history of } \\
\text { chronic physical illness, } \\
\text { not receiving mineral or } \\
\text { vitamin supplements. }\end{array}$ \\
\hline
\end{tabular}

EPS—extrapyramidal symptoms, ${ }^{*}$ - test group, ${ }^{* *}$-training group,$* *$ — cross-sectional study, ${ }^{* * * *}$ - prospective study, ${ }^{1}$ Collectively—studied and control group. 


\section{Iron}

Iron $(\mathrm{Fe})$ metabolism is crucial regarding all neurobehavioral aspects since this element is involved in the metabolism of various neurotransmitters (serotonin, norepinephrine, dopamine), myelin synthesis, proper cellular functioning, and brain development [186-189]. The abovementioned neurotransmitters are synthesized by several Fe-dependent enzymes including phenylalanine hydroxylase, tryptophan hydroxylase, and tyrosine hydroxylase [190]. Therefore, Fe deficiency might decrease serotonin and dopamine levels, as well as increase urinary norepinephrine; this phenomenon is also associated with the direct involvement of Fe on hydroxyl radicals and reactive oxygen species' formation [191]. Fe, being a required cofactor of cholesterol, is directly involved in the myelination processes [192]. Fe-mediated dopamine neurotoxicity is associated with quinones' formation [193]. Animal studies of Fe concentrations showed an association between Fe deficiency, abnormal behavior, and alterations of dopamine metabolism [194,195]. Further, several human studies, as well as animal models of Fe depletion, presented significant behavioral and electrophysiological findings [196-200]. Fe deficiency is associated with developmental delays in children and cognitive impairments in adolescents; furthermore, it might affect motor development, recognition memory, socio-emotional behavior, and the overall processes of CNS maturation. Fe deficiency alters the density and activity of dopamine type 2 (D2) receptors by mimicking their blockade, which is implicated in the pathophysiology of schizophrenia [169]. Contrarily, increased Fe concentrations can lead to neuronal death primarily due to the enhanced oxidative stress, which might subsequently promote a progression of a wide range of neuropsychiatric disorders and neurodegenerative diseases [201-205]. Animal models have also shown that Fe overload might reduce dopamine levels in the striatum, induce neurodegeneration in the midbrain, and enhance the vulnerability to toxic injury [206]. Besides, increased Fe levels influence emotional behavior, which is determined by various biological and physiological indicators such as neurotransmitters' concentration, density and affinity of neurotransmitter receptors, or Fe concentrations in specific brain regions [207]. Disturbed Fe metabolism impairs dopaminergic activity, resulting in a progression of negative symptoms of schizophrenia [169]. In the available literature, there is still no consensus on the altered levels of Fe in the serum of schizophrenic patients.

\subsection{Serum Iron Levels}

The results of the studies regarding serum Fe levels remain inconsistent. Generally, acutely schizophrenic patients present with decreased serum Fe concentrations [174]. Apart from lowered Fe levels, schizophrenic patients display decreased Mn and elevated Cu concentrations [208]. However, other researchers showed increased serum $\mathrm{Fe}$ and Ni levels among schizophrenic patients [156]. There is no correlation between $\mathrm{Fe}, \mathrm{Mn}, \mathrm{Cu}$, Se, and $\mathrm{Zn}$ levels and duration of schizophrenia, doses of antipsychotic drugs, protein content, or smoking habits of patients. Despite altered serum Fe levels, there is no significant difference in ferroxidase II levels and Fe-binding capacity; besides schizophrenic patients present elevated levels of ceruloplasmin by approximately 20\% [165]. Furthermore, schizophrenic patients exhibit a positive correlation between serum Fe concentrations and aspartate aminotransferase (AST) with alanine transaminase (ALT) levels [156]. It was suggested that altered serum Fe levels in schizophrenic patients might be due to the imbalanced diet, rather than being a separate characteristic of schizophrenia [181]. Moreover, increased $\mathrm{Fe}, \mathrm{Cu}, \mathrm{Pb}$, $\mathrm{Ca}$, Se, and Mn serum levels might be protective, whereas increased $\mathrm{B}, \mathrm{Cr}, \mathrm{Mg}$, $\mathrm{K}$, and As levels might constitute risk factors for schizophrenia [161]. Due to significant inconsistencies regarding serum Fe levels in schizophrenic patients, serum Fe levels can be considered neither as diagnostic nor as a prognostic factor of schizophrenia.

\subsection{Iron Levels in the CNS}

Casanova et al. observed a greater mean content of Fe per internal segment of globus pallidus in the post-mortem study of schizophrenic patients; however, these findings might be limited due to the 
small number of patients [209]. Even though several post-mortem studies showed the presence of basal ganglia mineralization (especially Fe deposition) in schizophrenic patients, the results remain inconsistent among researchers [210,211]. Microscopic examination of basal ganglia of schizophrenics revealed Fe deposition in the walls of small blood vessels [209]. Other studies showed no significant alterations in $\mathrm{Fe}, \mathrm{Cu}, \mathrm{Zn}, \mathrm{Mg}$, and $\mathrm{Ca}$ concentrations in the post-mortem brains of schizophrenic patients and control groups. However, both schizophrenic patients and control groups present with increased Fe and $\mathrm{Cu}$ concentrations in the caudate nucleus compared to the hippocampus and amygdala [212,213]. Demmel et al. presented a case of a schizophrenic patient whose element concentrations $(\mathrm{Fe}, \mathrm{Co}, \mathrm{Rb}$, $\mathrm{Se}$, and $\mathrm{Zn}$ ) were at normal range in contrast to patients with alcohol abuse (decreased levels of $\mathrm{Rb}$ in cerebral nuclei and $\mathrm{Co}$ with $\mathrm{Rb}$ in cortical regions) or endogenous psychosis (increased levels of $\mathrm{Fe}, \mathrm{Co}$, $\mathrm{Rb}$, Se, and $\mathrm{Zn}$ in the caudate nucleus) [214].

To the best of authors' knowledge, there is no study that was investigating serum Fe and Fe levels in the brain at the same time. According to the reviewed literature, serum Fe levels tend to be decreased in schizophrenic patients. Contrarily, post-mortem studies focusing on Fe levels in the CNS showed that Fe might accumulate in several regions such as globus pallidus or basal ganglia.

\subsection{Prenatal Iron Deficiency}

Maternal Fe deficiency is an early environmental factor, which significantly enhances the probability of schizophrenia onset in offspring since $\mathrm{Fe}$ is involved in early behavioral and reflex neurodevelopment $[169,186,215-218]$. Moreover, low maternal hemoglobin concentrations might be associated with a nearly 4-fold elevated risk for schizophrenia in offspring [219]. The mechanism involves anemia induced by maternal Fe depletion and further reduction of oxygen delivery in the developing fetus [220]. Since proper Fe metabolism is a crucial component in myelination and dopaminergic transmission, any pathological alterations in its levels might disrupt fetal neurodevelopment. Apart from schizophrenia, fetal or postnatal Fe deficiency might influence the development of other psychiatric conditions including ASD, intellectual disability, hyperactivity disorder, anemia, anxiety, or depression in offspring [219-221].

\subsection{Schizophrenic Patients with Akathisia}

There is a significant inconsistency in the results of the studies regarding serum Fe levels in schizophrenic patients with coexisting symptoms such as akathisia. Barnes et al. showed that schizophrenic patients with chronic akathisia do not present lowered serum Fe concentrations; further, there is no relationship between serum Fe levels and the severity of akathisia [167]. Similar results were presented by Soni et al., where serum Fe, ferritin, and total iron-binding capacity (TIBC) parameters were not altered in schizophrenic patients with neuroleptic-induced akathisia [171]. Likewise, schizophrenic patients with acute dystonia are not characterized by low serum Fe, transferrin, or ferritin levels [172]. Wirshing et al. suggested that serum ferritin levels are associated with choreoathetoid movements especially among male schizophrenic patients treated permanently [173].

Contrarily, other studies showed that schizophrenic patients (either akathisic or non-akathisic) have significantly lowered serum Fe and ferritin levels compared to control groups [170]. The difference was more pronounced in schizophrenics with akathisia; those patients also presented elevated TIBC values. Furthermore, male schizophrenic patients present lowered ferritin but higher serum Fe levels comparing to females [168].

\subsection{Serum Iron Levels during Treatment}

The majority of studies have proven that antipsychotic treatment induces alterations in trace elements serum concentrations in schizophrenic patients, among which $\mathrm{Na}, \mathrm{Ca}, \mathrm{K}, \mathrm{Mg}, \mathrm{Al}, \mathrm{P}, \mathrm{Zn}$, and $\mathrm{Fe}$ are mostly affected. However, several studies proved that $\mathrm{Fe}$, ferritin, or transferrin levels may remain unchanged during treatment with neuroleptics [172]. Sussulini et al. (2017) observed that antipsychotic treatment (risperidone, olanzapine, quetiapine) induces the increase of Fe levels only 
in good responders, which provides the possibility to investigate Fe levels in monitoring responses to antipsychotic treatment among schizophrenic patients [222]. Contrarily, Chen et al. showed that antipsychotic drugs decrease Fe and increase P serum levels [157]. A long-term haloperidol treatment leads to Fe deficiency anemia, possibly due to haloperidol chelation abilities [166]. Furthermore, haloperidol-induced Fe deficiency alters the dopamine receptor D2 (DRD2) number. The reduction of serum Fe and ferritin levels with physiological TIBC status might be due to lurasidone treatment [223]. Besides, Li treatment significantly increases serum Fe concentrations in schizophrenics when compared to healthy controls [154].

\section{Serum Nickel, Molybdenum, Phosphorus, Lead, Chromium, Antimony, and Uranium Levels}

Increased $\mathrm{Ni}$ levels might induce alterations within the central as well as peripheral nervous systems, proving its cytotoxicity by various underlying mechanisms including mitochondrial dysfunctions [224]. Accumulation of Ni within the CNS disrupts neurotransmission and leads to the apoptosis of olfactory sensory and cerebral cortex neurons [191]. Further, some animal research showed that $\mathrm{Ni}$ exposure might increase the probability of aggressive behavior and affective disorders [225]. $\mathrm{Ni}$ affects the acetylcholine release, as well as decreases dopamine, norepinephrine, and serotonin levels within the CNS; it might also affect the gene expression of Glu receptors [226]. Nevertheless, literature specifically concerned with serum $\mathrm{Ni}$ levels in schizophrenic patients is scarce. Cao et al. (2019) showed that compared to healthy controls, patients with recurrent schizophrenic episodes presented elevated serum $\mathrm{Ni}$ and Fe concentrations [156]. Furthermore, an adjusted odds ratio (OD) revealed that serum $\mathrm{Ni}$ and Co levels are positively associated with schizophrenia.

Liu et al. did not point to any correlation between serum Mo or $\mathrm{Zn}$ levels and increased risk of schizophrenia [153]. However, patients with schizophrenia tend to present significantly lower serum concentrations of Mo [156].

Several studies suggest that altered P metabolism might reflect the degree of psychiatric symptoms and correlate with the presence of positive or negative symptoms $[227,228]$. Chen et al. observed that lower P levels are associated with increased schizophrenia risk and antipsychotic treatment might increase its serum levels, presenting its impact on the P metabolism [157]. These results were supported by Jamilian et al. who reported significantly lower levels of serum P in schizophrenics compared to healthy controls [181].

Ma et al. showed that increased serum antimony $(\mathrm{Sb})$ and $\mathrm{U}$ levels might be associated with an elevated risk of schizophrenia [184]. Further studies showed that also increased serum concentrations of $\mathrm{Pb}$ and $\mathrm{Cr}$ constitute a risk factor for schizophrenia [185]. Even though, more research should be carried out in order to assess whether any of the above-described elements could act as a potential diagnostic and/or prognostic factor of schizophrenia.

\section{Magnesium}

$\mathrm{Mg}$ is the fourth most abundant element in human organism, involved in more than 300 enzymatic reactions including protein, DNA, and RNA synthesis [68]. Several human and animal molecular studies have proven its neuroprotective role. Its protective role in the nervous system includes the prevention of excessive excitation and potential excitotoxicity involved in the onset of numerous neurological disorders [71]. Therefore, any imbalances in $\mathrm{Mg}$ concentrations (primarily hypomagnesemia) might be associated with various disorders, including those with psychiatric/psychotic background such ADHD, depression, anxiety, Alzheimer and Parkinson diseases, migraine pain, epilepsy, or schizophrenia $[229,230]$. However, higher $\mathrm{Mg}$ and lower $\mathrm{Zn}$ levels are related to more severe psychopathology after metal exposure [152]. There is no consistency regarding serum Mg levels in schizophrenic patients $[178,231,232]$. However, it might be probably due to researchers' tendency to determine only extracellular concentrations, while $\mathrm{Mg}$ constitutes an intracellular ion [233]. Furthermore, there are still no data regarding the concentration of ionized Mg levels in schizophrenic patients. Likewise, no altered levels in brain $\mathrm{Mg}$ concentrations in post-mortem studies have been 
reported [212]. Nevertheless, there is a significant number of studies regarding altered Mg levels after different types of medications used to treat schizophrenia.

\section{Serum Magnesium Levels during Treatment of Schizophrenia}

Pimozide and fluphenazine induced a decrease of both serum $\mathrm{Mg}$ and Ca levels in the study by Alexander et al. on schizophrenics treated with neuroleptics [175]. Further studies confirmed the fact that treatment with pimozide, fluphenazine, or loxapine might slightly alter both serum $\mathrm{Mg}$ and $\mathrm{Ca}$ levels, also inducing extrapyramidal symptoms; however, according to researchers, the slight increase of $\mathrm{Mg}$ levels is not statistically significant [177]. Schizophrenic patients who tolerate higher doses of neuroleptics present higher serum $\mathrm{Mg}$ and Ca levels. Besides, $\mathrm{Mg}$ and $\mathrm{Ca}$ concentrations together correlate with pimozide dosage at which extrapyramidal symptoms might develop; this might be a result of impaired dopaminergic and cholinergic activity affected by altered $\mathrm{Mg}$ and Ca levels [176]. Contrarily, patients treated with major tranquilizers did not show any differences in serum $\mathrm{Mg}$ levels [178]. Mg levels in schizophrenics might be higher compared to healthy control groups, however, antipsychotic treatment (risperidone, clozapine, olanzapine, aripiprazole, quetiapine, perphenazine, sulpiride, ziprasidone) leads to a decrease of serum Mg levels [157,161].

\section{Aluminum}

$\mathrm{Al}$, as a toxic metal, can accumulate in every organ particularly within the CNS, which is implicated in the onset or progression of neurodegenerative disorders. Increased $\mathrm{Al}$ concentrations are associated with the induction of oxidative stress, modification of membrane biophysics, impaired cell signaling, and neurotransmission [234]. Al increases the permeability of the blood-brain barrier and accumulation of this metal might induce the impairments of higher cognitive functions $[235,236]$. Besides, chronic $\mathrm{Al}$ exposure is associated with neurochemical, behavioral, and neuropathological impairments.

Kaya et al. observed higher $\mathrm{Al}, \mathrm{Fe}, \mathrm{Cu}$, and $\mathrm{Mg}$ levels and lower $\mathrm{Zn}$ and $\mathrm{Mg}$ levels in the sera of schizophrenic patients compared to healthy controls [237]. Nevertheless, a more recent study by Liu et al. (2015) showed that lower concentrations of $\mathrm{Al}, \mathrm{Fe}, \mathrm{Cu}, \mathrm{Se}$, and As along with higher concentrations of $\mathrm{Mg}$ and $\mathrm{Cr}$ are associated with the increased risk of schizophrenia onset; however, these results were not statistically significant [153]. This inconsistency should be further evaluated in order to provide statistically significant results.

\section{Zinc}

Zn constitutes an essential trace element across the human lifespan, being involved in the control of early neonatal brain development and proper functioning of the CNS. Zn-containing neurons are found in the highest amounts primarily in the forebrain, being responsible for the interconnections between the limbic system and the majority of cerebral cortices [82]. At the molecular level, $\mathrm{Zn}$ is responsible for neuronal metabolism and plasticity, as well as synaptic activity. Thus, imbalances in Zn levels (especially increased concentrations) and further Zn accumulation within the CNS leads to neuronal damage via excitotoxicity, oxidative stress, and impaired cellular energy generation $[80,238,239]$. Zn deficiency during pregnancy and its insufficient levels during child development are associated with a higher probability of mental retardation, apathy, lethargy, and impaired learning ability $[240,241]$. Imbalanced $\mathrm{Zn}$ homeostasis is associated with an induction of various neurological and psychiatric conditions such as Alzheimer and Parkinson diseases, depression, amyotrophic lateral sclerosis, epilepsy, or schizophrenia [242-244].

\subsection{Serum Zinc Levels}

There is an inconsistency in the current literature regarding serum $\mathrm{Zn}$ levels in schizophrenic patients; nonetheless, in a majority of cases, serum $\mathrm{Zn}$ levels are usually reported to be decreased $[183,245]$. Cruz et al. showed significantly lower serum Zn, Se, and Fe levels, as well as higher $\mathrm{Cu} / \mathrm{Zn}$ ratio among patients with schizophrenia compared to healthy controls [154]. Furthermore, 
the authors have suggested that $\mathrm{Cu} / \mathrm{Zn}$ ratio might constitute a useful parameter related to oxidative stress in schizophrenics. Other researchers have suggested that there is no association between serum $\mathrm{Zn}$ and Mo levels and the increased risk of schizophrenia [153]. These results were confirmed by Cao et al., who showed that serum $\mathrm{Zn}, \mathrm{Mn}$, and Mo levels are negatively correlated, whereas serum $\mathrm{Ni}$ and Co levels are positively correlated with schizophrenia [156]. Besides, Saghazadeh et al. showed that schizophrenic patients tend to present lower $\mathrm{Zn}, \mathrm{Fe}$, and Mn serum concentrations, along with excessive $\mathrm{Cu}$ amounts [246]. Based on the results of the evaluated studies it can be assumed that $\mathrm{Zn}$ levels are rather decreased in schizophrenic patients; however, it cannot yet be stated whether serum $\mathrm{Zn}$ concentrations can be treated as either a prognostic or diagnostic factor of schizophrenia.

\subsection{Zinc Levels in the CNS}

A post-mortem study, which included 10 brains obtained from the schizophrenic patients during the autopsy, revealed the ionic Zn staining especially within the hippocampal formation [247]. Terminal zones of the mossy fiber system within the dentate hilus and the CA3 region of the hippocampus presented the highest density of $\mathrm{Zn}$ staining. A lighter $\mathrm{Zn}$ staining was present within the outer and inner layers of the dentate gyrus molecular layer, as well as within the CA1 region of the hippocampus. Another study, which included 12 subjects, showed that $\mathrm{Zn}$ levels were highest in the hippocampus, with lower $\mathrm{Zn}$ concentrations within the amygdala and the caudate nucleus; however, there were no significant differences between $\mathrm{Zn}$ levels among schizophrenics and a control group [212]. The results of these studies are intriguing since serum $\mathrm{Zn}$ levels in schizophrenic patients tend to be rather decreased. However, there are no studies that were investigating serum $\mathrm{Zn}$ and $\mathrm{Zn}$ levels in the CNS of schizophrenic patients at the same time.

\subsection{Serum Zinc Levels during Treatment}

Antipsychotic treatment leads to a decrease of serum $\mathrm{Zn}$ levels regardless of the treatment duration. $\mathrm{Chen}$ et al. observed that serum of both $\mathrm{Zn}$ and $\mathrm{Cu}$ were lowered after the antipsychotic treatment (which included risperidone, clozapine, olanzapine, aripiprazole, quetiapine, perphenazine, sulpiride, and ziprasidone) immediately, as well as after three weeks of treatment duration [157]. The authors also showed a significant decrease in serum $\mathrm{Zn}$ levels after risperidone treatment, whereas there was no association between $\mathrm{Zn}$ levels and olanzapine treatment. Valproate treatment was also reported to stabilize decreased $\mathrm{Zn}$ and K levels [248].

\section{Copper}

$\mathrm{Cu}$ is an essential micronutrient required for numerous cellular functions such as cellular respiration, neurotransmitter synthesis, neuronal myelination, or proper maintenance of $\mathrm{Fe}$ metabolism [249]. Cu constitutes a crucial element during the synthesis of ceruloplasmin, zyklopen, hephaestin, and dopamine- $\beta$-monooxygenase, which is crucial in dopamine metabolism and dopaminergic activity. Since $\mathrm{Cu}$ participates in reactions that generate free radicals' contribution to oxidative stress, excessively high amounts of this transition metal might be toxic. $\mathrm{Cu}$ distribution within the brain parenchyma is generally even. However, the subventricular zone of brain ventricles was observed with higher $\mathrm{Cu}$ levels compared to other regions in the brain [250]. Post-mortem studies of $\mathrm{Cu}$ concentration within the CNS showed increased $\mathrm{Cu}$ concentrations mainly in the caudate nucleus in schizophrenic patients [212]. Disturbed distribution and homeostasis of $\mathrm{Cu}$ within the CNS contributes to the promotion of many neurodegenerative diseases: Alzheimer and Parkinson diseases, Huntington disease, amyotrophic lateral sclerosis, as well as psychiatric conditions such as depressive disorder, ASD, epilepsy, or schizophrenia primarily due to the impaired neuronal myelination, catecholamine imbalances, and disturbed brain architecture [251-255]. Neurobehavioral abnormalities might be a consequence of maternal $\mathrm{Cu}$ deficiency as well [186]. Schoonover et al. showed impaired intracellular $\mathrm{Cu}$ binding and transport into the cell via high-affinity $\mathrm{Cu}$ uptake protein 1 (Ctr1) in schizophrenic patients [256]. 


\subsection{Serum Copper Levels}

Regarding serum $\mathrm{Cu}$ concentrations among patients diagnosed with schizophrenia, there is still no consensus, as in the case of serum Fe and $\mathrm{Zn}$ levels. Several studies did not show any significant difference in serum $\mathrm{Cu}$ or ceruloplasmin levels in schizophrenics $[159,160,162,163]$. Other results have shown increased serum $\mathrm{Cu}$ levels among schizophrenic males and females compared to the control group [164]. Besides, serum Cu levels were higher in females, however, without statistical significance. Further, Cruz et al. observed increased serum $\mathrm{Cu}$ levels among patients with schizophrenia or bipolar disorder compared to control groups; however, these results were not statistically significant [154]. Cao et al. did not observe any significant differences in serum $\mathrm{Cu}, \mathrm{Co}$, and Fe levels in sera of schizophrenics [156]. A study on 40 male schizophrenic patients without any treatment for four weeks before the study revealed higher $\mathrm{Cu}$, ceruloplasmin, LDL-cholesterol, total cholesterol, and high-sensitivity C-reactive protein (hs-CRP) levels, as well as a significant decrease in HDL-level [158]. Further, there was a significant correlation between serum $\mathrm{Cu}$ and hs-CRP levels. Wolf et al. also proved significantly elevated serum $\mathrm{Cu}$ levels among schizophrenics [165]. Furthermore, as approximately $95 \%$ of blood $\mathrm{Cu}$ is bound to ceruloplasmin, the researchers confirmed that increased $\mathrm{Cu}$ levels correlate with increased ceruloplasmin levels. Therefore, it can be assumed that schizophrenic patients tend to present greater serum $\mathrm{Cu}$ concentrations compared to healthy controls.

\subsection{Serum Copper Levels during Treatment}

Herran et al. showed that schizophrenic patients treated with a depot neuroleptic tend to have higher serum $\mathrm{Cu}$ levels compared to patients treated with oral antipsychotics [155]. The researchers observed that either typical or atypical antipsychotic treatment or neuroleptic dosage does not affect serum $\mathrm{Cu}$ levels. However, Saghazadeh et al. showed that schizophrenic patients treated with antipsychotic drugs tend to present higher serum $\mathrm{Cu}$ levels compared to controls [246]. Clozapine and aripiprazole treatment significantly decrease serum $\mathrm{Cu}$ levels compared to levels before treatment [157]. Intake of Se supplements elevates serum $\mathrm{Cu}$ and $\mathrm{Zn}$ levels [161].

\section{Selenium}

Various antioxidant selenoproteins such as glutathione peroxidase (GPx), thioredoxin reductase (TrxR), or selenoproteins- $\mathrm{P}, \mathrm{S}$, or H ((SelP), (SelS), or (SelH)) require incorporation of Se. Selenoproteins are involved in the free radical defense system, due to their antioxidant activity. They are responsible for proper CNS functioning. Furthermore, Se provides the response to oxidative stress primarily via mitochondrial biogenesis and regulation of $\mathrm{Ca}^{2+}$ channels [257]. SelP, being found primarily in neurons, also exhibits a neuroprotective effect. A neuroprotective role of Se supplementation is achieved via several mechanisms including antioxidant activity and selenoprotein synthesis de novo. Deficient or excessive Se exposure might be associated with the onset and progression of various diseases; however, the knowledge concerning the amount of exposure, as well as Se ranges and specific health outcomes, is still scarce [258]. Animal studies proved that Se deficiency induces neurological dysfunctions, examples of which are seizures, or neurodegeneration especially within the brain areas related to auditory and motor functions $[259,260]$. Indeed, patients with deficient Se supplementation or mutations in the gene encoding selenocysteine synthase are more susceptible to neurological impairments [261]. Imbalances in Se levels, as well as their disturbed distribution within CNS, might be a trigger of such conditions as schizophrenia, depression, bipolar disorder, or Alzheimer disease $[100,149,262,263]$. Schizophrenia and bipolar disorder are characterized by an elevated level of selenium binding protein 1 (SELENBP1) gene expression; however, it is yet unclear whether enhanced expression of SELENBP1 correlates with a higher incidence of psychosis [264,265]. It was hypothesized that schizophrenia onset might be not due to the Se deficiency itself, but rather due to the impaired Se transport [266,267]. 


\section{Serum Selenium Levels}

Alertsen et al. did not show a statistically significant difference in serum Se levels between schizophrenics and the healthy controls [179]. A study on 114 schizophrenic patients revealed decreased levels of serum Se; the researchers also observed that lower serum $\mathrm{Se}, \mathrm{Fe}, \mathrm{Cu}, \mathrm{Al}$, and $\mathrm{As}$ might be associated with the increased risk of schizophrenia onset [153]. Schizophrenic patients usually present with reduced concentrations of serum Se [154,161,183]. Li et al. showed that Se supplementation by schizophrenics might increase appetite, as well as improve memory abilities-these results concern $60 \%$ and $18 \%$ of studied females and males, respectively [161]. Besides, the researchers observed that higher concentrations of $\mathrm{Se}, \mathrm{Mn}, \mathrm{Ca}, \mathrm{Pb}, \mathrm{Fe}$, and $\mathrm{Cu}$ act protectively regarding schizophrenic patients. Thus, serum Se levels seem to be rather decreased in schizophrenics and the elevation of its concentrations might potentially improve the course of schizophrenia.

\section{Calcium}

Under physiological conditions, serum Ca levels and brain interstitial fluids maintain equilibrium; therefore, any changes in physiological Ca concentrations might affect neuronal and cognitive functions. Free intracellular Ca concentration in neurons is fairly low (a range of 10-100 nM), but some of the organelles such as mitochondria act as 'Ca stores' [268]. Numerous neuronal processes such as neurotransmitter release, intracellular signaling, proper homeostasis of glial cells, or N-methyl-D-aspartate (NMDA)-mediated neuroplasticity require the influx of extracellular Ca and its balanced homeostasis. Sharma et al. reported a relationship between higher Ca levels and poorer cognitive functioning in individuals aged 75 and above [269]. Recently, $\mathrm{Ca}^{2+} / \mathrm{CAMP}^{2}$ interaction, the so-called 'calcium paradox', was implemented to enhance neurotransmission and neuroprotection [270]. Further, voltage-gated Ca channels are implemented in the pathogenesis of schizophrenia. Other distortions associated with schizophrenia include altered $\mathrm{C}^{2+}$-dependent gene transcription, which affects signaling components. Schizophrenic patients present with increased $\mathrm{Ca}^{2+}$ intracellular levels, involving plasma membrane $\mathrm{Ca}^{2+}$ ATPase (PMCA) in the alterations of $\mathrm{Ca}$ levels [271]. The literature concerning serum Ca concentrations in schizophrenic patients is still scarce. Ruljancic et al. pointed to decreased serum Ca levels in suicidal schizophrenic patients compared to the nonsuicidal group of schizophrenics [180]. Besides, there is evidence that schizophrenic patients show an upregulation of Ca-binding proteins particularly within the cerebellum, which indicates impaired Ca signaling and disrupted cerebellar circuits [272]. Even though, more research should be conducted in order to assess whether any differences in serum Ca levels in schizophrenic patients are significant and whether they are truly associated with the course of this psychiatric condition.

\section{Manganese}

Studies suggest that some metals $(\mathrm{Mn}, \mathrm{Zn}, \mathrm{Cd}, \mathrm{Pb})$ are associated with schizophrenia or psychotic conditions [116,273]. These metals are involved in the induction of alterations in neurotransmission, excitotoxicity, and inflammation [112,274]. Excessive exposure to Mn might induce initial clinical psychotic manifestations, which include mood changes, emotional lability, hallucinations, and uncontrolled laughter, collectively referred to as 'Mn psychosis' [275]. Excessive Mn exposure is associated with behavioral and cognitive impairments, decreased IQ levels, reduced educational achievement, or abnormalities within the frontal lobe [276-280]. High levels of Mn were documented to cause Parkinson-like neuromuscular condition and neurocognitive dysfunctions that were primarily found in miners [274]. There is also evidence that large and long-lasting administration of manganese chloride $\left(\mathrm{MnCl}_{2}\right)$ in rats, due to decreased activity of tyrosine hydroxylase, causes the development of schizophrenia-like behaviors [246]. It was also noted that higher concentrations of Mn decrease Gln uptake into astrocytes and reduce the activity of Gln synthetase in the neurons and astrocytes of the striatum and globus pallidus in the brain [281]. High level of free radicals due to the impaired activity of manganese superoxide dismutase (MnSOD) damage cell membranes causing malfunctioning 
of neurotransmission, abnormal neuronal apoptosis, and neurodegeneration, which is believed to induce the development of symptomatology in schizophrenia [282]. Researchers suggest that lower concentrations of Mn are associated with reduced MnSOD activity, which might be associated with schizophrenia [156]. So far, the majority of studies have shown that schizophrenic patients present with increased blood concentrations of Mn. However, Yanik et al. showed significantly lower plasma Mn concentrations in schizophrenics compared to control groups [208]. Besides, Cao et al. observed decreased serum Mn levels in cases of first-episode and recurrent schizophrenia, compared to healthy controls [156]. Contrarily, Saghazadeh et al. concluded that there are no significant changes in serum Mn concentrations in patients with schizophrenia; however, the researchers found lower levels of $\mathrm{Mn}$ in the subgroups of patients with previously diagnosed or chronic schizophrenia [246]. Plasma MnSOD activity is decreased in schizophrenic patients either with or without tardive dyskinesia [283]. Further, decreased MnSOD activity is associated with impaired cognitive functions in schizophrenics. Serum Mn levels might also be associated with an increased risk of schizophrenia [153]. Some studies suggest that Mn serum levels can be altered by psychoactive substances: They increase with the usage of tobacco or alcohol and decrease by antipsychotic medication $[39,284,285]$. Another evidence indicates that antipsychotic drugs do not alter the Mn concentrations but instead chelate Mn, making it less available as an enzyme activator [237]. Therefore, at the current state of knowledge, it is quite hard to assess what serum Mn levels might be associated with schizophrenia.

\section{Conclusions}

At the current state of knowledge, none of the investigated trace elements has presented its utility as a diagnostic or treatment tool of schizophrenia. The results of the analyzed studies were usually contradictory. Thus, the epidemiological evidence of altered serum trace element levels and the risk of schizophrenia onset is slightly controversial. The differences in the results of the abovementioned studies can be due to the heterogeneity of methodology, as well as different inclusion and exclusion criteria. Analytical methods regarding concentrations of trace elements are to some extent limited since, during gel electrophoresis or liquid chromatography, chelated metals can be easily released from proteins, preventing an accurate analysis [286]. Accuracy of the results might be to some extent limited particularly because the concentrations of trace elements are determined usually only in extracellular compartments, while some of the elements (e.g., $\mathrm{Mg}$ ) are specifically intracellular ions; besides, for the majority of elements, there is a lack of strict concentrations' ranges.

According to the results of the analyzed studies, maternal deficiency of essential trace elements with micro- and macronutrients along with subsequent dysregulation of early life trace elements' concentrations might be associated with an increased risk of psychotic disorders including schizophrenia. Furthermore, the causation might be related to maternal stress, as it disrupts the placental transfer of nutrients. Prenatal deficiency of essential trace elements such as $\mathrm{Zn}$ induces epigenetic alterations, affecting the levels of other trace elements $[152,287]$. Alterations in serum trace elements' levels in schizophrenic patients might be caused by numerous factors, among which current treatment (antipsychotics), exposure and inhalation of particular elements, or dietary intake are crucial.

Since the amount of literature is still scarce and the results are often contradictory, more research should be done in this field with the aim of investigating potential diagnostic and prognostic parameters of schizophrenia.

Funding: This research received no external funding.

Conflicts of Interest: The authors declare no conflict of interest. 


\section{Abbreviations}

\begin{tabular}{|c|c|}
\hline $\mathrm{AChE}$ & acetylcholinesterase \\
\hline ADHD & attention deficit hyperactivity disorder \\
\hline $\mathrm{Al}$ & aluminum \\
\hline ALT & alanine aminotransferase \\
\hline ASD & autism spectrum disorder \\
\hline AST & aspartate transaminase \\
\hline $\mathrm{Ca}$ & calcium \\
\hline $\mathrm{Cd}$ & cadmium \\
\hline CNS & central nervous system \\
\hline $\mathrm{Cu}$ & copper \\
\hline $\mathrm{Fe}$ & iron \\
\hline GABA & $\gamma$-aminobutyric acid \\
\hline GABAA & $\gamma$-aminobutyric acid type A \\
\hline Gln & glutamine \\
\hline Glu & glutamate \\
\hline GPx & glutathione peroxidase \\
\hline HDL & high-density lipoprotein \\
\hline hs-CRP & high-sensitivity C-reactive protein \\
\hline IDD & iodothyronine deiodinases \\
\hline K & potassium \\
\hline LDL & low-density lipoprotein \\
\hline $\mathrm{Li}$ & lithium \\
\hline $\mathrm{Mg}$ & magnesium \\
\hline $\mathrm{Mn}$ & manganese \\
\hline MnSOD & manganese superoxide dismutase \\
\hline Mo & molybdenum \\
\hline $\mathrm{Ni}$ & nickel \\
\hline NMDA & N-methyl-D-aspartate \\
\hline $\mathrm{P}$ & phosphorus \\
\hline PMCA & plasma membrane $\mathrm{Ca}^{2+}$-ATPase \\
\hline $\mathrm{Rb}$ & rubidium \\
\hline $\mathrm{Sb}$ & antimony \\
\hline Se & selenium \\
\hline SELENBP1 & selenium binding protein 1 gene \\
\hline SelH & selenoprotein $\mathrm{H}$ \\
\hline SelP & selenoprotein $\mathrm{P}$ \\
\hline SelS & selenoprotein S \\
\hline TIBC & total iron-binding capacity \\
\hline $\operatorname{Tr} x \mathrm{R}$ & thioredoxin reductase \\
\hline $\mathrm{U}$ & uranium \\
\hline VLDL & very-low-density lipoprotein \\
\hline $\mathrm{Zn}$ & zinc \\
\hline
\end{tabular}

\section{References}

1. Howes, O.; Mccutcheon, R.; Stone, J. Glutamate and dopamine in schizophrenia: An update for the 21st century. J. Psychopharmacol. 2015, 29, 97-115. [CrossRef] [PubMed]

2. Werf, M.V.D.; Hanssen, M.; Köhler, S.; Verkaaik, M.; Verhey, F.R.; Winkel, R.V.; van Os, J.; Allardyce, J. Systematic review and collaborative recalculation of 133693 incident cases of schizophrenia. Psychol. Med. 2012, 44, 9-16. [CrossRef] [PubMed]

3. Picchioni, M.M.; Murray, R.M. Schizophrenia. BMJ 2007, 335, 91-95. [CrossRef] [PubMed] 
4. Tandon, R.; Gaebel, W.; Barch, D.M.; Bustillo, J.; Gur, R.E.; Heckers, S.; Malaspina, D.; Owen, M.J.; Schultz, S.; Tsuang, M.; et al. Definition and description of schizophrenia in the DSM-5. Schizophr. Res. 2013, 150, 3-10. [CrossRef]

5. Valton, V.; Romaniuk, L.; Steele, J.D.; Lawrie, S.; Seriès, P. Comprehensive review: Computational modelling of schizophrenia. Neurosci. Biobehav. Rev. 2017, 83, 631-646. [CrossRef]

6. Jauhar, S.; Nour, M.M.; Veronese, M.; Rogdaki, M.; Bonoldi, I.; Azis, M.; Turkheimer, F.; McGuire, P.; Young, A.H.; Howes, O.D. A Test of the Transdiagnostic Dopamine Hypothesis of Psychosis Using Positron Emission Tomographic Imaging in Bipolar Affective Disorder and Schizophrenia. JAMA Psychiatry 2017, 74, 1206. [CrossRef]

7. Szczypiński, J.J.; Gola, M. Dopamine dysregulation hypothesis: The common basis for motivational anhedonia in major depressive disorder and schizophrenia? Rev. Neurosci. 2018, 29, 727-744. [CrossRef]

8. Howes, O.D.; McCutcheon, R.; Owen, M.J.; Murray, R.M. The Role of Genes, Stress, and Dopamine in the Development of Schizophrenia. Biol. Psychiatry 2017, 81, 9-20. [CrossRef]

9. Mccutcheon, R.A.; Abi-Dargham, A.; Howes, O.D. Schizophrenia, Dopamine and the Striatum: From Biology to Symptoms. Trends Neurosci. 2019, 42, 205-220. [CrossRef]

10. Howes, O.D.; Kapur, S. The Dopamine Hypothesis of Schizophrenia: Version III-The Final Common Pathway. Schizophr. Bull. 2009, 35, 549-562. [CrossRef]

11. Lau, C.-I.; Wang, H.-C.; Hsu, J.-L.; Liu, M.-E. Does the dopamine hypothesis explain schizophrenia? Rev. Neurosci. 2013, 24, 389-400. [CrossRef] [PubMed]

12. Zhuo, C.; Hou, W.; Li, G.; Mao, F.; Li, S.; Lin, X.; Jiang, D.; Xu, Y.; Tian, H.; Wang, W.; et al. The genomics of schizophrenia: Shortcomings and solutions. Prog. Neuro Psychopharmacol. Biol. Psychiatry 2019, 93, 71-76. [CrossRef] [PubMed]

13. Lichtenstein, P.; Yip, B.H.; Björk, C.; Pawitan, Y.; Cannon, T.D.; Sullivan, P.F.; Hultman, C.M. Common genetic determinants of schizophrenia and bipolar disorder in Swedish families: A population-based study. Lancet 2009, 373, 234-239. [CrossRef]

14. Hoftman, G.D.; Dienel, S.J.; Bazmi, H.H.; Zhang, Y.; Chen, K.; Lewis, D.A. Altered Gradients of Glutamate and Gamma-Aminobutyric Acid Transcripts in the Cortical Visuospatial Working Memory Network in Schizophrenia. Biol. Psychiatry 2018, 83, 670-679. [CrossRef]

15. Tregellas, J.R.; Wylie, K.P. Alpha7 Nicotinic Receptors as Therapeutic Targets in Schizophrenia. Nicotine Tob. Res. 2019, 21, 349-356. [CrossRef]

16. Rodríguez-Muñoz, M.; Sánchez-Blázquez, P.; Callado, L.F.; Meana, J.J.; Garzón-Niño, J. Schizophrenia and depression, two poles of endocannabinoid system deregulation. Transl. Psychiatry 2017, 7, 1-12. [CrossRef]

17. Sawa, A.; Sedlak, T.W. Oxidative stress and inflammation in schizophrenia. Schizophr. Res. 2016, 176, 1-2. [CrossRef]

18. Mendrek, A.; Mancini-Marie, A. Sex/gender differences in the brain and cognition in schizophrenia. Neurosci. Biobehav. Rev. 2016, 67, 57-78. [CrossRef]

19. Gonçalves, V.F.; Cuperfain, A.B.; Kennedy, J.L. Sex differences in schizophrenia: Estrogen and mitochondria. Neuropsychopharmacology 2018, 44, 216-217. [CrossRef]

20. Mcgregor, C.; Riordan, A.; Thornton, J. Estrogens and the cognitive symptoms of schizophrenia: Possible neuroprotective mechanisms. Front. Neuroendocrinol. 2017, 47, 19-33. [CrossRef]

21. Rodrigues-Amorim, D.; Rivera-Baltanás, T.; Regueiro, B.; Spuch, C.; Heras, M.E.D.L.; Méndez, R.V.-N.; Nieto-Araujo, M.; Barreiro-Villar, C.; Olivares, J.M.; Agis-Balboa, R.C. The role of the gut microbiota in schizophrenia: Current and future perspectives. World J. Biol. Psychiatry 2018, 19, 571-585. [CrossRef] [PubMed]

22. Kočovská, E.; Gaughran, F.; Krivoy, A.; Meier, U.-C. Vitamin-D Deficiency as a Potential Environmental Risk Factor in Multiple Sclerosis, Schizophrenia, and Autism. Front. Psychiatry 2017, 8, 47. [CrossRef] [PubMed]

23. Mayne, P.E.; Burne, T.H. Vitamin D in Synaptic Plasticity, Cognitive Function, and Neuropsychiatric Illness. Trends Neurosci. 2019, 42, 293-306. [CrossRef] [PubMed]

24. Cirulli, F.; Laviola, G.; Ricceri, L. Risk factors for mental health: Translational models from behavioural neuroscience. Neurosci. Biobehav. Rev. 2009, 33, 493-497. [CrossRef] [PubMed]

25. Martin, J.; Taylor, M.J.; Lichtenstein, P. Assessing the evidence for shared genetic risks across psychiatric disorders and traits. Psychol. Med. 2017, 48, 1759-1774. [CrossRef] [PubMed] 
26. Baj, J.; Sitarz, E.; Forma, A.; Wróblewska, K.; Karakuła-Juchnowicz, H. Alterations in the Nervous System and Gut Microbiota after $\beta$-Hemolytic Streptococcus Group A Infection-Characteristics and Diagnostic Criteria of PANDAS Recognition. Int. J. Mol. Sci. 2020, 21, 1476. [CrossRef]

27. Altmann, D.M. Neuroimmunology and neuroinflammation in autoimmune, neurodegenerative and psychiatric disease. Immunology 2018, 154, 167-168. [CrossRef]

28. Owen, L.; Corfe, B. The role of diet and nutrition on mental health and wellbeing. Proc. Nutr. Soc. 2017, 76, 425-426. [CrossRef]

29. Meltzer-Brody, S.; Howard, L.M.; Bergink, V.; Vigod, S.; Jones, I.; Munk-Olsen, T.; Honikman, S.; Milgrom, J. Postpartum psychiatric disorders. Nat. Rev. Dis. Primers 2018, 4, 1-18. [CrossRef]

30. Pickard, H.; Fazel, S. Substance abuse as a risk factor for violence in mental illness. Curr. Opin. Psychiatry 2013, 26, 349-354. [CrossRef]

31. Teicher, M.H.; Samson, J.A.; Anderson, C.M.; Ohashi, K. The effects of childhood maltreatment on brain structure, function and connectivity. Nat. Rev. Neurosci. 2016, 17, 652-666. [CrossRef] [PubMed]

32. Wood, H. Brain iron correlates with cognitive change in Parkinson disease. Nat. Rev. Neurol. 2020, 16, 184. [CrossRef] [PubMed]

33. Qian, R.; Ma, Y.; You, L.; Zhao, Y.; Li, S.; Shen, J.; Jiang, L.; Yang, C.; Jiang, P.; Yuan, Z.; et al. The Blood Levels of Trace Elements Are Lower in Children with Tic Disorder: Results from a Retrospective Study. Front. Neurol. 2019, 10, 1324. [CrossRef] [PubMed]

34. Martínez-Hernanz, Á.; González-Estecha, M.; Blanco, M.; Fuentes, M.; Ordóñez-Iriarte, J.M.; Palazón-Bru, I.; Calvo-Manuel, E.; Bodas-Pindeo, A. Blood lead in children and associations with trace elements and sociodemographic factors. J. Trace Elem. Med. Biol. 2020, 58, 126424. [CrossRef] [PubMed]

35. Grochowski, C.; Blicharska, E.; Baj, J.; Mierzwińska, A.; Brzozowska, K.; Forma, A.; Maciejewski, R. Serum iron, Magnesium, Copper, and Manganese Levels in Alcoholism: A Systematic Review. Molecules 2019, 24, 1361. [CrossRef]

36. Grochowski, C.; Blicharska, E.; Bogucki, J.; Proch, J.; Mierzwińska, A.; Baj, J.; Litak, J.; Podkowiński, A.; Flieger, J.; Teresiński, G.; et al. Increased Aluminum Content in Certain Brain Structures is Correlated with Higher Silicon Concentration in Alcoholic Use Disorder. Molecules 2019, 24, 1721. [CrossRef]

37. Grochowski, C.; Szukała, M.; Litak, J.; Budny, A.; Proch, J.; Majerek, D.; Blicharska, E.; Niedzielski, P. Correlations Between Trace Elements in Selected Locations of the Human Brain in Individuals with Alcohol Use Disorder. Molecules 2020, 25, 359. [CrossRef]

38. Grochowski, C.; Blicharska, E.; Krukow, P.; Jonak, K.; Maciejewski, M.; Szczepanek, D.; Jonak, K.; Flieger, J.; Maiejewski, R. Analysis of Trace Elements in Human Brain: Its Aim, Methods, and Concentration Levels. Front. Chem. 2019, 7, 115. [CrossRef]

39. Scassellati, C.; Bonvicini, C.; Benussi, L.; Ghidoni, R.; Squitti, R. Neurodevelopmental disorders: Metallomics studies for the identification of potential biomarkers associated to diagnosis and treatment. J. Trace Elem. Med. Biol. 2020, 60, 126499. [CrossRef]

40. Abbaspour, N.; Hurrell, R.; Kelishadi, R. Review on iron and its importance for human health. J. Res. Med. Sci. 2014, 19, 164-174.

41. Zhang, D.-L.; Ghosh, M.C.; Rouault, T.A. The physiological functions of iron regulatory proteins in iron homeostasis-An update. Front. Pharmacol. 2014, 5, 124. [CrossRef] [PubMed]

42. Murray-Kolb, L.E. Iron and brain functions. Curr. Opin. Clin. Nutr. Metab.Care 2013, 16, $703-707$. [CrossRef] [PubMed]

43. Jáuregui-Lobera, I. Iron deficiency and cognitive functions. Neuropsychiatr. Dis. Treat. 2014, 10, 2087. [CrossRef] [PubMed]

44. Muñoz, M.; Villar, I.; García-Erce, J.A. An update on iron physiology. World J. Gastroenterol. 2009, $15,4617$. [CrossRef] [PubMed]

45. Dev, S.; Babitt, J.L. Overview of iron metabolism in health and disease. Hemodial. Int. 2017, 21, S6-S20. [CrossRef]

46. Cairo, G.; Bernuzzi, F; Recalcati, S. A precious metal: Iron, an essential nutrient for all cells. Genes Nutr. 2006, 1, 25-39. [CrossRef]

47. Coughlan, M.P. The role of molybdenum in human biology. J. Inherit. Metab. Dis. 1983, 6, 70-77. [CrossRef]

48. Mendel, R.R.; Kruse, T. Cell biology of molybdenum in plants and humans. Biochim. Biophys. Acta Mol. Cell Res. 2012, 1823, 1568-1579. [CrossRef]

49. Schwarz, G. Molybdenum cofactor and human disease. Curr. Opin. Chem. Biol. 2016, 31, 179-187. [CrossRef] 
50. Novotny, J.A.; Peterson, C.A. Molybdenum. Adv Nutr. 2018, 9, 272-273. [CrossRef]

51. Novotny, J.A. Molybdenum Nutriture in Humans. J. Evid. Based Complementary Altern. Med. 2011, 16, 164-168. [CrossRef]

52. Bourke, C.A. Molybdenum Deficiency Produces Motor Nervous Effects That Are Consistent with Amyotrophic Lateral Sclerosis. Front. Neurol. 2016, 7, 28. [CrossRef] [PubMed]

53. Calvo, M.S. Phosphorus. Adv Nutr. 2015, 6, 860-862. [CrossRef] [PubMed]

54. Takeda, E.; Taketani, Y.; Sawada, N.; Sato, T.; Yamamoto, H. The regulation and function of phosphate in the human body. Biofactors 2004, 21, 345-355. [CrossRef]

55. Penido, M.G.M.G.; Alon, U.S. Phosphate homeostasis and its role in bone health. Pediatric Nephrol. 2012, 27, 2039-2048. [CrossRef]

56. Kendrick, J.; Chonchol, M. The Role of Phosphorus in the Development and Progression of Vascular Calcification. Am. J. Kidney Dis. 2011, 58, 826-834. [CrossRef]

57. Moore, L.W.; Nolte, J.V.; Gaber, A.O.; Suki, W.N. Association of dietary phosphate and serum phosphorus concentration by levels of kidney function. Am. J. Clin Nutr. 2015, 102, 444-453. [CrossRef]

58. Bacchetta, J.; Salusky, I.B. Evaluation of Hypophosphatemia: Lessons from Patients with Genetic Disorders. Am. J. Kidney Dis. 2012, 59, 152-159. [CrossRef]

59. Shaman, A.M.; Kowalski, S.R. Hyperphosphatemia Management in Patients with Chronic Kidney Disease. Saudi Pharm. J. 2016, 24, 494-505. [CrossRef]

60. Kumar, S.; Trivedi, A. A Review on Role of Nickel in the Biological System. Int. J. Curr. Microbiol. Appl. Sci. 2016, 5, 719-727. [CrossRef]

61. Duda-Chodak, A.; Blaszczyk, U. The Impact of Nickel on human health. J. Elementol. 2008, 13, 685-696.

62. Zambelli, B.; Ciurli, S. Nickel and human health. Met. Ions Life Sci. 2013, 13, 321-357. [PubMed]

63. Das, K.K.; Reddy, R.C.; Bagoji, I.B.; Das, S.; Bagali, S.; Mullur, L.; Khodnapur, J.P.; Biradar, M.S. Primary concept of nickel toxicity-An overview. J. Basic Clin. Physiol. Pharmacol. 2018, 30, 141-152. [CrossRef] [PubMed]

64. Genchi, G.; Carocci, A.; Lauria, G.; Sinicropi, M.S.; Catalano, A. Nickel: Human Health and Environmental Toxicology. Int. J. Environ. Res. Public Health 2020, 17, 679. [CrossRef]

65. Al Alawi, A.M.; Majoni, S.W.; Falhammar, H. Magnesium and Human Health: Perspectives and Research Directions. Int. J. Endocrinol. 2018, 2018, 9041694. [CrossRef]

66. Jahnen-Dechent, W.; Ketteler, M. Magnesium basics. Clin. Kideny J. 2012, 5 (Suppl. 1), i3-i14. [CrossRef]

67. Schwalfenberg, G.K.; Genuis, S.J. The Importance of Magnesium in Clinical Healthcare. Scientifica 2017, 2017, 1-14. [CrossRef]

68. Gröber, U.; Schmidt, J.; Kisters, K. Magnesium in Prevention and Therapy. Nutrients 2015, 7, 8199-8226. [CrossRef]

69. Dinicolantonio, J.J.; O'Keefe, J.H.; Wilson, W. Subclinical magnesium deficiency: A principal driver of cardiovascular disease and a public health crisis. Open Heart 2018, 5, e000668. [CrossRef]

70. Ahmed, F.; Mohammed, A. Magnesium: The Forgotten Electrolyte-A Review on Hypomagnesemia. Med. Sci. 2019, 7, 56. [CrossRef]

71. Kirkland, A.; Sarlo, G.; Holton, K. The Role of Magnesium in Neurological Disorders. Nutrients 2018, 10, 730. [CrossRef] [PubMed]

72. Inan-Eroglu, E.; Ayaz, A. Is aluminium exposure a risk factor for neurological disorders? J. Res. Med. Sci. 2018, 23, 51. [PubMed]

73. Krewski, D.; Yokel, R.A.; Nieboer, E.; Borchelt, E.; Cohen, J.; Harry, J.; Kacew, S.; Lindsay, J.; Mahfouz, A.M.; Rondeau, V. Human health risk assessment for aluminium, aluminium oxide, and aluminium hydroxide. J. Toxicol. Environ. Health B Crit. Rev. 2007, 10 (Suppl. 1), 1-269. [CrossRef] [PubMed]

74. Akinrinade, I.D.; Memudu, A.E.; Ogundele, O.M. Fluoride and aluminium disturb neuronal morphology, transport functions, cholinesterase, lysosomal and cell cycle activities. Pathophysiology 2015, 22, 105-115. [CrossRef] [PubMed]

75. Sood, P.K.; Nahar, U.; Nehru, B. Stress Proteins and Glial Cell Functions during Chronic Aluminium Exposures: Protective Role of Curcumin. Neurochem. Res. 2011, 37, 639-646. [CrossRef] [PubMed]

76. Ivanovski, I.; Ivanovski, A.; Nikolić, D.; Ivanovski, P. Aluminium in brain tissue in autism. J. Trace Elem. Med. Biol. 2019, 51, 138-140. [CrossRef]

77. Exley, C. The Chemistry of Human Exposure to Aluminium. In Neurotoxicity of Aluminum; Advances in Experimental Medicine and Biology; Niu, Q., Ed.; Springer: Singapore, 2018; Volume 1091, pp. 33-37. 
78. Lukiw, W.J. Evidence supporting a biological role for aluminum in chromatin compaction and epigenetics. J. Inorg. Biochem. 2010, 104, 1010-1012. [CrossRef]

79. Klotz, K.; Weistenhofer, W.; Neff, F.; Hartwig, A.; van Thriel, C.; Drexler, H. The Health Effects of Aluminium Exposure. Dtsch Arztebl Int. 2017, 114, 653-659.

80. Gower-Winter, S.D.; Levenson, C.W. Zinc in the central nervous system: From molecules to behavior. BioFactors 2012, 38, 186-193. [CrossRef]

81. Blakemore, L.J.; Trombley, P.Q. Zinc as a Neuromodulator in the Central Nervous System with a Focus on the Olfactory Bulb. Front. Cell. Neurosci. 2017, 11, 297. [CrossRef]

82. Frederickson, C.J.; Suh, S.W.; Silva, D.; Frederickson, C.J.; Thompson, R.B. Importance of Zinc in the Central Nervous System: The Zinc-Containing Neuron. J. Nutr. 2000, 130, 1471S-1483S. [CrossRef] [PubMed]

83. Gammoh, N.Z.; Rink, L. Zinc in Infection and Inflammation. Nutrients 2017, 9, 624. [CrossRef] [PubMed]

84. Prasad, A.S. Zinc in Human Health: Effect of Zinc on Immune Cells. Mol. Med. 2008, 14, 353-357. [CrossRef]

85. Collins, J.F. Copper. Adv. Nutr. 2011, 2, 520-522. [CrossRef] [PubMed]

86. Tapiero, H.; Townsend, D.M.; Tew, K.D. Trace elements in human physiology and pathology. Copp. Biomed. Pharmacother. 2003, 57, 386-398. [CrossRef]

87. Scheiber, I.F.; Mercer, J.F.; Dringen, R. Metabolism and functions of copper in brain. Prog. Neurobiol. 2014, 116, 33-57. [CrossRef] [PubMed]

88. Gaetke, L.M.; Chow-Johnson, H.S.; Chow, C.K. Copper: Toxicological relevance and mechanisms. Arch. Toxicol. 2014, 88, 1929-1938. [CrossRef]

89. Kardos, J.; Héja, L.; Simon, Á.; Jablonkai, I.; Kovács, R.; Jemnitz, K. Copper signalling: Causes and consequences. Cell Commun. Signal. 2018, 16, 1-22. [CrossRef]

90. Gaier, E.; Eipper, B.; Mains, R. Copper signaling in the mammalian nervous system: Synaptic effects. J. Neurosci. Res. 2012, 91, 2-19. [CrossRef]

91. Opazo, C.M.; Greenough, M.A.; Bush, A.I. Copper: From neurotransmission to neuroproteostasis. Front. Aging Neurosci. 2014, 6, 143. [CrossRef]

92. Schlief, M.L.; Gitlin, J.D. Copper Homeostasis in the CNS: A Novel Link Between the NMDA Receptor and Copper Homeostasis in the Hippocampus. Mol. Neurobiol. 2006, 33, 81-90. [CrossRef]

93. Desai, V.; Kaler, S.G. Role of copper in human neurological disorders. Am. J. Clin. Nutr. 2008, 88, 855S-858S. [CrossRef] [PubMed]

94. Wazir, S.M.; Ghobrial, I. Copper deficiency, a new triad: Anemia, leucopenia, and myeloneuropathy. J. Community Hosp. Intern. Med. Perspect. 2017, 7, 265-268. [CrossRef] [PubMed]

95. Tinggi, U. Selenium: Its role as antioxidant in human health. Environ. Health Prev. Med. 2008, 13, 102-108. [CrossRef]

96. Mehdi, Y.; Hornick, J.-L.; Istasse, L.; Dufrasne, I. Selenium in the Environment, Metabolism and Involvement in Body Functions. Molecules 2013, 18, 3292-3311. [CrossRef]

97. Kurokawa, S.; Berry, M.J. Selenium. Role of the Essential Metalloid in Health. In Metal Ions in Life Sciences Interrelations between Essential Metal Ions and Human Diseases; Springer: Dordrecht, The Netherlands, 2013; pp. 499-534.

98. Rederstorff, M.; Krol, A.; Lescure, A. Understanding the importance of selenium and selenoproteins in muscle function. Cell. Mol. Life Sci. 2005, 63, 52-59. [CrossRef]

99. Rayman, M.P. The importance of selenium to human health. Lancet 2000, 356, 233-241. [CrossRef]

100. Solovyev, N.D. Importance of selenium and selenoprotein for brain function: From antioxidant protection to neuronal signalling. J. Inorg. Biochem. 2015, 153, 1-12. [CrossRef]

101. Cormick, G.; Belizán, J.M. Calcium Intake and Health. Nutrients 2019, 11, 1606. [CrossRef]

102. Vannucci, L.; Fossi, C.; Quattrini, S.; Guasti, L.; Pampaloni, B.; Gronchi, G.; Giusti, F.; Romagnoli, C.; Cianferotti, L.; Marcucci, G.; et al. Calcium Intake in Bone Health: A Focus on Calcium-Rich Mineral Waters. Nutrients 2018, 10, 1930. [CrossRef]

103. Young, W. Role of calcium in central nervous system injuries. J. Neurotrauma 1992, 9 (Suppl. 1), S9-S25. [PubMed]

104. Braet, K.; Cabooter, L.; Paemeleire, K.; Leybaert, L. Calcium signal communication in the central nervous system. Biol. Cell 2004, 96, 79-91. [CrossRef] [PubMed]

105. Nedergaard, M.; Rodríguez, J.J.; Verkhratsky, A. Glial calcium and diseases of the nervous system. Cell Calcium 2010, 47, 140-149. [CrossRef] [PubMed] 
106. Mata, A.M.; Sepulveda, M.R. Calcium pumps in the central nervous system. Brain Res. Brain Res. Rev. 2005, 49, 398-405. [CrossRef]

107. Nicholls, D.G. Mitochondrial calcium function and dysfunction in the central nervous system. Biochim. Biophys. Acta Bioenerg. 2009, 1787, 1416-1424. [CrossRef]

108. Ruat, M.; Traiffort, E. Roles of the calcium sensing receptor in the central nervous system. Best Pract. Res. Clin. Endocrinol. Metab. 2013, 27, 429-442. [CrossRef]

109. Andersen, T.L.; Sondergaard, T.E.; Skorzynska, K.E.; Dagnaes-Hansen, F.; Plesner, T.L.; Hauge, E.M.; Plesner, T.; Delaisse, J.-M. A Physical Mechanism for Coupling Bone Resorption and Formation in Adult Human Bone. Am. J. Pathol. 2009, 174, 239-247. [CrossRef]

110. Aschner, J.L.; Aschner, M. Nutritional aspects of manganese homeostasis. Mol. Asp. Med. 2005, 26, 353-362. [CrossRef]

111. Chen, P.; Bornhorst, J.; Aschner, M. Manganese metabolism in humans. Front. Biosci. 2018, 123, 1655-1679. [CrossRef]

112. Horning, K.J.; Caito, S.W.; Tipps, K.G.; Bowman, A.B.; Aschner, M. Manganese Is Essential for Neuronal Health. Annu. Rev. Nutr. 2015, 35, 71-108. [CrossRef]

113. Bowman, A.B.; Kwakye, G.F.; Hernandez, E.H.; Aschner, M. Role of manganese in neurodegenerative diseases. J. Trace Elem. Med. Biol. 2011, 25, 191-203. [CrossRef] [PubMed]

114. Sidoryk-Wegrzynowicz, M.; Aschner, M. Manganese toxicity in the central nervous system: The glutamine/glutamate- $\gamma$-aminobutyric acid cycle. J. Intern. Med. 2013, 273, 466-477. [CrossRef] [PubMed]

115. Rivera-Mancía, S.; Ríos, C.; Montes, S. Manganese accumulation in the CNS and associated pathologies. BioMetals 2011, 24, 811-825. [CrossRef] [PubMed]

116. Chen, P.; Chakraborty, S.; Mukhopadhyay, S.; Lee, E.; Paoliello, M.M.B.; Bowman, A.B.; Aschner, M. Manganese Homeostasis in the Nervous System. J. Neurochem. 2015, 134, 601-610. [CrossRef] [PubMed]

117. Won, E.; Kim, Y.K. An Oldie but Goodie: Lithium in the Treatment of Bipolar Disorder through Neuroprotective and Neurotrophic Mechanisms. Int. J. Mol. Sci. 2017, 18, 2679. [CrossRef]

118. Demling, J.; Eglau, M.; Autenrieth, T. On the physiological function oflithium from a psychiatric view point. Med. Hypotheses 2001, 57, 506-509. [CrossRef]

119. Malhi, G.S.; Outhred, T. Therapeutic Mechanisms of Lithium in Bipolar Disorder: Recent Advances and Current Understanding. CNS Drugs 2016, 30, 931-949. [CrossRef]

120. Eker, C.; Simsek, F.; Y1lmazer, E.E.; Kitis, O.; Cinar, C.; Eker, O.D.; Coburn, K.; Gonul, A.S. Brain regions associated with risk and resistance for bipolar I disorder: A voxel-based MRI study of patients with bipolar disorder and their healthy siblings. Bipolar Disord. 2014, 16, 249-261. [CrossRef]

121. Wijeratne, C.; Sachdev, S.; Wen, W.; Piguet, O.; Lipnicki, D.M.; Malhi, G.S.; Mitchell, P.B.; Sachdev, P.S. Hippocampal and amygdala volumes in an older bipolar disorder sample. Int. Psychogeriatr. 2012, 25, 54-60. [CrossRef]

122. Chen, X.; Wen, W.; Malhi, G.S.; Ivanovski, B.; Sachdev, P.S. Regional Gray Matter Changes in Bipolar Disorder: A Voxel-Based Morphometric Study. Aust. N. Z. J. Psychiatry 2007, 41, 327-336. [CrossRef]

123. Sousa, R.T.D.; Streck, E.L.; Zanetti, M.V.; Ferreira, G.K.; Diniz, B.S.; Brunoni, A.R.; Busatto, G.F.; Gattaz, W.F.; Machado-Vieira, R. Lithium increases leukocyte mitochondrial complex I activity in bipolar disorder during depressive episodes. Psychopharmacology 2014, 232, 245-250. [CrossRef] [PubMed]

124. Macêdo, D.S.; Lucena, D.F.D.; Queiroz, A.I.G.; Cordeiro, R.C.; Araújo, M.M.; Sousa, F.C.; Vasconcelos, S.M.; Hyphantis, T.N.; Quevedo, J.; McIntyre, R.S.; et al. Effects of lithium on oxidative stress and behavioral alterations induced by lisdexamfetamine dimesylate: Relevance as an animal model of mania. Prog. Neuro Psychopharmacol. Biol. Psychiatry 2013, 43, 230-237. [CrossRef] [PubMed]

125. Nielsen, F.H. Other elements: Sb, Ba, B, Br, Cs, Ge, Rb, Ag, Sr, Sn, Ti, Zr, Be, Bi, Ga, Au, In, Nb, Sc, Te, Tl, W. In Trace Elements in Human and Animal Nutrition; Mertz, W., Ed.; Academic Press: San Diego, CA, USA, 2012; Volume 2, pp. 415-463.

126. Paschalis, C.; Jenner, F.A.; Lee, C.R. Effects of rubidium chloride on the course of manic-depressive illness. J. R Soc. Med. 1978, 71, 343-352. [CrossRef] [PubMed]

127. Meltzer, H.L. A pharmacokinetic analysis of long-term administration of rubidium chloride. J. Clin. Pharmacol. 1991, 31, 179-184. [CrossRef]

128. Mehri, A. Trace Elements in Human Nutrition (II)—An Update. Int. J. Prev. Med. 2020, 11, 2. 
129. Sun, Y.; Byon, C.H.; Yang, Y.; Bradley, W.E.; Dell'Italia, L.J.; Sanders, P.W.; Agarwal, A.; Wu, H.; Chen, Y. Dietary potassium regulates vascular calcification and arterial stiffness. JCI Insight 2017, 2, e94920. [CrossRef]

130. D'Elia, L.; Barba, G.; Cappuccio, F.; Strazzullo, P. Potassium Intake, Stroke, and Cardiovascular Disease: A Meta-Analysis of Prospective Studies. J. Am. Coll. Cardiol. 2011, 57, 1210-1219. [CrossRef]

131. Lanham-New, S.A.; Lambert, H.; Frassetto, L. Potassium. Adv. Nutr. 2012, 3, 820-821. [CrossRef]

132. Yue, Y.C.; Li, M.H.; Wang, H.B.; Zhang, B.L.; He, W. The toxicological mechanisms and detoxification of depleted uranium exposure. Environ. Health Prev. Med. 2018, 23, 18. [CrossRef]

133. Hao, Y.; Li, R.; Leng, Y.; Ren, J.; Liu, J.; Ai, G.; Xu, H.; Su, Y.; Cheng, T. A study assessing the genotoxicity in rats after chronic oral exposure to a low dose of depleted uranium. J. Radiat. Res. 2009, 50, 521-528. [CrossRef]

134. Carmona, A.; Malard, V.; Avazeri, E.; Roudeau, S.; Porcaro, F.; Paredes, E.; Vidaud, C.; Bresson, C.; Ortega, R. Uranium exposure of human dopaminergic cells results in low cytotoxicity, accumulation within sub-cytoplasmic regions, and down regulation of MAO-B. Neurotoxicology 2018, 68, 177-188. [CrossRef] [PubMed]

135. Briner, W. The toxicity of depleted uranium. Int J. Environ. Res. Public Health 2010, 7, $303-313$. [CrossRef] [PubMed]

136. Dublineau, I.; Grandcolas, L.; Grison, S.; Baudelin, C.; Paquet, F.; Voisin, P.; Aigueperse, J.; Gourmelon, P. Modifications of inflammatory pathways in rat intestine following chronic ingestion of depleted uranium. Toxicol. Sci. 2007, 98, 458-468. [CrossRef] [PubMed]

137. Bertin, G.; Averbeck, D. Cadmium: Cellular effects, modifications of biomolecules, modulation of DNA repair and genotoxic consequences (a review). Biochimie 2006, 88, 1549-1559. [CrossRef]

138. Waalkes, M.P. Cadmium carcinogenesis. Mutat. Res. 2003, 533, 107-120. [CrossRef]

139. Satarug, S.; Baker, J.R.; Reilly, P.E.; Moore, M.R.; Williams, D.J. Cadmium levels in the lung, liver, kidney cortex, and urine samples from Australians without occupational exposure to metals. Arch. Environ. Health 2002, 57, 69-77. [CrossRef]

140. Uetani, M.; Kobayashi, E.; Suwazono, Y.; Honda, R.; Nishijo, M.; Nakagawa, H.; Kido, T.; Nogawa, K. Tissue cadmium (Cd) concentrations of people living in a Cd polluted area, Japan. Biometals 2006, 19, 521-525. [CrossRef]

141. Wills, N.K.; Ramanujam, V.M.; Chang, J.; Kalariya, N.; Lewis, J.R.; Weng, T.X.; van Kuijk, F.J. Cadmium accumulation in the human retina: Effects of age, gender, and cellular toxicity. Exp. Eye Res. 2008, 86, 41-51. [CrossRef]

142. Satarug, S.; Garrett, S.H.; Sens, M.A.; Sens, D.A. Cadmium, environmental exposure, and health outcomes. Environ. Health Perspect 2010, 118, 182-190. [CrossRef]

143. Rodríguez-Barranco, M.; Lacasaña, M.; Gil, F.; Lorca, A.; Alguacil, J.; Rohlman, D.S.; González-Alzaga, B.; Molina-Villalba, I.; Mendoza, R.; Aguilar-Garduño, C. Cadmium exposure and neuropsychological development in school children in southwestern Spain. Environ. Res. 2014, 134, 66-73. [CrossRef]

144. Saghazadeh, A.; Ahangari, N.; Hendi, K.; Saleh, F.; Rezaei, N. Status of essential elements in autism spectrum disorder: Systematic review and meta-analysis. Rev. Neurosci. 2017, 28, 783-809. [CrossRef] [PubMed]

145. Ayton, S.; Lei, P.; Bush, A.I. Biometals and Their Therapeutic Implications in Alzheimer's Disease. Neurotherapeutics 2014, 12, 109-120. [CrossRef] [PubMed]

146. Kim, M.-J.; Oh, S.-B.; Kim, J.; Kim, K.; Ryu, H.-S.; Kim, M.S.; Ayton, S.; Bush, A.I.; Lee, J.-Y.; Chung, S.J. Association of metals with the risk and clinical characteristics of Parkinsons disease. Parkinsonism Relat. Disord. 2018, 55, 117-121. [CrossRef] [PubMed]

147. Dominguez, J.F.D.; Ng, A.C.L.; Poudel, G.; Stout, J.C.; Churchyard, A.; Chua, P.; Egan, G.F.; Georgiou-Karistianis, N. Iron accumulation in the basal ganglia in Huntingtons disease: Cross-sectional data from the IMAGE-HD study. J. Neurol. Neurosurg. Psychiatry 2015, 87, 545-549. [CrossRef]

148. Bartnicka, J.J.; Blower, P.J. Insights into Trace Metal Metabolism in Health and Disease From PET: "PET Metallomics". J. Nucl. Med. 2018, 59, 1355-1359. [CrossRef]

149. Wang, J.; Um, P.; Dickerman, B.A.; Liu, J. Zinc, Magnesium, Selenium and Depression: A Review of the Evidence, Potential Mechanisms and Implications. Nutrients 2018, 10, 584. [CrossRef]

150. Tseng, P.-T.; Cheng, Y.-S.; Yen, C.-F.; Chen, Y.-W.; Stubbs, B.; Whiteley, P.; Carvalho, A.F.; Li, D.-J.; Chen, T.-Y.; Yang, W.-C.; et al. Peripheral Iron Levels in Children with Attention-Deficit Hyperactivity Disorder: A Systematic Review and Meta-Analysis. Sci. Rep. 2018, 8, 788. [CrossRef] 
151. Royal, B. Schizophrenia: Nutrition and Alternative Treatment Approaches. Schizophr. Bull. 2015, 42, 1083-1085. [CrossRef]

152. Velthorst, E.; Smith, L.; Bello, G.; Austin, C.; Gennings, C.; Modabbernia, A.; Franke, N.; Frangou, S.; Wright, R.; de Haan, L.; et al. New Research Strategy for Measuring Pre- and Postnatal Metal Dysregulation in Psychotic Disorders. Schizophr. Bull. 2017, 43, 1153-1157. [CrossRef]

153. Liu, T.; Lu, Q.-B.; Yan, L.; Guo, J.; Feng, F.; Qiu, J.; Wang, J. Comparative Study on Serum Levels of 10 Trace Elements in Schizophrenia. PLoS ONE 2015, 10, e0133622. [CrossRef]

154. Cruz, E.C.S.; Madrid, K.C.; Arruda, M.A.; Sussulini, A. Association between trace elements in serum from bipolar disorder and schizophrenia patients considering treatment effects. J. Trace Elem. Med. Biol. 2020, 59, 126467. [CrossRef] [PubMed]

155. Herrán, A.; García-Unzueta, M.T.; Fernández-González, M.D.; Vázquez-Barquero, J.L.; Alvarez, C.; Amado, J.A. Higher levels of serum copper in schizophrenic patients treated with depot neuroleptics. Psychiatry Res. 2000, 94, 51-58. [CrossRef]

156. Cao, B.; Yan, L.; Ma, J.; Jin, M.; Park, C.; Nozari, Y.; Kazmierczak, O.P.; Zukerman, H.; Lee, Y.; Pan, Z.; et al. Comparison of serum essential trace metals between patients with schizophrenia and healthy controls. J. Trace Elem. Med. Biol. 2019, 51, 79-85. [CrossRef] [PubMed]

157. Chen, X.; Li, Y.; Zhang, T.; Yao, Y.; Shen, C.; Xue, Y. Association of Serum Trace Elements with Schizophrenia and Effects of Antipsychotic Treatment. Biol. Trace Elem. Res. 2017, 181, 22-30. [CrossRef] [PubMed]

158. Devanarayanan, S.; Nandeesha, H.; Kattimani, S.; Sarkar, S.; Jose, J. Elevated copper, hs C-reactive protein and dyslipidemia in drug free schizophrenia: Relation with psychopathology score. Asian J. Psychiatry 2016, 24, 99-102. [CrossRef]

159. Edelstein, E.L.; Krassilowsky, D.; Gdalia, J. A Study on Serum Copper Level in 20 Acute Schizophrenics. J. Ment. Sci. 1959, 105, 511-513. [CrossRef]

160. Frohman, C.E. Ceruloplasmin, Transferrin, and Tryptophan in Schizophrenia. Arch. Neurol. Psychiatry 1958, 79, 730. [CrossRef]

161. Li, Z.; Liu, Y.; Li, X.; Ju, W.; Wu, G.; Yang, X.; Fu, X.; Gao, X. Association of Elements with Schizophrenia and Intervention of Selenium Supplements. Biol. Trace Elem. Res. 2017, 183, 16-21. [CrossRef]

162. Maas, J.W.; Gleser, G.C.; Gottschalk, L.A. Schizophrenia, Anxiety, and Biochemical Factors: The Rate of Oxidation of N,N-Dimethyl-p-Phenylenediamine by Plasma and Levels of Serum Copper and Plasma Ascorbic Acid. Arch. Gen. Psychiatry 1961, 4, 109-118. [CrossRef]

163. Munch-Petersen, S. On Serum Copper in Patients with Schizophrenia. Acta Psychiatr. Scand. 1950, 25, 423-427. [CrossRef]

164. Olatunbosun, D.A.; Akindele, M.O.; Adadevoh, B.K.; Asuni, T. Serum Copper in Schizophrenia in Nigerians. Br. J. Psychiatry 1975, 127, 119-121. [CrossRef] [PubMed]

165. Wolf, T.L.; Kotun, J.; Meador-Woodruff, J.H. Plasma copper, iron, ceruloplasmin and ferroxidase activity in schizophrenia. Schizophr. Res. 2006, 86, 167-171. [CrossRef] [PubMed]

166. Wasti, A.Z.; Zahid, S.; Ahmed, N. Antipsychotic Drugs Induced Iron Deficiency Anemia in Schizophrenic Patients. Int. J. Adv. Res. 2013, 1, 111-118.

167. Barnes, T.R.E.; Halstead, S.M.; Little, P.W.A. Relationship Between Iron Status and Chronic Akathisia in an In-patient Population with Chronic Schizophrenia. Br. J. Psychiatry 1992, 161, 791-796. [CrossRef]

168. Hofmann, M.; Seifritz, E.; Botschev, C.; Kräuchi, K.; Müller-Spahn, F. Serum iron and ferritin in acute neuroleptic akathisia. Psychiatry Res. 2000, 93, 201-207. [CrossRef]

169. Kim, S.-W.; Stewart, R.; Park, W.-Y.; Jhon, M.; Lee, J.-Y.; Kim, S.-Y.; Kim, J.-M.; Amminger, P.; Chung, Y.-C.; Yoon, J.-S. Latent Iron Deficiency as a Marker of Negative Symptoms in Patients with First-Episode Schizophrenia Spectrum Disorder. Nutrients 2018, 10, 1707. [CrossRef]

170. Kuloglu, M.; Atmaca, M.; Üstündag, B.; Canatan, H.; Gecici, O.; Tezcan, E. Serum iron levels in schizophrenic patients with or without akathisia. Eur. Neuropsychopharmacol. 2003, 13, 67-71. [CrossRef]

171. Soni, S.D.; Tench, D.; Routledge, R.C. Serum Iron Abnormalities in Neuroleptic-Induced Akathisia in Schizophrenic Patients. Br. J. Psychiatry 1993, 163, 669-672. [CrossRef]

172. Spina, E.; Ancione, M.; Rosa, A.E.D.; Artemisia, A.; Natoli, C.; Caputi, A.P. Iron status in schizophrenic patients with acute neuroleptic-induced dystonic reactions. Prog. Neuro Psychopharmacol. Biol. Psychiatry 1994, 18, 891-898. [CrossRef] 
173. Wirshing, D.A.; Bartzokis, G.; Pierre, J.M.; Wirshing, W.C.; Sun, A.; Tishler, T.A.; Marder, S.R. Tardive dyskinesia and serum iron indices. Biol. Psychiatry 1998, 44, 493-498. [CrossRef]

174. Wiser, M.; Levkowitch, Y.; Neuman, M.; Yehuda, S. Decrease of Serum Iron in Acutely Psychotic Schizophrenic Patients. Int. J. Neurosci. 1994, 78, 49-52. [CrossRef] [PubMed]

175. Alexander, P.E.; Kammen, D.P.V.; Bunney, W.E. Serum Calcium and Magnesium in Schizophrenia: Relationship to Clinical Phenomena and Neuroleptic Treatment. Br. J. Psychiatry 1978, 133, 143-149. [CrossRef] [PubMed]

176. Alexander, P.E. Serum Calcium and Magnesium Levels in Schizophrenia. Arch. Gen. Psychiatry 1979, 36, 1372. [CrossRef] [PubMed]

177. Athanassenas, G.; Papadopolos, E.; Kourkoubas, A.; Tsitourides, S.; Gabriel, J.; Hoidas, S.; Frangos, E. Serum Calcium and Magnesium Levels in Chronic Schizophrenics. J. Clin. Psychopharmacol. 1983, 3, 212-216. [CrossRef] [PubMed]

178. Levine, J.; Rapoport, A.; Mashiah, M.; Dolev, E. Serum and Cerebrospinal Levels of Calcium and Magnesium in Acute versus Remitted Schizophrenic Patients. Neuropsychobiology 1996, 33, 169-172. [CrossRef]

179. Alertsen, A.R.; Aukrust, A.; Skaug, O.E. Selenium concentrations in blood and serum from patients with mental diseases. Acta Psychiatr. Scand. 1986, 74, 217-219. [CrossRef]

180. Ruljancic, N.; Mihanovic, M.; Cepelak, I.; Bakliza, A. Platelet and serum calcium and magnesium concentration in suicidal and non-suicidal schizophrenic patients. Psychiatry Clin. Neurosci. 2013, 67, 154-159. [CrossRef]

181. Jamilian, H.; Bagherzadeh, K.; Nazeri, Z.; Hassanijirdehi, M. Vitamin D, parathyroid hormone, serum calcium and phosphorus in patients with schizophrenia and major depression. Int. J. Psychiatry Clin. Pract. 2012, 17, 30-34. [CrossRef]

182. Lin, T.; Liu, T.; Lin, Y.; Yan, L.; Chen, Z.; Wang, J. Comparative study on serum levels of macro and trace elements in schizophrenia based on supervides learning methods. J. Trace Elem. Med. Biol. 2017, 43, 202-208. [CrossRef]

183. Cai, L.; Chen, T.; Yang, J.; Zhou, K.; Yan, X.; Chen, W.; Sun, L.; Li, L.; Qin, S.; Wang, P.; et al. Serum trace element differences between Schizophrenia patients and controls in the Han Chinese population. Sci. Rep. 2015, 5, 15013. [CrossRef]

184. Ma, J.; Wang, B.; Gao, X.; Wu, H.; Wang, D.; Li, N.; Tan, J.; Wang, J.; Yan, L. A comparative study of the typical toxic metals in serum by patients of schizophrenia and healthy controls in China. Psychiatry Res. 2018, 269, 558-564. [CrossRef] [PubMed]

185. Ma, J.; Yan, L.; Guo, T.; Yang, S.; Guo, C.; Liu, Y.; Xie, Q.; Wang, J. Association of Typical Toxic Heavy Metals with Schizophrenia. Int. J. Environ. Res. Public Health 2019, 16, 4200. [CrossRef] [PubMed]

186. Gambling, L.; Kennedy, C.; Mcardle, H.J. Iron and copper in fetal development. Semin. Cell Dev. Biol. 2011, 22, 637-644. [CrossRef] [PubMed]

187. Piñero, D.J.; Connor, J.R. Iron in the Brain: An Important Contributor in Normal and Diseased States. Neuroscientist 2000, 6, 435-453. [CrossRef]

188. Moreno-Fernandez, J.; Ochoa, J.J.; Latunde-Dada, G.O.; Diaz-Castro, J. Iron Deficiency and Iron Homeostasis in Low Birth Weight Preterm Infants: A Systematic Review. Nutrients 2019, 11, 1090. [CrossRef]

189. Wessling-Resnick, M. Excess iron: Considerations related to development and early growth. Am. J. Clin. Nutr. 2017, 10 (Suppl. 6), 1600S-1605S. [CrossRef]

190. Hare, D.; Ayton, S.; Bush, A.; Lei, P. A Delicate Balance: Iron Metabolism and Diseases of the Brain. Front. Aging Neurosci. 2013, 5. [CrossRef]

191. Lamtai, M.; Chaibat, J.; Ouakki, S.; Zghari, O.; Mesfioui, A.; Hessni, A.E.; Rifi, E.-H.; Marmouzi, I.; Essamri, A.; Ouichou, A. Effect of Chronic Administration of Nickel on Affective and Cognitive Behavior in Male and Female Rats: Possible Implication of Oxidative Stress Pathway. Brain Sci. 2018, 8, 141. [CrossRef]

192. Todorich, B.; Pasquini, J.M.; Garcia, C.I.; Paez, P.M.; Connor, J.R. Oligodendrocytes and myelination: The role of iron. Glia 2009, 57, 467-478. [CrossRef]

193. Hare, D.J.; Double, K.L. Iron and dopamine: A toxic couple. Brain 2016, 139, 1026-1035. [CrossRef]

194. Felt, B.T.; Beard, J.L.; Schallert, T.; Shao, J.; Aldridge, J.W.; Connor, J.R.; Georgieff, M.K.; Lozoff, B. Persistent neurochemical and behavioral abnormalities in adulthood despite early iron supplementation for perinatal iron deficiency anemia in rats. Behav. Brain Res. 2006, 171, 261-270. [CrossRef] [PubMed]

195. Beard, J.L.; Felt, B.; Schallert, T.; Burhans, M.; Connor, J.R.; Georgieff, M.K. Moderate iron deficiency in infancy: Biology and behavior in young rats. Behav. Brain Res. 2006, 170, 224-232. [CrossRef] 
196. Pisansky, M.T.; Wickham, R.J.; Su, J.; Fretham, S.; Yuan, L.-L.; Sun, M.; Gewirtz, J.C.; Georgieff, M.K. Iron deficiency with or without anemia impairs prepulse inhibition of the startle reflex. Hippocampus 2013, 23, 952-962. [CrossRef] [PubMed]

197. Iglesias, L.; Canals, J.; Arija, V. Effects of prenatal iron status on child neurodevelopment and behavior: A systematic review. Crit. Rev. Food Sci. Nutr. 2017, 58, 1604-1614. [CrossRef] [PubMed]

198. Lozoff, B. Early Iron Deficiency Has Brain and Behavior Effects Consistent with Dopaminergic Dysfunction. J. Nutr. 2011, 141, 740S-746S. [CrossRef] [PubMed]

199. East, P.; Delker, E.; Lozoff, B.; Delva, J.; Castillo, M.; Gahagan, S. Associations among Infant Iron Deficiency, Childhood Emotion and Attention Regulation, and Adolescent Problem Behaviors. Child. Dev. 2017, 89, 593-608. [CrossRef]

200. Wenger, M.J.; Dellavalle, D.M.; Murray-Kolb, L.E.; Haas, J.D. Effect of iron deficiency on simultaneous measures of behavior, brain activity, and energy expenditure in the performance of a cognitive task. Nutr. Neurosci. 2017, 22, 196-206. [CrossRef]

201. Ferreira, A.C.; Sousa, N.; Bessa, J.M.; Sousa, J.C.; Marques, F. Metabolism and adult neurogenesis: Towards an understanding of the role of lipocalin-2 and iron-related oxidative stress. Neurosci. Biobehav. Rev. 2018, 95, 73-84. [CrossRef]

202. Imam, M.; Zhang, S.; Ma, J.; Wang, H.; Wang, F. Antioxidants Mediate Both Iron Homeostasis and Oxidative Stress. Nutrients 2017, 9, 671. [CrossRef]

203. Ng, F.; Berk, M.; Dean, O.; Bush, A.I. Oxidative stress in psychiatric disorders: Evidence base and therapeutic implications. Int. J. Neuropsychopharmacol. 2008, 11, 851-876. [CrossRef]

204. Smythies, J. The neurotoxicity of glutamate, dopamine, iron and reactive oxygen species: Functional interrelationships in health and disease: A review-Discussion. Neurotox. Res. 1999, 1, 27-39. [CrossRef] [PubMed]

205. Andersen, H.H.; Johnsen, K.B.; Moos, T. Iron deposits in the chronically inflamed central nervous system and contributes to neurodegeneration. Cell. Mol. Life Sci. 2013, 71, 1607-1622. [CrossRef] [PubMed]

206. Wang, Y.; Wu, Y.; Li, T.; Wang, X.; Zhu, C. Iron Metabolism and Brain Development in Premature Infants. Front. Physiol. 2019, 10, 463. [CrossRef]

207. Kim, J.; Wessling-Resnick, M. Iron and mechanisms of emotional behavior. J. Nutr. Biochem. 2014, 25, 1101-1107. [CrossRef] [PubMed]

208. Yanik, M.; Kocyigit, A.; Tutkun, H.; Vural, H.; Herken, H. Plasma manganese, selenium, zinc, copper, and iron concentrations in patients with schizophrenia. Biol. Trace Elem. Res. 2004, 98, 109-117. [CrossRef]

209. Casanova, M.F.; Waldman, I.N.; Kleinman, J.E. A postmortem quantitative study of iron in the globus pallidus of schizophrenic patients. Biol. Psychiatry 1990, 27, 143-149. [CrossRef]

210. Casanova, M.F.; Prasad, C.M.; Waldman, I.; Illowsky Karp, B.; Stein, B.; Weinberger, D.R.; Kleinman, J.B. No difference in basal ganglia mineralization between schizophrenic and nonschizophrenic patients: A quantitative computerized tomographic study. Biol. Psychiatry 1990, 27, 138-142. [CrossRef]

211. Sachdev, P. The neuropsychiatry of brain iron. J. Neuropsychiatry Clin. Neurosci. 1993, 5, 18-29.

212. Kornhuber, J.; Lange, K.W.; Kruzik, P.; Rausch, W.-D.; Gabriel, E.; Jellinger, K.; Riederer, P. Iron, copper, zinc, magnesium, and calcium in postmortem brain tissue from schizophrenic patients. Biol. Psychiatry 1994, 36, 31-34. [CrossRef]

213. Casanova, M.F.; Comparini, S.O.; Kim, R.W.; Kleinman, J.E. Staining intensity of brain iron in patients with schizophrenia: A postmortem study. J. Neuropsychiatry Clin. Neurosci. 1992, 4, 36-41.

214. Demmel, U.; Höck, A.; Feinendegen, L.; Sebek, P. Trace elements in brains of patients with alcohol abuse, endogeneous psychosis and schizophrenia. Sci. Total Environ. 1984, 38, 69-77. [CrossRef]

215. Insel, B.J.; Schaefer, C.A.; Mckeague, I.W.; Susser, E.S.; Brown, A.S. Maternal Iron Deficiency and the Risk of Schizophrenia in Offspring. Arch. Gen. Psychiatry 2008, 65, 1136. [CrossRef] [PubMed]

216. Tran, P.V.; Kennedy, B.C.; Pisansky, M.T.; Won, K.-J.; Gewirtz, J.C.; Simmons, R.A.; Georgieff, M.K. Prenatal Choline Supplementation Diminishes Early-Life Iron Deficiency-Induced Reprogramming of Molecular Networks Associated with Behavioral Abnormalities in the Adult Rat Hippocampus. J. Nutr. 2016, 146, 484-493. [CrossRef] [PubMed]

217. Mireku, M.O.; Davidson, L.L.; Boivin, M.J.; Zoumenou, R.; Massougbodji, A.; Cot, M.; Bodeau-Livinec, F. Prenatal Iron Deficiency, Neonatal Ferritin, and Infant Cognitive Function. Pediatrics 2016, 138, e20161319. [CrossRef] [PubMed] 
218. Lozoff, B.; Beard, J.; Connor, J.; Barbara, F.; Georgieff, M.; Schallert, T. Longlasting neural and behavioral effects of iron deficiency in infancy. Nutr. Rev. 2006, 64, S34-S43. [CrossRef] [PubMed]

219. Sorensen, H.J.; Nielsen, P.R.; Pedersen, C.B.; Mortensen, P.B. Association Between Prepartum Maternal Iron Deficiency and Offspring Risk of Schizophrenia: Population-Based Cohort Study with Linkage of Danish National Registers. Schizophr. Bull. 2010, 37, 982-987. [CrossRef] [PubMed]

220. Wiegersma, A.M.; Dalman, C.; Lee, B.K.; Karlsson, H.; Gardner, R.M. Association of Prenatal Maternal Anemia with Neurodevelopmental Disorders. JAMA Psychiatry 2019, 76, 1294. [CrossRef]

221. Berglund, S.K.; Torres-Espínola, F.J.; García-Valdés, L.; Segura, M.T.; Martínez-Zaldívar, C.; Padilla, C.; Rueda, R.; Garcia, M.P.; McArdle, H.J.; Campoy, C. The impacts of maternal iron deficiency and being overweight during pregnancy on neurodevelopment of the offspring. Br. J. Nutr. 2017, 118, 533-540. [CrossRef]

222. Sussulini, A.; Erbolato, H.M.; Pessôa, G.D.S.; Arruda, M.A.Z.; Steiner, J.; Martins-De-Souza, D. Elemental fingerprinting of schizophrenia patient blood plasma before and after treatment with antipsychotics. Eur. Arch. Psychiatry Clin. Neurosci. 2017, 268, 565-570. [CrossRef]

223. Faye, A.; Kirpekar, V.; Bhave, S.; Tadke, R.; Gawande, S. Lurasidone-induced anemia: Is there a need for hematological monitoring? Indian J. Pharmacol. 2019, 51, 276. [CrossRef]

224. Song, X.; Kenston, S.S.F.; Kong, L.; Zhao, J. Molecular mechanisms of nickel induced neurotoxicity and chemoprevention. Toxicology 2017, 392, 47-54. [CrossRef] [PubMed]

225. He, M.D.; Xu, S.C.; Zhang, X.; Wang, Y.; Xiong, J.C.; Zhang, X.; Lu, Y.H.; Zhang, L.; Yu, Z.P.; Zhou, Z. Disturbance of aerobic metabolism accompanies neurobehavioral changes induced by nickel in mice. Neurotoxicology 2013, 38, 9-16. [CrossRef] [PubMed]

226. Fatehyab, S.; Hasan, M.; Hasan, M.Z.; Anwar, J. Effect of Nickel on the Levels of Dopamine, Noradrenaline and Serotonin in Different Regions of the Rat Brain. Acta Pharmarol. Toxicol. 1980, 47, 318-320.

227. Deicken, R.F.; Calabrese, G.; Merrin, E.L.; Meyerhoff, D.J.; Dillon, W.P.; Weiner, M.W.; Fein, G. 31phosphorus Magnetic Resonance Spectroscopy of the Frontal and Parietal Lobes in Chronic Schizophrenia. Biol. Psychiatry 1994, 36, 503-510. [CrossRef]

228. Fukuzako, H.; Fukuzako, T.; Takeuchi, K.; Ohbo, Y.; Ueyama, K.; Takigawa, M.; Fujimoto, T. Phosphorus magnetic resonance spectroscopy in schizophrenia: Correlation between membrane phospholipid metabolism in the temporal lobe and positive symptoms. Prog. Neuro Psychopharmacol. Biol. Psychiatry 1996, 20, 629-640. [CrossRef]

229. Yamanaka, R.; Shindo, Y.; Oka, K. Magnesium is a Key Player in Neuronal Maturation and Neuropathology. Int. J. Mol. Sci. 2019, 20, 3439. [CrossRef]

230. Modabbernia, A.; Velthorst, E.; Gennings, C.; Haan, L.D.; Austin, C.; Sutterland, A.; Mollon, J.; Frangou, S.; Wright, R.; Arora, M.; et al. Early-life metal exposure and schizophrenia: A proof-of-concept study using novel tooth-matrix biomarkers. Eur. Psychiatry 2016, 36, 1-6. [CrossRef]

231. Kirov, G.K.; Tsachev, K.N. Magnesium, Schizophrenia and Manic-Depressive Disease. Neuropsychobiology 1990, 23, 79-81. [CrossRef]

232. Plisza, S.R.; Rogeness, G.A. Calcium and magnesium in children with schizophrenia and major depression. Biol. Psychiatry 1983, 19, 871-876.

233. Ordak, M.; Matras, J.; Muszynska, E.; Nasierowski, T.; Bujalska-Zadrozny, M. Magnesium in schizophrenia. Pharmacol. Rep. 2017, 69, 929-934. [CrossRef]

234. Verstraeten, S.V.; Aimo, L.; Oteiza, P.I. Aluminium and lead: Molecular mechanisms of brain toxicity. Arch. Toxicol. 2008, 82, 789-802. [CrossRef] [PubMed]

235. Banks, W.; Kastin, A. Aluminium increases permeability of the blood-brain barrier to labelled dsip and $\beta$-endorphin: Possible implications for senile and dialysis dementia. Lancet 1983, 322, 1227-1229. [CrossRef]

236. Meiri, H.; Banin, E.; Roll, M.; Rousseau, A. Toxic effects of aluminium on nerve cells and synaptic transmission. Prog. Neurobiol. 1993, 40, 89-121. [CrossRef]

237. Kaya, B.; Akdağ, N.; Fadillioğlu, E.; Taycan, S.E.; Emre, M.H.; Unal, S.; Sayal, A.; Erdogan, H. Elements levels and glucose-6-phosphate dehydrogenase activity in blood of patients with schizophrenia. Düşünen Adam J. Psychiatry Neurol. Sci. 2012, 25, 198-205.

238. Marger, L.; Schubert, C.; Bertrand, D. Zinc: An underappreciated modulatory factor of brain function. Biochem. Pharmacol. 2014, 91, 426-435. [CrossRef] 
239. Zhifeng Qi, K.E.J.L. The Interaction of Zinc and the Blood-Brain Barrier Under Physiological and Ischemic Conditions. Toxicol. Appl. Pharmacol. 2019, 364, 114-119.

240. Pfeiffer, C.C.; Braverman, E.R. Zinc, the Brain and Behavior. Biol. Psychiatry 1982, 17, 513-532.

241. Vela, G.; Stark, P.; Socha, M.; Sauer, A.K.; Hagmeyer, S.; Grabrucker, A.M. Zinc in Gut-Brain Interaction in Autism and Neurological Disorders. Neural Plast. 2015, 2015, 1-15. [CrossRef]

242. Portbury, S.; Adlard, P. Zinc Signal in Brain Diseases. Int. J. Mol. Sci. 2017, 18, 2506. [CrossRef]

243. Pochwat, B.; Nowak, G.; Szewczyk, B. Relationship between Zinc (Zn2+) and Glutamate Receptors in the Processes Underlying Neurodegeneration. Neural Plast. 2015, 2015, 591563. [CrossRef]

244. Doboszewska, U.; Młyniec, K.; Wlaź, A.; Poleszak, E.; Nowak, G.; Wlaź, P. Zinc signaling and epilepsy. Pharmacol. Ther. 2019, 193, 156-177. [CrossRef] [PubMed]

245. Joe, P.; Petrilli, M.; Malaspina, D.; Weissman, J. Zinc in schizophrenia: A meta-analysis. Gen. Hosp. Psychiatry 2018, 53, 19-24. [CrossRef] [PubMed]

246. Saghazadeh, A.; Mahmoudi, M.; Shahrokhi, S.; Mojarrad, M.; Dastmardi, M.; Mirbeyk, M.; Rezaei, N. Trace elements in schizophrenia: A systematic review and meta-analysis of 39 studies ( $\mathrm{N}=5151$ participants). Nutr. Rev. 2019, 78, 278-303. [CrossRef] [PubMed]

247. Adams, C.E.; Demasters, B.; Freedman, R. Regional zinc staining in postmortem hippocampus from schizophrenic patients. Schizophr. Res. 1995, 18,71-77. [CrossRef]

248. Paulsen, B.D.S.; Cardoso, S.C.; Stelling, M.P.; Cadilhe, D.V.; Rehen, S.K. Valproate reverts zinc and potassium imbalance in schizophrenia-derived reprogrammed cells. Schizophr. Res. 2014, 154, 30-35. [CrossRef]

249. Dambrosi, N.; Rossi, L. Copper at synapse: Release, binding and modulation of neurotransmission. Neurochem. Int. 2015, 90, 36-45. [CrossRef]

250. Lutsenko, S.; Washington-Hughes, C.; Ralle, M.; Schmidt, K. Copper and the brain noradrenergic system. JBIC J. Biol. Inorg. Chem. 2019, 24, 1179-1188. [CrossRef]

251. Davies, K.M.; Hare, D.J.; Cottam, V.; Chen, N.; Hilgers, L.; Halliday, G.; Mercer, J.F.B.; Double, K.L. Localization of copper and copper transporters in the human brain. Metallomics 2013, 5, 43-51. [CrossRef]

252. Mital, M.; Bal, W.; Fraczyk, T.; Drew, S.C. Interplay between Copper, Neprilysin, and N-Truncation of $\beta$-Amyloid. Inorg. Chem. 2018, 57, 6193-6197. [CrossRef]

253. Gokhale, A.; Vrailas-Mortimer, A.; Larimore, J.; Comstra, H.S.; Zlatic, S.A.; Werner, E.; Manvich, D.F.; Iuvone, P.M.; Weinshenker, D.; Faundez, V. Neuronal copper homeostasis susceptibility by genetic defects in dysbindin, a schizophrenia susceptibility factor. Hum. Mol. Genet. 2015, 24, 5512-5523. [CrossRef]

254. Ni, M.; You, Y.; Chen, J.; Zhang, L. Copper in depressive disorder: A systematic review and meta-analysis of observational studies. Psychiatry Res. 2018, 267, 506-515. [CrossRef] [PubMed]

255. Bowman, M.B.; Lewis, M.S. The copper hypothesis of schizophrenia: A review. Neurosci. Biobehav. Rev. 1982, 6, 321-328. [CrossRef]

256. Schoonover, K.E.; Queern, S.L.; Lapi, S.E.; Roberts, R.C. Impaired copper transport in schizophrenia results in a copper-deficient brain state: A new side to the dysbindin story. World J. Biol. Psychiatry 2018, 21, 13-28. [CrossRef] [PubMed]

257. Cardoso, B.R.; Roberts, B.R.; Bush, A.I.; Hare, D.J. Selenium, selenoproteins and neurodegenerative diseases. Metallomics 2015, 7, 1213-1228. [CrossRef]

258. Vinceti, M.; Filippini, T.; Wise, L.A. Environmental Selenium and Human Health: An Update. Curr. Environ. Health Rep. 2018, 5, 464-485. [CrossRef]

259. Valentine, W.M.; Abel, T.W.; Hill, K.E.; Austin, L.M.; Burk, R.F. Neurodegeneration in mice resulting from loss of functional selenoprotein P or its receptor apolipoprotein E receptor 2. J. Neuropathol. Exp. Neurol. 2008, 67, 68-77. [CrossRef]

260. Pitts, M.W.; Kremer, P.M.; Hashimoto, A.C.; Torres, D.J.; Byrns, C.N.; Williams, C.S.; Berry, J.B. Competition between the Brain and Testes under Selenium-Compromised Conditions: Insight into Sex Differences in Selenium Metabolism and Risk of Neurodevelopmental Disease. J. Neurosci. 2015, 35, 15326-15338. [CrossRef]

261. Steinbrenner, H.; Sies, H. Selenium homeostasis and antioxidant selenoproteins in brain: Implications for disorders in the central nervous system. Arch. Biochem. Biophys. 2013, 536, 152-157. [CrossRef]

262. Reddy, V.S.; Bukke, S.; Dutt, N.; Rana, P.; Pandey, A.K. A systematic review and meta-analysis of the circulatory, erythrocellular and CSF selenium levels in Alzheimers disease: A metal meta-analysis (AMMA study-I). J. Trace Elem. Med. Biol. 2017, 42, 68-75. [CrossRef] 
263. Pillai, R.; Uyehara-Lock, J.H.; Bellinger, F.P. Selenium and selenoprotein function in brain disorders. Iubmb Life 2014, 66, 229-239. [CrossRef]

264. Kanazawa, T.; Glatt, S.J.; Faraone, S.V.; Hwu, H.G.; Yoneda, H.; Tsuang, M.T. Family-based association study of SELENBP1 in schizophrenia. Schizophr. Res. 2009, 113, 268-272. [CrossRef] [PubMed]

265. Kanazawa, T.; Chana, G.; Glatt, S.J.; Mizuno, H.; Masliah, E.; Yoneda, H.; Tsuang, M.T.; Everall, I.P. The utility of SELENBP1 gene expression as a biomarker for major psychotic disorders: Replication in schizophrenia and extension to bipolar disorder with psychosis. Am. J. Med. Genet. B Neuropsychiatr Genet. 2008, 147, 686-689. [CrossRef] [PubMed]

266. Berry, T. A selenium transport protein model of a sub-type of schizophrenia. Med. Hypotheses 1994, 43, 409-414. [CrossRef]

267. Benton, D. Selenium Intake, Mood and Other Aspects of Psychological Functioning. Nutr. Neurosci. 2002, 5, 363-374. [CrossRef]

268. Segal, M.; Korkotian, E. Roles of Calcium Stores and Store-Operated Channels in Plasticity of Dendritic Spines. Neuroscientist 2016, 22, 477-485. [CrossRef]

269. Sharma, A.; Schray, A.; Bartolovic, M.; Roesch-Ely, D.; Aschenbrenner, S.; Weisbrod, M. Relationship between serum calcium and neuropsychological performance might indicate etiological heterogeneity underlying cognitive deficits in schizophrenia and depression. Psychiatry Res. 2017, 252, 80-86. [CrossRef]

270. Bergantin, L.B.; Caricati-Neto, A. Challenges for the pharmacological treatment of neurological and psychiatric disorders: Implications of the Ca 2 /cAMP intracellular signalling interaction. Eur. J. Pharmacol. 2016, 788, 255-260. [CrossRef]

271. Lisek, M.; Boczek, T.; Zylinska, L. Calcium as a Trojan horse in mental diseases-The role of PMCA and PMCA-interacting proteins in bipolar disorder and schizophrenia. Neurosci. Lett. 2018, 663, 48-54. [CrossRef]

272. Vidal-Domènech, F.; Riquelme, G.; Pinacho, R.; Rodriguez-Mias, R.; Vera, A.; Monje, A.; Ferrer, I.; Callado, L.F.; Meana, J.J.; Villen, J.; et al. Calcium-Binding Proteins are Altered in the Cerebellum in Schizophrenia. bioRxiv 2020. [CrossRef]

273. Li, L.; Yang, X. The Essential Element Manganese, Oxidative Stress, and Metabolic Diseases: Links and Interactions. Oxid. Med. Cell. Longev. 2018, 2018, 7580707. [CrossRef]

274. Finley, J.W. Does environmental exposure to manganese pose a health risk to healthy adults. Nutr. Rev. 2004, 62, 148-153. [CrossRef] [PubMed]

275. Sidoryk-Wegrzynowicz, M.; Lee, E.; Albrecht, J.; Aschner, M. Manganese disrupts astrocyte glutamine transporter expression and function. J. Neurochem. 2009, 110, 822-830. [CrossRef] [PubMed]

276. Dobson, A.; Erikson, K.; Aschner, M. Manganese Neurotoxicity. Ann. N. Y. Acad. Sci. 2004, 1012, 115-128. [CrossRef] [PubMed]

277. Peres, T.V.; Schettinger, M.R.C.; Chen, P.; Carvalho, F.; Avila, D.S.; Bowman, A.B.; Aschner, M. Manganese-induced neurotoxicity: A review of its behavioral consequences and neuroprotective strategies. BMC Pharm. Toxicol. 2016, 17, 57. [CrossRef] [PubMed]

278. Firth, J.; Carney, R.; Stubbs, B.; Teasdale, S.B.; Vancampfort, D.; Ward, P.B.; Berk, M.; Sarris, J. Nutritional Deficiencies and Clinical Correlates in First-Episode Psychosis: A Systematic Review and Meta-analysis. Schizophr. Bull. 2017, 44, 1275-1292. [CrossRef] [PubMed]

279. Wu, J.; Kosten, T.; Zhang, X. Free radicals, antioxidant defense systems, and schizophrenia. Prog. Neuro Psychopharmacol. Biol. Psychiatry 2013, 46, 200-2006. [CrossRef]

280. Wang, D.-F.; Cao, B.; Xu, M.-Y.; Liu, Y.-Q.; Yan, L.-L.; Liu, R.; Wang, J.-Y.; Lu, Q.-B. Meta-Analyses of Manganese Superoxide Dismutase Activity, Gene Ala-9Val Polymorphism, and the Risk of Schizophrenia. Medicine 2015, 94, e1507. [CrossRef]

281. Morello, M.; Zatta, P.; Zambenedetti, P.; Martorana, A.; D'Angelo, V.; Melchiorri, G.; Bernardi, G.; Sancesario, G. Manganese intoxication decreases the expression of manganoproteins in the rat basal ganglia: An immunohistochemical study. Brain Res. Bull. 2007, 74, 406-415. [CrossRef]

282. Flatow, J.; Buckley, P.; Miller, B. Meta-Analysis of Oxidative Stress in Schizophrenia. Biol. Psychiatry 2013, 74, 400-409. [CrossRef]

283. Wu, J.Q.; Chen, D.C.; Tan, Y.L.; Tan, S.P.; Wang, Z.R.; Xiu, M.H.; Yang, F.D.; Zhang, X.Y. Cognition impairment in schizophrenia patients with tardive dyskinesia: Association with plasma superoxide dismutase activity. Schizophr. Res. 2014, 152, 210-216. [CrossRef] 
284. Arinola, O.; Idonije, O. Status of plasma nitric oxide and non-enzymatic antioxidants before and after antipsychotic treatment in Nigerian patients with schizophrenia. J. Res. Med. Sci. 2009, 14, 37-42. [PubMed]

285. Rivera-Mancía, S.; Colin-Ramirez, E.; Montes, S.; Cartas, R.; Vargas-Barrón, J.; Vallejo, M. Dyslipidemia and tobacco smoking synergistically increase serum manganese. Investig. Clínica 2017, 58, 238-249.

286. Bulska, E.; Ruszczyńska, A. Analytical Techniques for Trace Element Determination. Phys. Sci. Rev. 2017, 2, 20178002. [CrossRef]

287. Kurita, H.; Ohsako, S.; Hashimoto, S.; Yoshinaga, J.; Tohyama, C. Prenatal zinc deficiency-dependent epigenetic alterations of mouse metallothionein-2 gene. J. Nutr. Biochem. 2013, 24, 256-266. [CrossRef] [PubMed]

Publisher's Note: MDPI stays neutral with regard to jurisdictional claims in published maps and institutional affiliations.

(C) 2020 by the authors. Licensee MDPI, Basel, Switzerland. This article is an open access article distributed under the terms and conditions of the Creative Commons Attribution (CC BY) license (http://creativecommons.org/licenses/by/4.0/). 